\title{
Poul Martin Møller: \\ KieRKEGAARD Y EL CONFIDENTE DE SócrATeS
}

Finn Gredal Jensen

Society for Danish Language and Literature

Traducción de F. Nassim Bravo Jordán

\section{Resumen}

Poul Martin Møller, una de las principales figuras literarias en la Edad de Oro de Dinamarca, constituyó una de las influencias más importantes en la obra y pensamiento de Søren Kierkegaard. En el presente artículo se ofrece una descripción de la vida y obra de Møller, para después examinar su relación con Kierkegaard. Por último, se analizarán con detalle las referencias y alusiones a los escritos de Møller dentro del corpus kierkegaardiano.

Palabras clave

Møller, Kierkegaard, Sócrates, Edad de Oro de Dinamarca.

\section{Abstract}

Poul Martin Møller, himself a leading literary figure in Golden Age Denmark, was a big influence in the thought and work of Søren Kierkegaard. In the following piece a sketch is made of Møller's life and works; thereupon, his relationship with Kierkegaard is examined. Lastly, I analyze thoroughly the references and allusions to Møller's writings in Kierkegaard's authorship.

Keywords

Møller, Kierkegaard, Socrates, Golden Age Denmark.

De acuerdo con uno de los epítetos en la dedicatoria de Søren Kierkegaard en El concepto de la angustia, Poul Martin Møller era "el confidente de Sócrates". Con el título del presente artículo me gustaría sugerir que Møller no solo conocía muy bien a Platón y las otras fuentes socráticas —incluso llegó a considerar los diálogos platónicos como tema para una disertación ${ }^{1}$-,

\footnotetext{
${ }^{1}$ Esto es evidente a partir de una carta escrita en 1823 de Møller a su padre (Poul Møller og hans Familie i Breve, vols. 1-3, ed. por Morten Borup, Sociedad para el Idioma y la Literatura Danesas, Copenhague: C. A. Reitzel 1976, vol. 1, no. 52; en lo sucesivo me
} 
sino que, todavía de forma más importante, él mismo, en cuanto figura socrática y en virtud de su personalidad, tuvo un especial impacto mayéutico en el joven Kierkegaard. Sin embargo, la relación entre ambos está también rodeada por varios mitos o suposiciones no documentadas que intentaré explicar. El artículo se divide en tres secciones principales: (I) Un resumen de la vida y obra de Poul Martin Møller; (II) una discusión sobre los testimonios acerca de la relación personal entre Møller y Søren Kierkegaard; y (III) una discusión sobre las referencias y posibles alusiones a los escritos de Møller en el corpus kierkegaardiano. Por último, en lo que será una breve conclusión (IV) me concentraré en algunos aspectos relevantes de la descripción que Møller hiciera de Sócrates.

\section{Un resumen de la vida y obra de Møller}

Poul Martin Møller nació en la casa parroquial en Uldum cerca de Vejle, en Jutlandia, el 21 de marzo de 1794, y murió en Copenhague el 13 de marzo de 1838, antes de cumplir los cuarenta y cuatro años. ${ }^{2}$ Sus padres fueron Rasmus Møller (1763-1842) y Bodil Maria Thaulow (1765-1810). A partir de 1802, Rasmus Møller fue el pastor de la aldea Købelev en la isla de Lolland y, ya siendo un anciano, fue nombrado obispo de Maribo en 1831. Sin embargo, no era solo un teólogo, sino también un filólogo entusiasta que tradujo y publicó, entre otras cosas, a Salustio, partes de Tito Livio (libros 1-7) y varios discursos de Cicerón. ${ }^{3}$ Poul y su hermano menor, Hans Ulrik,

referiré a esta edición como "Borup", seguido por el número de carta). Él planeaba escribir una disertación en cuanto terminara sus traducciones de Homero, pero, al año siguiente, en otra carta a su padre, fechada el 1 de julio de 1824 (Borup, carta no. 56), Møller menciona la posibilidad de no hacerla: "A menudo he considerado la posibilidad de saltarme la disertación de maestría (no por indolencia, sino por una cuestión financiera)”.

${ }^{2}$ El primer biógrafo de Møller fue Frederik Christian Olsen (1802-1874). Su Poul Martin Møllers Levnet, med Breve fra hans Haand fue publicado por separado y también como parte de los Efterladte Skrifter de Møller, $1^{\circ}$ edición, vol. 3, Copenhague: C. A. Reitzel 1843, pp. 1-116. La principal monografía acerca de Møller sigue siendo la obra de Vilhelm Andersen, Poul Martin Moller. Hans Liv og Skrifter efter trykte og utrykte Kilder $i$ Hundredaaret for han Fødsel, Copenhague: G. E. C. Gad, 1894 (2 edición, vols. 1-2, 1904; $3^{\circ}$ edición, 1944). Para más bibliografía secundaria sobre Møller (y Kierkegaard), consultar las notas al pie y la bibliografía del presente artículo. En general, ver también Henrik Denman, Poul Martin Møller. En kommenteret bibliografi, Roskilde: Denmans Forlag, 1986.

${ }^{3}$ Søren Kierkegaard tenía las traducciones de Rasmus Møller de Salustio: Sallusts Catilinariske Krig oversat fra det Latinske. Et Forsøg, Copenhague: Fr. Brummer, 1811 (tenía dos copias, ASKB 1273 y ASKB A I 184); Sallusts Jugurthinske Krig oversat fra det Latinske. Et Forsøg, Copenhague: Fr. Brummer, 1812 (ASKB A I 1184); y su edición latina de Tito 
recibieron (a diferencia de sus cuatro hermanas menores) clases particulares de su padre. Aquí estaba el origen de sus extraordinarias habilidades para las lenguas y la literatura clásicas. Durante los años 1807-1809 asistió a la escuela en Nakskov y, en 1810, fue enviado junto con su hermano a la escuela secundaria de Nykøbing Falster, donde conoció y entabló amistad con quien se convertiría en su hermanastro, el poeta Christian Winther (17961876). Después de la muerte de su esposa, Rasmus Møller volvió a casarse en 1811. Su nueva esposa era la madre de Winther, Johanna Dorothea Borchsenius (1769-1830).

En 1812, Poul Martin Møller comenzó sus estudios de teología en la Universidad de Copenhague. Los concluyó en menos de tres años y medio en enero de 1816 con las máximas calificaciones, a pesar de que, mientras estudiaba, era también maestro de religión en el Colegio Borgerdyd de Copenhague, y de latín en el otro Colegio Borgerdyd en Christianshavn ${ }^{4}$. Mucho más importante que la teología, no obstante, fue su participación en la vida estudiantil y las estimulantes amistades que estableció con personalidades notables como Bernhard Severin Ingemann (1789-1862), Carsten Hauch (1790-1872), Johan Ludvig Heiberg (1791-1860), Niels Bygorn Krarup (1792-1842), Peder Hjort (1793-1871), Just Mathias Thiele (1795-1874) y Nicolai Christian Mohl (1798-1830). De la generación anterior conoció, por ejemplo, a la madre de Heiberg, Thomasine Gyllembourg-Ehrensvärd (1773-1856) y a los Rahbek en la "Bakkehus": Knud Lyne Rahbek (1760-

Livio, libros 1-10, basada en las ediciones de F. A. Strith y F. W. Döring, Titi Livii Operum omnium volumen I [libros 1-5], Copenhague: Gyldendal, 1815 (ASKB A II 31), Titi Livii Patavini Historiarum libri I-X... volumen II, libros VI-X continens, Copenhague: Gyldendal, 1819 (ASKB A II 32), y la $2^{\circ}$ edición del vol. 1, ed. por C. F. Ingerslev ( $A S K B$ 1256). Rasmus Møller también publicó varias obras teológicas. De estas, Kierkegaard tenía su Vejledning til en andægtig og forstandig Læsning af det Nye Testamente, især for ulærde Læsere, $1^{\circ}$ edición, Copenhague: Andreas Seidelin, 1820 (ASKB A I 18), y $2^{\circ}$ edición, 1824 (ASKB 83). Cfr. también, la entrada del diario NB:123, SKS 20, 88 / JP 2, 1997. Tenía también Vejledning til en andægtig og forstandig Læsning af det Gamle Testamente, især for ulærde Læsere, vols. 1-2, Copenhague: Andreas Seidelin, 1826 (ASKB 81-82), y sus traducciones de los profetas en Det Gamle Testamentes poetiske og prophetiske Skrifter, efter Grundtexten paa ny oversatte og med Indholdsfortegnelse samt Anmzrkninger forsynede, publicado en colaboración con Jens Møller (quien no era su hermano, como se afirma en SKS K22, nota a 179, 8), Copenhague: Andreas Seidelin, 1828-1830 (dos copias, ASKB 86-88, 89-91).

${ }^{4}$ Cfr. Holger Lund, Borgerdydsskolen $i$ Kjøbenhavn 1787-1887. Et Mindeskrift i Anledning af Skolens Hundredaarsfest, Copenhague: Otto B. Wroblewskys Forlag, 1887, p. 238; T. H. Erslew, Almindeligt Forfatter-Lexicon for Kongeriget Danmark med tilhørende Bilande, fra 1814-1840, vols. 1-3, Copenhague: Forlagsforeningens Forlag, 1843-1853; vol. 2, 1847, p. 407. 
1830) y Kamma Rahbek (1775-1829). En 1815, Møller publicó su primer poema en un diario (en los años siguientes publicaría varios poemas más, aunque siempre escribía más de lo que publicaba) y le propuso matrimonio en vano a Margrethe Bloch, hija de su antiguo director en Nykøbing. La teología nunca le interesó mucho. Sí, en cambio, la filología. Su primera publicación importante en 1816 fue una traducción del libro 9 de la Odisea 5 . Después de una etapa intermedia como tutor de dos jóvenes condes en la hacienda de Espe, cerca de Korsør, regresó a Copenhague, donde participó en 1818 en la controversia literaria en torno a Jens Baggesen (1764-1826). Aquí también compuso una sátira titulada "Esbozo de una carta desde el cielo” acerca del partidario de Baggesen, N. F. S. Grundtvig (1783-1872) . Al mismo tiempo comenzó en serio sus estudios de filología clásica.

$\mathrm{El}$ año siguiente, cinco meses después de que la antes mencionada Miliss Bloch contrajera matrimonio, Møller se embarcó como pastor en la fragata "Christianshavn", la cual navegaba hacia China7. El barco levó anclas el 1 de noviembre de 1819 y no regresó sino hasta el 14 de julio de 1821 . En este largo viaje, Møller tenía la esperanza de poder estudiar mientras estuviera a bordo. Entre otras cosas, parece que leyó todas las obras de Cicerón. También escribió bastante. Por ejemplo, su famoso poema, "Gozo por Dinamarca" . Pero, en primer lugar, empezó a reunir sus ideas en aforismos, los así llamados Pensamientos dispersos. De vuelta en Copenhague, reanudó su participación en la vida estudiantil, pero con más madurez que antes. Se encontró con sus antiguos amigos, aunque también conoció a otros como el filólogo Christen Thaarup (1795-1849), quien sería uno de los editores de sus Escritos póstumos. Participó en la Unión de Estudiantes, donde, en 1824, leyó partes de su novela inconclusa, Aventuras de un estudiante danés. Sus escritos de estos años incluyen el poema "Una hoja del diario de la muerte" y una espléndida traducción al danés de "El sueño" de Lord Byron. Publicó también poemas como "Canción de abril" y partes de "Escenas en el Jardín de Rosenborg". Prosiguió asimismo con sus estudios

5 "Forsøg til en metrisk Oversættelse af Odysseus Eventyr i Kyklopens Hule, ved $P$. M. Møller, Candid. Theol.”, en Indbydelsesskrift til den offentlige Examen i Borgerdydskolen i September 1816, Copenhague: Johan Frederik Schultz, 1816, pp. 3-20.

${ }^{6}$ Acerca de esto, ver Sección III, A, más adelante.

${ }^{7}$ Sobre este viaje, ver, por ejemplo, Lone Klem, "Rejoicing over Denmark: Poul Martin Møller's Voyage to China on the Frigate 'Christianshavn' 1819-21”, en The Golden Age Revisited: Art and Culture in Denmark 1800-1850, ed. por Bente Scavenius, Copenhague: Gyldendal, 1996, pp. 84-91.

8 Discutiré la importancia kierkegaardiana de este poema en las Secciones II y III, B. 
filológicos y, en esta ocasión, tradujo los libros 1-6 de la Odisea, los cuales se publicarían en 1825 en el que, por extraño que parezca, sería su único libro'. Después de su regreso en 1821 de su viaje por el extranjero, retomó su empleo en el Colegio Borgerdyd, ahora enseñando griego, el mismo año en el que Søren Kierkegaard empezó a asistir ahí ${ }^{10}$. Sin embargo, a partir del 12 de noviembre del año siguiente obtuvo el puesto de adjunto en el Colegio Metropolitano como maestro de griego y latín ${ }^{11}$. Uno de los alumnos de Møller en esta escuela era el futuro obispo Hans Lassen Martensen (18081884), quien en sus memorias dice: "Entre los profesores, mencionaré al genial e inolvidable Poul Møller, a quien nosotros, los alumnos, mirábamos

${ }^{9}$ Homers Odyssees sex første Sange metrisk oversatte af Poul Møller, Adjunct ved Metropolitanskolen, Copenhague: Gyldendal, 1825, 99pp (una versión anterior de su traducción del libro 5 de la Odisea había sido publicada en 1822). En la carta antes mencionada, fechada el 1 de julio de 1824 (Borup, carta no. 56) en "Bakkehuset", en donde a veces se quedaba, Møller le escribe a su padre que, "con el tiempo", le gustaría traducir toda la Odisea, pero se percata de lo problemático que sería eso —en los primeros seis libros había pasado grandes complicaciones revisando las pruebas, pues no podía dejar de corregir el texto- $-\mathrm{y}$, añade, "Cuando sabes cuántos años he empleado para traducir a Homero, te das cuenta de que soy incapaz de terminar nada". Este conocimiento de sí mismo aparece de forma incluso más evidente en una carta de ese mismo verano (Borup, carta no. 55), también dirigida a su padre, en la que dice: "Si una persona hiciera las cosas como deben hacerse, entonces no podría hacer nada en toda su vida salvo traducir la Odisea; pero yo no quiero ser esa persona”.

${ }^{10}$ Cfr. Holger Lund, Borgerdydsskolen, p. 238. Søren Kierkegaard comenzó a asistir al colegio en 1821, aunque Per Krarup afirma que "en verdad no pudo tenerlo [a Møller] como profesor en la escuela. Se conocieron durante su época como estudiante universitario". Per Krarup, Søren Kierkegaard og Borgerdydsskolen, Copenhague: Gyldendal, 1977, pp. 61-62. Esto es indudable, ya que Møller enseñaba solo en la forma primera, es decir, a los alumnos de mayor edad. La sugerencia de Vilhelm Andersen (Poul Møller, pp. 151-153) de que el distraído maestro de latín que aparece en Etapas en el camino de la vida (SKS 6, 191-192 / SLW, 204-205) podría ser una descripción de Møller, desaparece en la segunda edición de su biografía (el maestro en el que Kierkegaard estaba pensando era Ernst Bojesen). En cualquier caso, Kierkegaard colegial debió haber visto a Møller de forma cotidiana cuando este iba a impartir sus clases. Por cierto, en esta época Møller estaba muy ocupado impartiendo también clases privadas, debido, como era usual, a razones económicas.

${ }^{11}$ Cfr. Metropolitanskolen gennem 700 Aar, ed. por C. A. S. Dalberg y P. M. Plum, Copenhague: Gyldendal, 1916, p. 116, y Apéndice, "Hundrede Aars Metropolitanere”, ed. por P. M. Plum, p. 11. El primer biógrafo de Møller y uno de los editores de sus escritos póstumos, su amigo Frederik Christian Olsen, también fue maestro de griego y latín en el colegio, pero no ocupó el puesto sino hasta 1828, cuando Møller ya se había ido (más tarde, Olsen enseñó por un tiempo — de 1830 a 1837— en la escuela secundaria de Elsinor, luego otra vez en el Colegio Metropolitano y, en 1844, se mudó a Jutlandia para convertirse en el director de la escuela catedralicia de Viborg). 
con admiración y que, sin intentarlo, ejerció una fructífera influencia sobre nosotros"12. En el "escrito de invitación" del colegio, Møller publicó en 1823 un tratado en latín acerca de Némesis, "De invidia diis ab Herodoto et æqualibus attributa pauca"13. En 1826, aprobó la parte escrita del examen de la universidad para filología y, ese mismo año, le propuso matrimonio con éxito a Betty Berg (1804-1834).

"No se debería intentar seducir o persuadir a alguien a que se inicie en la filosofía", dice Friedrich Schlegel en Athenäums-Fragmente, no. $417^{14}$. No obstante, esto es lo que el profesor Frederik Christian Sibbern (17851872), según parece, hizo con Møller. Lo convenció de convertirse en filósofo profesional. Más tarde siempre lo aconsejó, le dio listas de libros para leer, etcétera. Pero a pesar de la diligencia y el interés de Møller, nunca llegó a ser un filósofo original. A decir verdad, al ser un "feliz amante de la cultura griega" - para emplear las palabras de Kierkegaard_-, probablemente le hubiera resultado mejor quedándose con la poesía y la filología, que era donde estaba su más grande talento. En el verano de 1826, Sibbern se le acercó como intermediario con una oferta de un puesto como profesor. Primero Møller fue designado lector y, después, en 1828, profesor de filosofía en la Universidad Frederik de Christiania, Oslo en la actualidad. Møller hizo a un lado su examen oral final de filología y, en octubre de 1826, se fue a Noruega. El siguiente verano, se casó en Dinamarca y se llevó a su esposa de vuelta al norte. En 1828 y 1830 tuvieron dos hijos (dos más llegarían

${ }^{12}$ Hans Lassen Martensen, Af mit Levnet. Meddelelser, vols. 1-3, Copenhague: Gyldendal, 1882-1883, vol. 1, p. 16.

13 "De invidia diis ab Herodoto et æqualibus attributa pauca commentatus est Paulus Møller, Scholæ Adjunctus", en Examen publicum anniversarium in Schola Metropolitana X Calendarum Octobris A. MDCCCXXIII habendum indicit Rector Scholx Nicolaus Lang Nissen, doctor philosophize et magister artium atque professor, Copenhague: Schultz, 1823, pp. 1-32. Este tratado, el cual es la obra en latín más extensa de Møller, no está incluido en los Efterladte Skrifter, aunque es calificado como "interesante" por J. L. Heiberg, quien lo menciona dos veces en su ensayo "Nemesis. Et popular-philosophisk Forsøg”, en Kjøbenhavns flyvende Post, 1827, nos. 41, 43, 44 y 45. Cfr. Heiberg's Contingency Regarded from the Point of View of Logic and Other Texts, trad. y ed. por Jon Stewart, Copenhague: Museum Tusculanum Press, 2008 (Texts from Golden Age Denmark, vol. 4), pp. 101-125; p. 109 y p. 120 .

${ }_{14}$ "Man soll niemanden zur Philosophie verführen oder bereden wollen". Athenaeum. Eine Zeitschrift. Ersten Bandes Zweytes Stück, ed. por A. W. Schlegel y F. Schlegel, Berlín: bey Friedrich Vieweg dem älteren, 1798, p. 304; Kritische Friedrich-Schlegel-Ausgabe, ed. por E. Behler et al., vol. 2, Charakteristiken und Kritiken I (1796-1801), ed. por H. Eichner, Munich-Paderborn-Viena: Verlag Ferdinand Schöningh/Zürich: Thomas-Verlag, 1967, p. 244. 
más adelante). Sin embargo, dado que durante estos años estuvo ocupado con las lecturas filosóficas y con la enseñanza, su producción literaria fue modesta. Él y su familia se sentían aislados; no estaban hechos para la vida en el extranjero. Sin duda, el empleo de Møller en Noruega siempre estuvo pensado como un trampolín para alcanzar un mejor puesto en Copenhague.

Esto se hizo posible cuando el 12 de octubre de 1830 fue nombrado profesor de filosofía en la Universidad de Copenhague ${ }^{15}$; ahí tuvo lugar su primera lección acerca de filosofía moral el 28 de mayo de $1831^{16}$. En los años siguientes, impartiría lecciones — públicas o privadas- en distintas disciplinas. De acuerdo con la lista de cursos, las lecciones anunciadas eran las siguientes: filosofía moral (todos los semestres de verano en 1831 y 1837); lógica (semestres de verano de 1832, 1833 y 1834); historia de la filosofía moderna (semestre de invierno 1831-1832); metafísica (semestres de invierno 1832-1833, 1835-1836, 1836-1837); historia de la filosofía antigua (semestres de invierno 1833-1834, 1834-1835); psicología (invierno 18341835, verano 1835, invierno 1836-1837, verano 1837); De Anima de Aristóteles (semestre de invierno 1835-1836); propedéutica filosófica (verano 1836) ${ }^{17}$. Por motivos de salud, Møller no pudo impartir el curso anunciado para el semestre de invierno 1837-1838 sobre "Ontología o el sistema de categorías”, acerca del cual también había empezado a escribir un libro de texto, ni una proyectada serie privatissime de lecciones sobre filosofía antigua $^{18}$. Es difícil no imaginar al joven Søren Kierkegaard asistiendo a estas

${ }^{15}$ Cfr. Akademiske Tidender, vol. 1, ed. por H. P. Selmer, Copenhague: Gyldendal, 1833, p. 165.

${ }^{16}$ Esto aparece en una carta a Sibbern (Borup, carta no. 122). En la lista de cursos, Index lectionum in Universitate Regia Hauniensi per semestre æestivum a Kalendis Maiis A. MDCCCXXXI habendarum, Copenhague: J. H. Schultz, 1831, p. 7, donde se lee lo siguiente: "P. M. Møller, Philosophiæ P. P. E. [Professor Publicus Extraordinarius], quum advenerit, lectiones e valvis publicis indicabit".

17 El semestre de invierno comenzaba el 1 de noviembre del primer año y concluía en marzo del año siguiente. El semestre de verano empezaba el 1 de mayo y terminaba a finales de septiembre.

${ }^{18}$ Kjøbenhavns Universitets Aarbog for 1838, ed. por H. P. Selmer, Copenhague: Gyldendal, 1839, p. 87; cfr. Kjøbenhavns Universitets Aarbog for 1837, ed. por H. P. Selmer, Copenhague: Gyldendal, 1838, p. 86. En una carta de Rasmus Møller al obispo Mynster (Borup, carta no. 179), se lee que Møller, antes de su muerte, "había arrojado un gran número de sus manuscritos al fuego", incluido el libro de texto sobre "Ontología o el sistema de categorías", el cual estaba a punto de terminar, pero del que solo una parte menor (la Introducción y el principio del Capítulo I) fue publicada en los Efterladte Skrifter, vol. 3, pp. 331-360 (el manuscrito se encuentra en la Biblioteca Real de Copenhague, Collinske Samling 378, $4^{\circ}$; en la Biblioteca Real, NKS 4000, $4^{\circ}$, también hay un manuscrito más 
lecciones. Pero, desafortunadamente, solo se conservan algunas pocas listas de alumnos y no hay otras fuentes que pudieran arrojar luz sobre el asunto. Solo en un caso aparece el nombre de Kierkegaard en una lista de las lecciones de Møller, a saber, en las lecciones de metafísica, las cuales fueron impartidas en "tres sesiones por semana" durante el semestre de invierno 1836-1837 ${ }^{19}$. En algunos casos, conocemos el número de alumnos, pero no su identidad ${ }^{20}$. Todo indica que Møller era un profesor popular. Su natural

grande, una copia que, si bien no es de la mano de Møller, incluye las notas de las lecciones planeadas). En una carta a F. C. Olsen (Borup, carta no. 177), H. U. Møller cita partes de una carta de su hermano (antes de destruirla, como se le indicó que hiciera). En esa carta de principios de 1837, P. M. Møller escribe que está trabajando en la última parte, las Secciones VIII-XI, de su tratado sobre la inmortalidad y que espera publicarlo en el número de abril del Maanedskrift for Litteratur, pero que más tarde en ese mismo año pretende publicar un libro sobre metafísica (es decir, la "Ontología o el sistema de categorías"), "el cual reviso durante mis lecciones [sobre metafísica en 1836-1837], es decir, que estoy volviendo a escribir por tercera vez... Cuando haya publicado esta obra estrictamente metodológica, la cual es tan árida que no muchos la leerán (excepto los estudiantes jóvenes, quienes, sin importarles los exámenes, asisten en gran número a mis lecciones sobre este tema, para gran sorpresa mía), me parece que me habré ganado el derecho de escribir en forma aforística, aleatoria y fragmentaria por un largo tiempo. A partir de ese momento empezaré a escribir. Hasta ahora solo he leído por muchos años". Con la expresión "en gran número", es preciso tener en consideración que para las lecciones de metafísica del semestre de invierno 1836-1837 habían asistido veintiséis alumnos; el año anterior habían asistido veinticuatro. Cfr. nota 20.

${ }_{19}$ Peter Tudvad, Kierkegaards København, Copenhague: Politikens Forlag, 2004, p. 181. De los años de Møller como profesor de la Facultad de Filosofía solo se conservan las listas de participantes del semestre de invierno 1832-1833, el semestre de verano 1833, el semestre de invierno 1833-1834 y, algunos años después, del semestre de invierno 18361837 y el semestre de verano 1837; cfr. Tudvad, ibid, pp. 177-181, con referencias a Rigsarkivet, Copenhague.

${ }^{20}$ De acuerdo con H. P. Selmer, hubo ciento sesenta alumnos para las lecciones de Møller sobre filosofía moral y lógica en el semestre de verano 1834. Cfr. Akademiske Tidender, vol. 2, ed. por H. P. Selmer, Copenhague: Gyldendal, 1834, p. 382. Veintiún alumnos para las lecciones sobre filosofía antigua y ciento sesenta y ocho alumnos en psicología en el semestre de invierno 1834-1835. Cfr. Akademiske Tidender, vol. 3, ed. por H. P. Selmer, Copenhague: Gyldendal, 1835, p. 151. Ciento setenta y cuatro alumnos para las lecciones sobre filosofía moral y psicología en el semestre de verano 1835; diez alumnos en las lecciones sobre el De anima y veinticuatro alumnos en metafísica en el semestre de invierno 1835-1836; ciento once alumnos en filosofía moral en el semestre de verano 1836. Cfr. Akademiske Tidender, vol. 4, ed. por H. P. Selmer, Copenhague: Gyldendal, 1841, p. 420. Se conservan las listas de alumnos de los últimos dos semestres de Møller como profesor. De acuerdo con éstos, hubo veintiséis alumnos en metafísica en el semestre de invierno 18361837 (uno de los cuales era Kierkegaard) y ciento cuarenta y tres en el semestre de verano 
temperamento amigable producía una buena impresión, pero también era conocido por sus repentinos episodios de distracción.

En estos años, Møller no tuvo tiempo más que para leer y prepararse para sus clases. Además, por razones económicas, desde 1832 también enseñaba composición en griego y latín en el Colegio Borgerdyd de Christianshavn, donde su amigo, el filólogo N. B. Krarup, era el director. Su vena poética estaba casi seca. Con todo, es importante su última obra maestra, "Kunstneren mellem Oprørerne [El artista entre los rebeldes]", la cual apareció en diciembre de 1837 en el Nytaarsgave fra danske Digtere [Regalo de año nuevo de los poetas daneses] de H. P. Holst y Christian Winther. También escribió varias reseñas, de las cuales la más importante es su extensa reseña de Extremerne [Los extremos] de Thomasine Gyllembourg, publicada en $1836^{21}$. En el género filosófico, con la excepción de una pequeña reseña de un libro de F. L. P. Zeuthen (1805-1874) y sus magníficas reseñas de la disertación acerca de la mentira de P. C. Kierkegaard (1805-1888) y de Sobre la poesía y el arte de Sibbern, solo publicó el gran tratado sobre la inmortalidad, "Pensamientos sobre la posibilidad de una demostración de la inmortalidad humana"22, la cual apareció en 1837 en el prestigioso Maanedskrift for Litteratur, de cuyo consejo editorial era miembro. Tenía muchos proyectos. Por ejemplo, le interesaba la figura nihilista de Ahasverus ${ }^{23}$ y el concepto de la afectación ${ }^{24}$, sobre el cual reflexionó por varios años en sus Pensamientos dispersos. Al final, no obstante, estaba demasiado enfermo para llevar a cabo estos planes. Después de su regreso de Noruega, su esposa quedó todavía más débil y murió en 1834, lo cual fue un duro golpe para él. Antes, también uno de sus hijos había muerto. Algunos años después, en diciembre de 1836, contrajo matrimonio con la amiga de su difunta esposa, Eline von Bülow (1804-1876), con quien tuvo una hija. Sin embargo, él mismo pronto cayó enfermo, al parecer de cáncer de hígado, y su condición, acompañada por el asma, empeoró. Murió el 13 de marzo de 1838.

En 1839, el año después de la muerte de Møller, apareció el primer volumen de sus Escritos póstumos, los cuales serían publicados en tres volúmenes entre 1839 y 1843 , editados por su hermanastro, Christian Winther,

1837. Cfr. Kjøbenhavns Universitets Aarbog for 1837, ed. por H. P. Selmer, Copenhague: Gyldendal, 1838, p. 81.

${ }^{21}$ Este texto será tratado más adelante en la Sección III, D.

${ }^{22}$ Ver Sección III, G.

${ }^{23}$ Ver Sección III, C.

${ }^{24}$ Ver Sección III, F. 
y sus dos amigos, Frederik Christian Olsen y Christian Thaarup ${ }^{25}$. Winther se hizo cargo lo mejor que pudo de los escritos poéticos, incluyendo las traducciones de Homero. El esfuerzo principal de Thaarup estuvo dirigido a la reconstrucción de las Aventuras de un estudiante danés. Olsen fue de forma principal el albacea de los escritos filosóficos; también incluyó una vita, la primera biografía de Møller, "Vida de Poul Martin Møller, con cartas de su mano"26. La segunda edición en seis volúmenes (1848-1850) incluye varias adiciones (por ejemplo, la traducción de la Batrachomyomachia), mientras que la tercera edición, publicada entre 1855-1856, es prácticamente idéntica a la segunda, con la excepción de una inclusión del nuevo editor, L. V. Petersen, el drama en un acto "Las historias inventadas" 27.

${ }^{25}$ Efterladte Skrifter af Poul M. Møller, vols. 1-3, ed. por C. Winther, F. C. Olsen y C. Thaarup, $1^{\circ}$ ed., Copenhague: C. A. Reitzel, 1839-1843 (vol. 1, 1839; vol. 2, 1842; vol. 3, 1843) (ASKB 1574-1576). En las notas sucesivas, me referiré a la primera edición de los Escritos póstumos con las siglas ES1.

26 Winther y Olsen editaron los escritos póstumos de acuerdo con los deseos de Møller. Cfr. el prólogo de Winther a ES1, vol. 1: "Cuando mi hermano Poul Møller sintió que la muerte se acercaba, me dijo: 'Puedo imaginar que, como suele ocurrir, también cuando muera yo alguien va a reunir y a publicar lo que he escrito. Por lo tanto, me gustaría encargarte, en este caso, la publicación de la parte estética, y que dejes fuera aquello que tú, conociéndome, pienses que yo mismo hubiera omitido. Dile a Olsen que haga lo mismo con la parte filosófica'”. Según el prólogo de F. C. Olsen a ES1, vol. 2, Møller en sus últimos días también había expresado el deseo de que Olsen buscara el consejo y la ayuda del profesor Sibbern para la publicación de la parte académica de los escritos. Eso hizo Olsen en el momento de decidir qué publicar y qué omitir. El tercer editor, Christen Thaarup, se involucró en la edición más tarde, cuando se hizo claro que era necesario un tercer volumen.

${ }^{27}$ Efterladte Skrifter af Poul Møller, vols. 1-6, ed. por C. Winther, F. C. Olsen, C. Thaarup y L. V. Petersen, $2^{\circ}$ edición (ES2), Copenhague: C. A. Reitzel, 1848-1850; Efterladte Skrifter af Poul M. Møller, vols. 1-6, ed. por L. V. Petersen, $3^{\circ}$ edición (ES3), Copenhague: C. A. Reitzel, 1855-1856. El nuevo editor, Lauritz Vilhelm Petersen (1817-1879), teólogo y un antiguo pupilo de Møller, es también conocido por traducir la disertación de H. L. Martensen, De autonomia conscientiae sui humanae in theologiam dogmaticam nostri temporis introducta, Copenhague: J. D. Quist, 1837 (ASKB 648); Den menneskelige Selvbevidstheds Autonomie, Copenhague: C. A. Reitzel, 1841 (ASKB 651). Las ediciones más importantes después de estas han sido las selecciones de Christian Winther de los escritos de Møller, Poul M. Møllers Efterladte Skrifter, vols. 1-2, Copenhague: C. A. Reitzel, 1873, y la edición de Vilhelm Andersen, también una selección, Udvalgte Skrifter af Poul Møller, vols. 1-2, Copenhague: G. E. C. Gad, 1895 (2 edición, Skrifter i Udvalg, 1930); en sus Poul Møller Studier, Copenhague: Gyldendal, 1940, Johannes Brøndum-Nielsen publicó algunos poemas hasta ese momento desconocidos (junto con un facsímil de la sátira Smørialis Digtervandringer (1823), que él juzgaba, seguramente de forma errónea, escrita por Møller). Las cartas de Møller han sido editadas y comentadas por Morten Borup en Poul Møller og hans Familie i Breve. En la actualidad se está elaborando una edición moderna, histórica, crítica 
Lo que ha faltado en las ediciones de Møller han sido en particular las lecciones filosóficas, de las cuales tan solo una pequeña parte ha sido publicada $^{28}$. Aun así, la primera edición de los Escritos Póstumos reveló por primera vez todo el alcance del genio de Møller para el público, el cual hasta ese momento solo había tenido acceso a una parte mínima de su obra. Møller era, en efecto, sumamente creativo. De esta forma, cuando Carsten Hauch, haciendo alusión a la Estética de Jean Paul, lo llama un genio "pasivo", parece referirse a que Møller era por naturaleza un pensador fragmentario y que, en consecuencia, nunca publicó mucho (principalmente porque no ambicionaba hacerlo) ${ }^{29}$. No obstante, su afirmación es tal vez precisa en el sentido de que Møller concebía ideas que Kierkegaard fue capaz de reunir y llevar a cabo. Discutiré en las siguientes secciones su posible impacto mayéutico sobre Kierkegaard.

\section{Kierkegaard: ¿El confidente de Møller?}

A menudo se ha señalado que Søren Kierkegaard y Poul Martin Møller eran "amigos", pero las fuentes que apoyan esta hipótesis son muy pocas. Sin embargo, es obvio - incluso con lo poco que sabemos- que en varios sentidos Møller representaba para Kierkegaard una figura socrática, un mentor,

y comentada de los escritos reunidos de P. M. Møller, editada por Finn Gredal Jensen, Kim Ravn y Niels Stengaard en la Sociedad para el Idioma y la Literatura Danesas, Copenhague. Esta nueva edición incluirá material no publicado anteriormente.

${ }^{28}$ De acuerdo con la estimación de Sibbern, solo se publicaron los manuscritos de las lecciones sobre historia de la filosofía antigua (ES1, vol. 2, pp. 273-527, "Udkast til Forelæsninger over den ældre Philosophies Historie") y sobre filosofía moral (ES1, vol. 3, pp. 351-369, "Forelæsnings-Paragrapher over Moral-Philosophien"). Las notas de Møller para sus lecciones sobre lógica forma ya habían sido incluidas antes en un libro de texto de Carl Berg, Grundtrækkene af en philosophisk Propædeutik eller Erkjendelseslare, tilligemed Poul Møllers kortfattede formelle Logik. Trykt som Manuskript til Brug for Elever af det kongl. Landcadetacademie, Copenhague: C. A. Reitzel, 1839 (ASKB 426, adquirida por Kierkegaard en 1844). Como ya se ha mencionado, para el semestre de invierno 1837-1838 Møller había planeado una serie de lecciones sobre "Ontología o el sistema de categorías", el cual se canceló por su enfermedad. Sin embargo, partes de su manuscrito para un libro planeado acerca del tema se publicaron en ES1, vol. 3, pp. 331-360.

${ }^{29}$ Carsten Hauch, Minder fra min Barndom og min Ungdom, Copenhague: C. A. Reitzel, 1867, pp. 297-298; cfr. Jean Paul [Johann Paul Friedrich Richter], Vorschule der Aesthetik, nebst einigen Vorlesungen in Leipzig über die Parteien der Zeit, vols. 1-3, Hamburgo: Friedrich Perthes, 1804; $2^{\circ}$ edición, Stuttgart y Tubinga: Cotta, 1813 (ASKB 13811383); ver, en general, el $2^{\circ}$ Programa, "Stufenfolge poetischer Kräfte", y el $3^{\circ}$ Programa, "Ueber das Genie". Se habla de los genios pasivos en $\$ 10$. 
y que ambos se trataban en términos familiares. Como se verá en la Sección III, es posible demostrar que existen varias huellas de los escritos de Møller en la obra de Kierkegaard. Para Kierkegaard, sin embargo, es indudable que la personalidad de Møller era más importante que su pensamiento, ya fuera en sus escritos o en la comunicación oral. Troels-Lund, quien en su Bakkehus y Solbjerg destaca no de forma sorpresiva la importancia de la personalidad de Møller, tiene razón cuando enfatiza también la gran importancia de su muerte: "De acuerdo con su naturaleza característica [de Kierkegaard], la muerte misma [de Møller], en virtud de la cual la relación se convirtió en memoria, los hizo incluso más íntimos" ${ }^{30}$. En la presente sección, hablaré de los comentarios de Kierkegaard acerca de Møller y de los testimonios sobre la relación entre ambos.

El mejor testimonio de su relación personal es, desde luego, la dedicatoria impresa en El concepto de la angustia (1844). Esta bien podría considerarse como un compendio de lo que Kierkegaard pensaba de Møller. Dice lo siguiente: “Al difunto profesor Poul Martin Møller, el feliz amante de la cultura griega, el admirador de Homero, el confidente de Sócrates, el intérprete de Aristóteles, el gozo de Dinamarca en el 'Gozo por Dinamarca', siempre 'recordado en el verano danés' a pesar de sus 'muchos viajes', mi admiración, mi pérdida, le dedico esta obra" ${ }^{31}$. Una dedicatoria de esta clase definitivamente no tiene un carácter formal. El genio de Møller queda inscrito en diversos epítetos y no es sorpresivo que se enfatice en primer lugar su interés por la cultura helénica, luego su poesía $a^{32}$ y se concluya con las muy personales observaciones, "mi admiración, mi pérdida".

Con un poco de cautela, es posible deducir algunas cosas a partir de la dedicatoria: Kierkegaard conoce las traducciones de Homero de Møller y sabe del conocimiento que este tenía de los diálogos de Platón y de otras fuentes relacionadas con Sócrates ${ }^{33}$; la parte de "el intérprete de Aristóteles"

${ }^{30}$ Troels Frederik Troels-Lund, Bakkehus og Solbjerg. Træk af et nyt Livssyns Udvikling i Norden, vols. 1-3, Copenhague: Gyldendal, 1920-1922, vol. 3, p. 200.

${ }^{31}$ SKS 4, 311 / CA, 5.

32 Ver más adelante la Sección III B acerca del poema “Gozo por Dinamarca”, que es el escrito al que se refiere la dedicatoria. Ver también la nota 49 de la presente sección sobre la teoría de H. P. Rohde en torno a la influencia de la obra Gjenboerne de Hostrup.

${ }^{33}$ Møller habla de forma directa o indirecta de Sócrates en varias partes de sus escritos. Por ejemplo, en sus Pensamientos dispersos. Pero merece una especial mención su descripción de Sócrates en las notas de sus lecciones sobre filosofía antigua. Esta descripción se encuentra en ES1, vol. 2, pp. 357-375. Discutiré brevemente algunos pasajes importantes de ella en la Sección IV del presente artículo. 
se refiere probablemente al análisis de Aristóteles en las lecciones de Møller sobre filosofía antigua ${ }^{34}$, aunque es indudable que alude en particular a sus lecciones acerca del De Anima de Aristóteles ${ }^{35}$. Como se mencionó antes, no hay evidencia de que Kierkegaard asistiera a estas o a otras lecciones de Møller, con la excepción de las lecciones sobre metafísica en el semestre de invierno 1836-1837, que es el único caso en el que su nombre aparece en una de las pocas listas de alumnos de las lecciones de Møller que se conser$\operatorname{van}^{36}$. Por desgracia, no se conservan las listas de los cinco semestres en el verano de 1834 y el verano de 1836, de manera que no se puede saber con seguridad si Kierkegaard asistió a alguno de los cursos de Møller de esos años. Con todo, la suposición natural es que sí lo hizo, aun cuando era un alumno perezoso. No existen otras fuentes en las que se documente esto y en ninguna parte de los escritos de Kierkegaard se pueden rastrear de forma precisa elementos identificables de las lecciones de Møller ${ }^{37}$. Desde luego, es preciso suponer que leyó la selección de las notas de las lecciones publicadas en la primera edición de los Escritos póstumos de Møller ${ }^{38}$.

${ }^{34}$ Se habla de Aristóteles en las notas de las lecciones en ES1, vol. 2, pp. 455-505.

35 Por desgracias, las notas de las lecciones sobre el De Anima — sin duda muy interesantes - se han perdido. En esa misma época, Møller tradujo también el De Anima, aunque solo los capítulos 1-3 del Libro 1. Este fragmento, “Om Sjælen”, se publicó por vez primera en ES2, vol. 3, 1848, pp. 213-228; no aparece en ES1, que es la edición que Kierkegaard tenía.

36 Sobre las listas de alumnos y, en general, sobre las lecciones de Møller, ver la Sección I. El nombre de Søren Kierkegaard no aparece en las listas de las lecciones de Møller del semestre de invierno 1832-1833 (metafísica), el semestre de verano 1833 (lógica y filosofía moral) o el semestre de invierno 1833-1834 (historia de filosofía antigua). Tampoco aparece en las listas de las lecciones de psicología del semestre de invierno 1836-1837, o de filosofía moral y psicología del semestre de verano 1837 . No obstante, a partir de esto no se puede deducir necesariamente que Kierkegaard no asistió a dichas lecciones; pudo haber estado presente sin inscribirse de forma oficial.

${ }^{37}$ Cuando, por ejemplo, Kierkegaard se refiere en SKS 20, 301, NB4:29 / JP 3, 3352 a la concepción según la cual Sócrates era un filósofo "práctico", esto no constituye necesariamente una referencia a la parte donde Møller llama a Sócrates "el fundador de la filosofía práctica” (ES1, vol. 2, p. 366), ya que esta idea no es original. Consideremos otro ejemplo, aunque no de las lecciones, sino del fragmento de la "Ontología o el sistema de categorías de Møller”. Cuando en Pap. VI C 1 / JP 5, 5798, Kierkegaard menciona la confusión hegeliana entre $\tau \rrbracket$ ov y $\tau \rrbracket \varepsilon \bigotimes v \alpha$, señala que su fuente es Rasmus Nielsen, Den propædeutiske Logik, Copenhague: P. G. Philipsen, 1845 (ASKB 699), y no el pasaje correspondiente en la obra de Møller. Cfr. ES1, vol. 3, p. 350.

${ }^{38}$ Kierkegaard también leyó las notas de Møller sobre lógica formal incluidas en el libro de texto de Berg, Grundtrækkerne af en philosophisk Propædeutik eller Erkjendel- 
Sin embargo, el borrador de la dedicatoria es más extenso y mucho más interesante, ya que contiene algunos elementos personales bastantes íntimos que quedaron fuera de la versión impresa:

\title{
Al difunto
}

Profesor Poul Martin Møller

El feliz amante de la cultura griega, el admirador de Homero, el confidente de Sócrates, el intérprete de Aristóteles, el gozo de Dinamarca en el "Gozo por Dinamarca", a pesar de "sus muchos viajes, siempre recordado en el verano danés"; el entusiasmo de mi juventud, la poderosa trompeta de mi despertar, el objeto deseado de mis sentimientos, el confidente de mis comienzos, mi amigo perdido, mi lector al que extraño

\author{
Dedico \\ Esta obra ${ }^{39}$.
}

Las partes "a pesar de 'sus muchos... verano danés' ” y "la poderosa trompeta... mis sentimientos” fueron incluidos después (en la traducción inglesa de El concepto de la angustia aparecen marcados con asteriscos). Otro detalle que vale la pena observar es que frente a "que extraño", Kierkegaard borró un "siempre". Más tarde, en la copia en limpio, borró por completo el pasaje "el entusiasmo de mi juventud... mi lector al que extraño" y lo sustituyó con una expresión más modesta: "mi admiración, mi pérdida" ${ }^{40}$.

Los traductores de El concepto de la angustia, Reidar Thomte y Albert B. Anderson, están en lo correcto cuando suponen que "la dedicatoria a Møller constituye en sí misma una evidencia de que El concepto de la angustia no es una obra seudónima en sentido estricto. Por medio del seudónimo y de las omisiones en la dedicatoria, Kierkegaard ocultó la privacidad de su relación con Møller" ${ }^{41}$. No obstante, las omisiones a las que aluden no son de la dedicatoria; probablemente están pensando en que, en el borrador, las

seslære, el cual adquirió en 1844. Acerca de las pocas partes de las lecciones que fueron publicadas en ES1, ver la Sección I.

${ }^{39}$ Pap. V B 46 / CA, Suplemento, p. 178. Citado de SKS K4, p. 344. El borrador de la dedicatoria se encuentra en el Archivo Kierkegaard, B, facsímil 15, mano 1, en la Biblioteca Real de Copenhague.

${ }^{40}$ Pap. V B 72, 3 / SKS K4, pp. 314-315. No se sabe con exactitud en qué momento se hizo esta corrección. De acuerdo con los editores de los $S K S$, la dedicatoria fue cambiada en el último minuto. SKS K4, p. 323.

${ }^{41} C A$, Notas, p. 223. 
iniciales "S. K." aparecían originalmente debajo del epígrafe o lema" ${ }^{42}$ En la copia en limpio, la página del título también cambia. El seudónimo "Vigilius Haufniensis" es insertado, mientras que la parte inferior de la hoja es suprimida. Probablemente ahí aparecía el nombre de Kierkegaard y, puesto que el libro era una obra "académica", su grado académico ${ }^{43}$. Esto es evidente si observamos el borrador del título: "Sobre / El concepto de la angustia / Una sencilla y simple deliberación psicológica sobre el problema dogmático del pecado hereditario / por / S. Kierkegaard / M. A." ${ }^{44}$. El hecho de que el seudónimo fuera introducido de forma tan tardía tal vez explica la peculiaridad de que un libro seudónimo contenga una dedicatoria ${ }^{45}$.

Existen varias teorías acerca del motivo por el que Kierkegaard decidió dedicar El concepto de la angustia de entre todos sus libros a Møller. Mencionaré brevemente algunas de estas teorías. Gregor Malantschuk sugiere que este libro constituye una realización de la idea de Møller de una nueva visión de mundo, tal como la desarrolló en su tratado sobre las pruebas de la inmortalidad ${ }^{46}$. Existe también una explicación altamente hipotética por parte de Frithiof Brandt que no tiene nada que ver con la inmortalidad en el sentido estricto, sino más bien con la juventud y los límites de la mortalidad. En El joven Søren Kierkegaard, se desarrolla una compleja teoría, basada en las ideas de P. A. Heiberg y Eduard Geismar, acerca de un trasfondo muy

42 SKS 4, 310 / CA, 3.

${ }^{43}$ Cfr. SKS K4, p. 323.

${ }^{44}$ Pap. V B 42 / CA, Suplemento, p. 177; cfr. SKS K4, p. 310.

${ }^{45}$ En una entrada del diario (SKS 18, 213, JJ:227 / KJN 2, 196), Kierkegaard se refiere al seudónimo de esta manera: "El dibujo de un observador [Vigilius, es decir, vigilante] que he garabateado en El concepto de la angustia probablemente molestará a algunas personas. No obstante, su sitio indicado es aquí y constituye una especie de marca de agua en la obra. En términos generales, siempre establezco una relación poética con mis obras, razón por la cual yo soy un seudónimo. A la par que se desarrolla algún tema en el libro, se dibuja la individualidad correspondiente. Ahora bien, Vigilius Haufniensis dibuja varias, pero además yo he incluido un dibujo de él en el libro". Este "dibujo" aparece en el Capítulo II. Cfr. SKS 4, 359-360 / CA, 54-56.

${ }^{46}$ Acerca de esto, ver Gregor Malantschuk, "Søren Kierkegaard og Poul M. Møller", en Kierkegaardiana, vol. 3, 1959, pp. 7-20 (reimpreso en Fribed og Eksistents. Studier i Søren Kierkegaards tænkning, ed. por Niels Jørgen Cappelørn y Paul Müller, Copenhague. C. A. Reizel, 1980, pp. 101-113). Sobre el tratado acerca de la inmortalidad, ver más adelante la Sección III. El concepto de "afectación cambiante" de Møller pudo haber inspirado el concepto de lo demoniaco de Kierkegaard en El concepto de la angustia. En términos generales, este libro es algo que Møller quizá hubiera llamado una "descripción moral de la naturaleza”, que es la expresión que él emplea en su teoría de la afectación. Acerca de esto, ver más adelante la Sección III, F. 
personal de El concepto de la angustia: se argumenta que Møller le ayudó a Kierkegaard en su crisis de 1836. Brandt concluye: "Entonces las explicación de la dedicatoria es obvia. El concepto de la angustia está dedicada al hombre que, con su poderosa trompeta, arrancó a Kierkegaard de su etapa libertina, y que, durante los tiempos complicados que siguieron, se convirtió en el objeto de deseo de sus sentimientos" ${ }^{47}$. Según parece, este es el resultado del minucioso análisis que Brandt hace de los elementos de la dedicatoria. Como una poderosa y apocalíptica figura paternal, una trompeta del despertar, Møller hizo que el joven Kierkegaard entrara en razón, se concentrara y, más adelante, que reflexionara sobre el pecado. Aunque no hay evidencia alguna acerca de cómo tuvo lugar este despertar, tiene que haber algo de verdad en ello. En el Diario EE, en una entrada del 28 de julio de 1839, Kierkegaard compara sus "excesos de la juventud" con el canto de las sirenas ${ }^{48}$. Møller, en cambio, lo condujo por el camino correcto ${ }^{49}$.

Møller es descrito como "el entusiasmo de mi juventud". ¿Qué significa esto? Los otros elementos del borrador también sugieren una relación personal muy fuerte y una gran confianza: "el objeto deseado de mis sentimientos, el confidente de mis comienzos, mi amigo perdido, mi lector al que extraño”. Con respecto al último punto, Møller como lector de Kierkegaard, existe evidencia limitada. De los papeles de alguien que todavía vive,

${ }^{47}$ Frithiof Brandt, Den unge Søren Kierkegaard. En række nye bidrag, Copenhague: Levin \& Munsgaard, 1929, p. 415 (el capítulo sobre Kierkegaard y Møller se encuentra en pp. 336-446).

48 SKS 18, 52, EE: 148 / KJN 2, 47.

${ }^{49}$ Para mencionar una teoría más dudosa, H. P. Rohde señala el hecho de que, en el prólogo de El concepto de la angustia (SKS 4, 314 / CA, 8), Vigilius Haufniensis dice que adoptaría con gusto el nombre "Christen Madsen". Dicha figura aparece como personaje en la obra de J. C. Hostrup (1818-1892), Gjenboerne, la cual fue estrenada en el Teatro de la Corte el 20 de febrero de 1844. En ella, tanto Kierkegaard como Møller son objeto de burla, el primero en el papel de "Søren Kirk" (en la versión impresa es cambiado por Søren Torp) y el segundo como el Teniente Buddinge. La burla gira en torno al poema "Gozo por Dinamarca". El hecho de mencionar el poema en la dedicatoria a El concepto de la angustia, libro que aparecería ese mismo año, constituiría una forma natural en la que Kierkegaard podía mostrar su reverencia y hacer una compensación por el sacrilegio cometido en contra del difunto Møller. Cfr. H. P. Rohde, "Poul Møller", en Kierkegaard's Teachers, ed. por Niels Thulstrup y Marie Mikulová Thulstrup, Copenhague: C. A. Reitzel, 1982 (Bibliotheca Kierkegaardiana, vol. 10), pp. 89-109, especialmente pp. 102-108. Cfr. también, H. P. Rohde, "Poul Møller y Søren Kierkegaard”, en Afhandlingerne på originalsproget i 'Søren Kierkegaard-Tæenkning og sprogbrug i Danmark'. Festskrift i anledning af prof. Dr. Masaru Otanis 70 års fødselsdag, Copenhague: impreso privadamente, 1983, pp. 1-22 (paginación separada; el libro original apareció en japonés en 1982). 
planeado originalmente para el Perseus de J. L. Heiberg, se publicó como libro el 7 de septiembre de 1838, medio año después de la muerte de Møller, y lo más posible es que Kierkegaard comenzara a escribir la obra a finales de abril ${ }^{50}$. Sin embargo, si nos referimos a los artículos polémicos publicados antes en el Kjøbenhavns flyvende Post de Heiberg, podemos estar seguros de que Møller leyó al menos uno, algo que es evidente a partir del Diario $A A$ :

Algo que puedo decir que, en el momento de plasmar esto, me hubiera gustado añadir, pero que omití a causa de una ridícula vanidad - pues temía que, al hacerlo, se me considerase como demasiado vano-, es el impacto producido tanto por los artículos como por su exposición. Tan solo mencionaré el hecho de que apareció un diario en el que, bajo la impresión de que el primer artículo (el que apareció en el no. 76) era de Heiberg, se decía "que él había escrito muchas cosas ingeniosas, pero nunca nada tan ingenioso; y que el viejo Rahbek, si todavía estuviera vivo, hubiera dicho que era invaluable”. También que P. Møller, quien creía asimismo que había sido escrito por Heiberg, corrió tras este en la calle para agradecérselo, "pues era lo mejor que había aparecido desde que el Flyvepost se había vuelto político". Pero no lo alcanzó y se encontró con E. Boesen, quien le dijo que había sido escrito por mín ${ }^{\text {. }}$

No cabe duda de que este gran reconocimiento significó mucho para Kierkegaard, algo que también resulta claro por el comienzo de la entrada ${ }^{52}$. El "primer artículo" al que alude es "Las observaciones matutinas en Kjøbenhavnsposten no. 43”, publicado en el Kjøbenhavns flyvende Post, no. 76, el

${ }^{50}$ Johnny Kondrup, "Tekstredegørelse til Af en endnu Levendes Papirer”, SKS K1, p. 70.

${ }^{51}$ SKS 17, 37.5-17, AA:19 / KJN 1, 31.

${ }^{52}$ Como será el caso más adelante con su preferencia del "cómo" sobre el "qué" (de una forma más compleja), en esta etapa de la obra temprana de Kierkegaard el estilo parecía ser más importante que el contenido (o al menos aquel tapaba a este), una obscuritas bastante "latina" con una sintaxis extremadamente intrincada, algo que también es obvio en sus primeros libros, De los papeles de alguien que todavía vive y Sobre el concepto de ironía. El entusiasmo de Møller por el artículo en cuestión del estudiante podría parecer un poco extraño, pero probablemente percibía el genio detrás de la forma, y reconocía que estaba bien escrito y que era humorístico. El artículo de Kierkegaard también fue reconocido por Heiberg, el editor, quien le escribió: "Una vez más, ¡mi agradecimiento por tu ensayo! En esta nueva lectura me ha complacido incluso más”. B \& A, vol. 1, p. 40 / LD, Letter 6, p. 51. 
18 de febrero de 1836, columnas 1-6 y firmado por el seudónimo "B." ${ }^{3}$. No existe evidencia de que Møller leyera los otros artículos, "Sobre la polémica de Fædrelandet" y "Al Sr. Orla Lehmann" 54 . Tampoco podemos saber si escuchó la exitosa conferencia pronunciada por Kierkegaard ante la Unión de Estudiantes el 28 de noviembre de 1835: "Nuestra literatura periodística: Un estudio de la naturaleza bajo la luz del mediodía" 55.

No obstante, lo esencial aquí no es si Møller leyó uno o más de estos artículos tal vez insignificantes, sino el hecho de que estaba bien familiarizado con el carácter polémico del joven Kierkegaard, no solo gracias a la lectura de sus escritos, sino de forma principal a través de sus conversaciones con él. Una entrada del Diario NB del 20 de enero de 1847 concluye con la siguiente observación:

Humanamente hablando, es preciso decir ahora de mí que no solo corro hacia algo incierto, sino que me precipito hacia una cierta ruina... confiando en Dios; aquí reside precisamente el triunfo. Así entendía la vida a los diez años; de ahí la extraordinaria polémica en mi alma. Así la entendía a los veinticinco años; así la entiendo ahora a los treinta y cuatro. Es por eso que Poul Møller me llamaba el más polémico de los hombres ${ }^{56}$.

Esta observación se repite en una importante entrada del verano de 1854 del Diario NB30, donde se lee el siguiente comentario retrospectivo acerca de la predisposición permanente de Kierkegaard para la polémica, una cualidad o vicio que, en esta última etapa de su vida, comenzó a desplegarse de forma incluso más intensa al servicio de "lo extraordinario". Sin embargo, recuerda bien que esta disposición suya era a menudo censurada por Møller (y, más tarde, por el "sucesor” de Møller, Sibbern):

${ }^{53}$ Cfr. Bl. art., 3-8 / EPW, 6-11.

54 "Om Fædrelandets Polemik", publicado en dos partes, Kjøbenhavns flyvende Post, no. 87, columnas $1-8$, y no. 83, columnas 1-4, 12 y 15 de marzo de 1836. Los artículos también fueron firmados con el seudónimo "B". "Til Hr. Orla Lehmann”, Kjøbenhavns flyvende Post, no. 87, columnas 1-8, 10 de abril de 1836; firmado por "Søren Kierkegaard". Cfr. Bl. art., 9-31 / EPW, 12-34. No está documentado que Møller leyera el primer artículo de Kierkegaard, “Ogsaa et Forsvar for Qvindens høie Anlæg”, firmado por “A”, en Kjøbenhavns flyvende Post, no. 34, 17 de diciembre de 1834, columnas 4-6; cfr. EPW, 3-5.

${ }^{55}$ Pap. I B 2 / JP 5, 5116; EPW, 35-52.

56 SKS 20, 83, 17-23, NB: 107 / JP 5, 5961. 


\section{Lo extraordinario}

En cierto sentido es terrible, casi fatal, ser lo extraordinario bajo las condiciones polémicas de lo extraordinario cristiano. No es solo que esto constituye el esfuerzo más grande, casi sobrehumano, sino que esta relación de oposición frente a los otros y las dimensiones de dicha oposición resultan casi fatales para toda simpatía meramente humana.

Es por ello que solo he deseado - la simpatía es mi pasión — señalar de forma constante lo extraordinario.

Recuerdo las palabras del moribundo Poul Møller, mismas que a menudo me dirigía en vida y que, si recuerdo bien, le recomendó a Sibbern que me las repitiera (más las palabras: Dile al pequeño Kierkegaard que debe cuidarse de no diseñar un plan de estudios demasiado grande, ya que eso ha sido muy perjudicial para mí): Eres tan polémico que da miedo.

A pesar de que soy tan polémico —y lo era ya incluso en mi juventud-, el cristianismo es casi demasiado polémico para mî́ ${ }^{57}$.

Según Møller, un plan de estudios demasiado grande había sido perjudicial para él y deseaba que el joven Kierkegaard no pasara por lo mismo. Es indudable que Møller estaba pensando de manera principal en sus tormentos personales al leer a Hegel y a otros autores — de acuerdo con las cuidadosas instrucciones de su amigo Sibbern-, y la gran cantidad de conocimientos que tuvo que adquirir cuando se convirtió en profesor de filosofía. Había sido un trabajo duro. En el caso del joven Kierkegaard, la palabra "estudios" se refiere más bien a las abundantes lecturas que emprendió en aquellos años: sus queridos estudios estéticos sobre el romanticismo, Fausto, Don Juan, Ahasverus y todo tipo de cosas. Por ejemplo, en la entrada BB:51 emplea la expresión "mis estudios" para referirse a su gran proyecto; en Not3:16, "mi proyecto" hace alusión a lo mismo ${ }^{58}$. Con relación a este fenómeno, Henning Fenger dice: "No tiene sentido intentar forzar algún plan o modelo sobre semejante masa incoherente de material. Esto nos muestra a Kierkegaard en su etapa Sturm und Drang, cuando su genio busca encontrarse a sí mismo de diversas maneras, a través de la religión, la filosofía, la estética y, por último, aunque no por ello menos importante, la literatura"59.

${ }^{57}$ SKS 25, 459-461, NB30:93 (hay un facsimilar de esta página del diario en p. 460) / JP 6, 6888 .

${ }^{58}$ Cfr. Finn Gredal Jensen y Kim Ravn, "Tekstredegørelse til journalen BB”, SKS K17, p. 139, nota, y Niels W. Brunn y Finn Gredal Jensen, "Tekstredegørelse til notesbog 3", SKS K19, pp. 145-146.

${ }^{59}$ Henning Fenger, Kierkegaard, the Myths and Their Origins: Studies in the Kierkegaardian Papers and Letters, trad. de George C. Schoolfield, New Haven y Londres: Yale 
En el margen, Kierkegaard añade una pequeña explicación. Con relación a su presunto carácter polémico, no está muy convencido de que ésas hayan sido las palabras que Møller le encomendó a Sibbern que repitiera, "Eres tan polémico que da miedo", pero está seguro de que Møller "siempre me lo decía en vida”. Según parece — de acuerdo con esta y muchas otras fuentes-, Sibbern asumió tiempo después el papel de consejero intelectual:

No recuerdo con exactitud si el moribundo P. M. le recomendó a Sibbern que me dijera esas palabras (Eres tan polémico, etcétera), y estoy casi tentado a dudarlo. No obstante, recuerdo muy bien las otras palabras que le pidió a S., en su último encuentro antes de morir, que me dijera. En cuanto a las primeras palabras (Eres tan polémico), eso siempre me lo decía en vida. También $\mathrm{S}$. me las ha dirigido en varias ocasiones tiempo después ${ }^{60}$.

En cualquier caso, la persona con la que Sibbern lidiaría más adelante era un Kierkegaard extremadamente parlanchín ${ }^{61}$. La hija de Sibbern, Augusta Sibbern Møller, le escribió a Harald Høffding: "Uno de mis recuerdos de infancia es el estar caminando de la mano con mi padre mientras S. Kierkegaard, al lado de nosotros, hablaba con entusiasmo y se detenía de forma frecuente para hablar con claridad acerca de cosas que eran importantes para él" ${ }^{2}$. Sibbern mismo escribe que Kierkegaard "estaba preocupado de forma constante consigo mismo... con aquello que se revolvía dentro de él y con la manera de expresarlo" ${ }^{63}$. No es sencillo determinar si esto era muy

University Press, 1980, p. 97.

${ }^{60}$ SKS 25, 461, NB30:93.a / JP 6, 6889. No se sabe cuándo fue la última vez que Sibbern habló con Møller. Se conserva una breve carta sin fecha; dice lo siguiente: “¡Querido Sibbern! / Hazme el favor de venir a visitarme, si tus asuntos te lo permiten, pero quédate tan solo cinco minutos. Mi sangre está algo agitada; no puedo hablar por mucho tiempo. / Tu / P. Møller”. Citado en Sejer Kühle, Søren Kierkegaard. Barndom og ungdom, Copenhague: Aschehoug, 1950, p. 108. La carta no se encuentra en la edición de Borup ni en las Breve til og fra Sibbern, vols. 1-2, ed. por C. L. N. Mynster, Copenhague: Gyldendal, 1866.

${ }^{61}$ Cfr. Kühle, Søren Kierkegaard. Barndom og ungdom, pp. 109-110.

${ }^{62}$ Carta de Augusta Sibbern Møller a Harald Høffding, fechada el 7 de diciembre de 1912, Biblioteca Real, NKS 4620, 4. Citada en Encounters with Kierkegaard, p. 19. Cfr. Jens Himmelstrup, Sibbern. En Monografi, Copenhague: J. H. Schultz, 1934, p. 262.

${ }^{63}$ Carta de Sibbern a H. P. Barfod, cfr. Encounters with Kierkegaard, pp. 216-217. En cuanto al papel de Sibbern después de la muerte de Møller, también es preciso tener en cuenta la carta de Kierkegaard desde Berlín a Sibbern del 15 de diciembre de 1841. Aquí se lee: "Incluso ahora que no puedo verificarlo por mí mismo de forma cotidiana, jamás Estudios Kierkegaardianos. Revista de filosofía (2015) 
diferente en el caso de su relación con Møller. El hecho de que Kierkegaard hablara la mayor parte del tiempo no implica, sin embargo, que su genio fuera el superior, sino más bien que ambos eran iguales, pero sus papeles eran muy diferentes: Møller era el liberador socrático de ideas que tal vez estaban ya ahí, y, Kierkegaard, aquel que las llevaba más allá.

Existe un único testimonio de Kierkegaard acerca de una conversación sostenida con Møller, a saber, una entrada del 6 de julio de 1837 en el Diario DD (citada completa en la Sección III, C, más adelante). Esta "muy interesante conversación", la cual tuvo lugar la tarde del 30 de junio, era sobre la ironía y el humor. Según la versión de Kierkegaard, Møller comparaba la relación entre Cristo y sus discípulos con el amor con el que "Sócrates ceñía a sus discípulos" ${ }^{64}$. Por este motivo, al hablar de Møller, "el objeto deseado de mis sentimientos", parece natural que Kierkegaard piense en seguida en Sócrates, el liberador, y en el carácter del amor por sus "discípulos" ${ }^{55}$.

En Møller mismo no hay ningún rastro de su discípulo, Søren Kierkegaard. Sin embargo, aparecen evidencias de una relación dialéctica con un "Kierkegaard" en una carta de 1837 dirigida a su hermano menor, Hans Ulrik Møller (1796-1862), con el que habla de su tratado sobre la inmortalidad, que acababa de publicarse. En esta carta, se lee lo siguiente: "Disfruto de forma especial los debates en conversación con gente que puede tolerar el ser refutada con habilidad y que, también, se apresura a entender lo que su interlocutor ha querido decir. Así, el año pasado sostuve en una ocasión

he puesto en duda que mantendrías algo del interés con el que siempre me has honrado, especialmente después de la muerte de Poul Møller”. B E A, vol. 1, p. 83 / LD, Carta 55, p. 106; Breve til og fra Sibbern, vol. 1, p. 196. Según esta misma carta, se lee que Sibbern le había aconsejado a Kierkegaard, en vano, que tradujera Sobre el concepto de ironía al alemán. Sibbern había fungido como opponens ex officio durante la defensa de Kierkegaard de su tesis algunos meses antes.

${ }^{64}$ SKS 17, 225, DD:18 / KJN 1, 216.

${ }^{65}$ También es importante observar la entrada JJ:54 de 1843, que lleva el encabezado "Mi juicio sobre O lo uno o lo otro": "Había un joven extraordinariamente talentoso como un Alcibíades. Se extravió en el mundo. En su necesidad, buscó a un Sócrates, pero no encontró a ninguno entre sus contemporáneos. Entonces les suplicó a los dioses que lo convirtieran en uno. ¡Y vean! Él, que tan orgulloso se había sentido de ser un Alcibíades, se rebajó y humilló en tal medida ante la merced de los dioses que, precisamente cuando obtuvo aquello de lo cual podía sentirse orgulloso, se sintió el más inferior de todos”. SKS 18, 157, JJ:54 / KJN 2, 146. Nótese la expresión "no encontró a ninguno entre sus contemporáneos”. Y es que Møller, su Sócrates, había muerto y no se encontraba ya, por tanto, entre sus contemporáneos. Georg Brandes, el primer biógrafo de Kierkegaard, habla de esta entrada, aunque en un contexto en el que no menciona a Møller. Cfr. Søren Kierkegaard. En kritisk Fremstilling $i$ Grundrids, Copenhague: Gyldendal, 1877, pp. 44-45. 
un largo debate con el Kierkegaard al que conoces, y me inspiró un gran interés" ${ }^{66}$. Lo más probable, sin embargo, es que el Kierkegaard al que aquí se refiere no sea Søren Kierkegaard, como algunos han supuesto ${ }^{67}$, sino su hermano, Peter Christian Kierkegaard, a quien Møller también conocía ${ }^{68}$.

A partir de fuentes de segunda mano, en cambio, resulta obvio que Søren Kierkegaard y Møller compartieron juntos mucho tiempo y, para una persona como Kierkegaard, tiempo es sinónimo de palabras. En su biografía de Møller, Vilhelm Andersen escribe que a menudo podía verse a los dos juntos en la calle, así como en otros lugares públicos ${ }^{69}$. En el diario del poeta Henrik Hertz (1797/8-1870) del 4 de junio de 1836 se lee lo siguiente: "Tarde donde los $\mathrm{Hb}$ [los Heiberg] y despedida antes de su viaje a París. Kierkegaard, Poul Møller, etcétera, estaban ahî"70. Esto no dice mucho; solo insinúa que visitaban los mismos círculos. De manera parecida, incluso el hecho de que, en sus últimos años (1836-1838), Møller vivió en Nytorv, la misma plaza en la que Kierkegaard vivió en el hogar paterno hasta el 1 de septiembre de 1837, no constituye una evidencia de que se vieran de forma $\operatorname{privada}^{71}$.

${ }^{66}$ Borup, carta no. 151. Publicada antes por Morten Borup en "F. C. Olsens brevarkiv på Det kgl. Bibliotek", Fund og Forskning i Det Kongelige Biblioteks Samlinger, vol. 3 , 1956, pp. 103-116; pp. 113-114.

${ }^{67}$ Cfr. Uffe Andersen, Poul Møller og romantismen — den filosofiske idealisme i Poul Møllers senere forfatterskab, Copenhague: Gyldendal, 1973, p. 86; cfr. pp. 67-68.

${ }^{68}$ Estoy de acuerdo con Morten Borup, quien, en su nota a la carta, señala que "Poul Møller conoció tanto a Peter Christian como a Søren K., pero todo indica que la persona en este caso es el mayor de los dos, P. C. K.”. Poul Møller og hans Familie i Breve, vol. 3, p. 120. En una carta anterior, escrita en un tono muy amigable y fechada el 17 de octubre de 1830, en la cual Møller responde a la pregunta de P. C. Kierkegaard sobre su puesto en Christiania (Oslo), para el que este estaba pensando postularse (Borup, carta no. 116), Møller le agradece por su disertación doctoral acerca del concepto de la mentira (la cual Møller reseñaría tiempo después de forma minuciosa en el Maanedskrift for Litteratur) y también "por la amable disposición con la que has guardado la memoria de nuestra vida social en Copenhague".

${ }^{69}$ Vilhelm Andersen, Poul Møller, p. 394. Como sucede de forma frecuente, Andersen no menciona ninguna fuente para fundamentar esta afirmación.

${ }^{70}$ Encounters with Kierkegaard, p. 218; la referencia se encuentra en la p. 328.

${ }^{71}$ Møller vivía en el no. 117, hoy 17, en Nytorv. Cfr. Tudvad, Kierkegaards København, p. 29. Kierkegaard vivió en el hogar paterno, Nytorv no. 2, en apariencia hasta el 1 de septiembre de 1837, cuando se mudó a Løvstræde. Cfr. Tudvad, Kierkegaards København, p. 31. A fin de ser minucioso, mencionaré un testimonio más. En el verano de 1851, Kierkegaard recibió una carta de Petronella Ross, la antigua ama de llaves de Rasmus Møller. Ella escribe: "Conozco a tu hermano en Selandia y en mi juventud fui amiga de su primera esposa, Marie B.; por muchos años viví en la casa del difunto obispo Møller (tú conociste a 
Más importante es el testimonio de Hans Brøchner (1820-1875). En sus "Recuerdos de Søren Kierkegaard", relata un episodio que resulta muy típico en la forma en que describe la personalidad de Møller. Tuvo lugar el 25 de octubre de 1836, durante la defensa doctoral de F. O. Lange, en la cual Møller y Madvig eran los oponentes ${ }^{72}$. Brøchner recuerda lo que Kierkegaard le contó:

S. K. a menudo mencionaba a Poul Møller, siempre con la más profunda devoción. Mucho más que sus escritos, aquello que hizo una impresión en él fue el carácter de Poul Møller. Le apenaba que pronto iba a llegar el momento — cuando la memoria nítida de su personalidad se hubiera desvanecido y los juicios sobre él se basaran en sus obras- en el que su importancia ya no sería comprendida. En cierta ocasión me contó un pequeño y divertido episodio relacionado con P. Møller. Este iba a fungir como oponente ex officio en una defensa doctoral y había apuntado sus observaciones en varias hojas sueltas colocadas en medio de la disertación. Cada objeción la iniciaba con la frase graviter vitupe-

Poul Martin, su querido hijo). La esposa del obispo Boisen me colocó aquí”. $B \in A$, vol. 1, p. 304 / LD, carta 280, p. 387. Sin embargo, decir que Kierkegaard "conocía" a Møller no es información demasiado útil, ya que esto puede significar casi cualquier cosa.

${ }^{72}$ Frederik Olaus Lange (1798-1862) había sido uno de los maestros de Kierkegaard en el Colegio Borgerdyd y Møller lo conocía de forma personal. En su biblioteca, Kierkegaard tenía la disertación de Lange, De casuum universis causis et rationibus commentatio grammatica, Copenhague: Popp, 1836 (ASKB 610); es obvio que Lange es el maestro de griego del que se habla en Johannes Climacus o De omnibus dubitandum est. Pap. IV B 1, p. 107 / JC, 121. Anteriormente, Møller había reseñado la gramática griega de Lange, Det græske Sprogs Grammatik til Skolernes Brug, en Dansk Litteratur-Tidende, 1827, no. 5, pp. 65-74 (la reseña no aparece en los Efterladte Skrifter). Møller y su esposa frecuentaron a los Lange hasta 1833, cuando éstos se mudaron a Vordingborg, donde Lange enseñaba en el colegio — del que fue director a partir de 1841- mientras trabajaba en su disertación. Cuando el colegio cerró en 1846, Los Lange regresaron a Copenhague y él recibió un puesto en la universidad. Gracias a uno de los hijos de Lange, el historiador del arte Julius Lange (1838-1896), conservamos la divertida evidencia — en una carta dirigida a Vilhelm Andersen fechada el 27 de diciembre de 1894- de que a su madre, Louise Paludan-Müller (1803-1862), Møller le parecía un "carnicero", y que ella no aprobaba su hábito perpetuo de hacer constantemente un análisis psicológico de sus alrededores. Según Julius Lange, el carácter de su madre tampoco le agradaba a Møller, ya que "con su poderosa y audaz habilidad de reflexión, ella se ocupaba de todo en el cielo, la tierra y lo intermedio, algo que sobrepasaba de forma importante los límites de la femineidad que él, quien era un poco estrecho de miras, deseaba determinar... Es más probable que hiriera los sentimientos de ella con sus afirmaciones un poco críticos sobre las primeras obras de su muy querido hermano menor, Frederik Paludan-Müller (1809-1876)". Breve fra Julius Lange, ed. por P. Købke, Copenhague: Det nordiske Forlag, 1902, pp. 315-316. 
randum est [es preciso criticar seriamente], pero en cuanto el doctorando respondía a su objeción, él decía en tono amistoso Concedo, y pasaba a la siguiente objeción. Después de un debate bastante breve, concluía expresando su pena sincera de que el tiempo asignado no le permitiera continuar con esta interesante conversación. Al retirarse, pasó junto a S. K., quien estaba en el auditorio, y le dijo en voz baja: "¿Vamos a Pleisch?” esta era la sala de té que solían frecuentar. Mientras hablaba en su posición de oponente, todas sus hojas sueltas cayeron del libro y salieron volando. Ver al gran hombre arrastrándose y recogiendo las hojas desperdigadas, contribuyó no poco a levantar el ánimo en el auditorio $^{73}$.

Como ya se mencionó antes, el primer biógrafo de Møller fue su amigo F. C. Olsen, el coeditor de los Escritos póstumos, quien incluyó su "Vida de Poul Martin Møller” en la edición. Kierkegaard, desde luego, la leyó cuando se publicó en 1843, y esto le proporcionó un motivo de queja, el cual expresa al final de una larga nota al pie en el Postscriptum definitivo y no científico de 1846. Tiene que ver con Møller y el hegelianismo, a saber, que, hacia el final de la vida de aquel, se estaba alejando de este (o, mejor dicho, de Heiberg) y estaba a punto de pasar a algo completamente nuevo, lo cual quedó interrumpido por una muerte temprana. Sin embargo, hacia el final de la nota, Kierkegaard tiene la oportunidad de ofrecer una descripción muy personal del carácter de Møller. De forma típica, escribe primero en la misma nota sobre Hegel y acerca de cómo Sócrates, el maestro, hubiera podido tener algo de qué reírse, justo como Møller hacía con frecuencia:

Tal vez esta nota sea un sitio adecuado para una queja que tengo. En la Vida de Poul Martin Møller hay una sola referencia que expresa la manera en que él consideraba a Hegel en sus últimos años. En su mesura, el editor probablemente se ha tomado la libertad de dejarse guiar por la parcialidad y por su reverencia por el difunto, por un respeto incómodo frente a lo que cierta gente podría decir, aquello que un público especulativo, casi hegeliano, podría juzgar. No obstante, precisamente cuando pensaba estar actuando a favor del difunto, el editor tal vez dañó su imagen. Más notable que varios aforismos incluidos en la colección impresa e igualmente digno de mención que varios episodios juveniles conservados por este editor cuidadoso y de buen gusto en su

${ }^{73}$ Encounters with Kierkegaard, p. 241. Las memorias de Brøchner fueron redactadas entre diciembre de 1871 y enero de 1872, y fueron publicadas de manera póstuma en 1877 (Brøchner murió en 1875) en Det nittende Aarbundrede, vol. 5, pp. 337-374. 
encantadora y noble presentación, es el hecho de que P. M., cuando todo aquí en casa era hegeliano, tuvo una opinión bastante diferente; el hecho de que por algún tiempo, al comienzo, habló de Hegel casi con indignación, hasta que su naturaleza íntegra y humorística le hizo sonreír, especialmente frente al hegelianismo, o, para recordar una imagen de P. M. más precisa, hasta que le hizo reír de corazón. ¿Quién ha estado encantado con P. M. y ha olvidado su humor? ¿Quién lo ha admirado y olvidado su integridad? ¿Quién lo ha conocido y olvidado su risa, la cual resultaba benéfica aunque no fuera del todo claro de qué se estaba riendo? Y es que su carácter despistado a veces lo dejaba a uno perplejo ${ }^{74}$.

Esta "sola referencia" que Kierkegaard menciona, pero que no explica, se encuentra en un contexto en el que Olsen describe la relación de Møller con Hegel en el tema de la metafísica. Møller se estaba alejando de Hegel, dice Olsen, "y seguía con gran interés la oposición a este filósofo y a sus seguidores. De hecho, llegaba a molestarse, aunque solo con los segundos"75. En una nota al pie, ofrece un ejemplo de esto último:

He aquí un ejemplo de uno de esos juicios sorpresivos y, de hecho, casi terribles que uno podía escuchar de su parte ocasionalmente. Un amigo le pidió en cierta ocasión que intentara expresar en una frase breve la clave de la filosofía hegeliana. Poul Møller se quedó callado por un instante, acariciándose la barbilla mientras estaba sentado en el sofá, y dijo: "Sí, Hegel en verdad está loco. Padece de una monomanía y piensa que el Concepto puede extenderse de esta manera”. En ese momento hizo unos movimientos circulares con las manos y ya no dijo nada más ${ }^{76}$.

El veredicto "loco" debió haber resultado demasiado fuerte para Kierkegaard, después de todo, así que este decidió omitirlo, pero aun así le pareció correcto incluirlo en un contexto diferente del Postscriptum. En la Parte 2, Sección 2, Capítulo $3, \mathbb{S} 2$, hay un pasaje en el que se lee: "Si el sistema carece, por lo demás, de una ética, termina por ser totalmente moral con el auxilio de la categoría de la mala infinitud, tan exageradamente moral que la

\footnotetext{
${ }^{74}$ SKS 7, 40.31-36 y 41.6-18 / CUP1, 34, nota.

${ }^{75}$ F. C. Olsen (en ES1), p. 109.

${ }^{76}$ Ibid., nota al pie. Una parte se encuentra traducida en CUP2, p. 189, nota 40.
} 
utiliza incluso en la lógica"77. Esto apareció en lugar de la siguiente reflexión acerca del escepticismo y la locura, la cual encontramos en el borrador:

La autorreflexión era un escepticismo; se supera en el pensamiento puro. Sin embargo, el pensamiento puro es un escepticismo aún más extremo. A pesar de toda la interioridad de la autorreflexión, ha sido incapaz de olvidar su relación con la realidad en el sentido de realidad, su relación con el an sich que la persigue. No obstante, el pensamiento puro es positivo cuando aborda todo este asunto de forma imaginativa y lo traslada a una esfera en la que no hay ninguna relación con la realidad. Al pensamiento puro ni siquiera se le ocurre que es escepticismo, aunque esto constituye por sí mismo el más extremo de los escepticismos. Sin insistir demasiado en esto, si se comparase el escepticismo con la locura, una persona que sospecha que padece de locura y que, en medio de este conflicto, va por la vida, estaría menos loca, pese a todo, que aquella que triunfa con júbilo como la más inteligente de todas ${ }^{78}$.

En un tono parecido, Kierkegaard añadió lo siguiente al margen: "Y los lectores daneses no olvidarán que Poul Møller pensaba que Hegel estaba loco"79. Con todo, nada de esto apareció en la edición final del Postscriptum, en la cual solo está la insinuación de la nota al pie antes mencionada.

Poul Martin Møller murió el 13 de marzo de 1838, antes de cumplir los cuarenta y cuatro años. En abril, Kierkegaard escribió en su diario: "Poul Møller está muerto" ${ }^{80}$. Lo breve del comentario —el cual, no obstante, está subrayado en el manuscrito- quizá resulte sorpresivo, pero antes de esto escribe sobre su pesar: "Otra vez ha pasado un largo tiempo sin que pudiera concentrarme en lo más mínimo. Intentaré tomar de nuevo impulso" ${ }^{81}$. En una nota marginal romántica y sumamente poética, fechada el 1 de abril, permite que sus pensamientos melancólicos se vayan volando: "Esta mañana vi una media docena de gansos que volaban en el frescor del aire. Primero estaban justo sobre mi cabeza, después se fueron alejando cada vez más, hasta que finalmente se dividieron en dos bandadas y se arquearon como las cejas de mis ojos, que ahora contemplaban la tierra de la poesía" ${ }^{82}$. La tierra de la poesía es un país en el que se parte de este mundo, el anticipo de

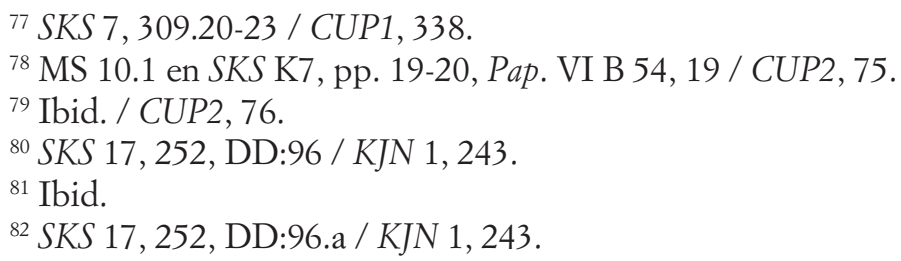


la vida eterna, de la cual hay también un reflejo en otra entrada, probablemente del mismo día: "Si para un verdadero cristiano todo se oscurece a la hora de su muerte, es porque la luz del sol de la bienaventuranza brilla con demasiada fuerza ante sus ojos" ${ }^{\prime 3}$. Al menos puede decirse que esta tierra de la poesía apareció con fuerza cuando la tarde del 1 de abril el joven Kierkegaard escuchó a un actor recitar el poema de Møller, "Gozo por Dinamarca”, y se sintió extrañamente conmovido por las palabras: “ ¿Recuerdan a ese hombre de muchos viajes? Sí, ahora ha viajado muy lejos. Pero al menos yo lo recordaré" $"$.

\section{Referencias a los escritos de P. M. Møller}

Por supuesto, Søren Kierkegaard compró la primera edición de los Escritos póstumos (1839-1843, ASKB 1574-1576) de Møller. De forma extraña, parece que en ninguna parte hay referencias o alusiones a la principal obra en prosa de Møller, la novela inconclusa Aventuras de un estudiante danés, partes de la cual Møller leyó en la Unión de Estudiantes en 1824. Los fragmentos se publicaron por primera vez en 1843, en el volumen 3 de los Escritos póstumos ${ }^{85}$. No obstante, sobra decir que debió escuchar de la novela en cuanto esta apareció; de forma parecida, debía conocer los otros escritos que se hicieron públicamente accesibles en esta edición ${ }^{86}$. Esto resulta claro por su reacción cuando, para su cumpleaños trece, le obsequió a su sobrina, Henriette Lund (1829-1909), una copia de los escritos de Møller y se enteró de que ya se había entretenido con la historia del "rizado Frits"

83 SKS 17, 252, DD:99 / KJN 1, 243.

${ }^{84}$ SKS 17, 253, DD:101 / KJN 1, 244. Regresaré al poema “Gozo por Dinamarca” en la Sección III, B.

${ }^{85}$ Existe una comparación particular de estas dos importantes publicaciones de 1843 , el volumen 3 de los Escritos póstumos de Møller y O lo uno o lo otro de Kierkegaard, en una carta de Signe Læssøe a Hans Christian Andersen, fechada el 7 de abril de 1843: "Aquí ha aparecido otro libro — como puedes ver, somos productivos, aunque no sea la temporada literaria - tan agradable como desagradable es $O$ lo uno o lo otro, a saber, la tercera parte de las Obras de Poul Møller”. Cfr. Encounters with Kierkegaard, p. 58.

${ }^{86}$ No hay evidencia de que Møller leyera en público su novela después de 1824. Tal vez lo hizo de forma privada, pero todo indica que Kierkegaard no la conoció sino hasta su publicación en 1843 .

${ }^{87}$ En sus memorias, publicadas después de su muerte en 1909, se lee que "el bueno de Anders [el criado de Kierkegaard] volvió con una nueva carta con contenidos bastante nuevos, acompañada con un paquete que, después de revisarlo, resultó que eran las obras póstumas de Poul Møller. Tan solo algunos días antes, en casa de mis primos, me encon- 
Es importante destacar que, como se ha observado, puede percibirse que Kierkegaard había leído y estaba al tanto de todos los escritos de Møller a los que tenía acceso, aunque, desde luego, no estimaba necesario mencionar o reflexionar acerca de cada uno de estos textos. Esto debe tenerse en cuenta cuando, en lo sucesivo, se hable de las referencias y alusiones a los escritos de Møller en Kierkegaard. Nótese bien que partes que se encuentran en los escritos póstumos de Møller a veces son mencionadas por Kierkegaard en un momento anterior a su publicación (por ejemplo, aquellas que se refieren a la ironía), pero en esos casos es importante considerar la posible influencia de las fuentes orales, es decir, aquello que Kierkegaard podía recordar de sus conversaciones.

En el siguiente planteamiento del uso - o posible uso- de los escritos de Møller por parte de Kierkegaard, el orden será cronológico en la medida de lo posible. Comenzaré con la sátira temprana en contra de Grundtvig, "Esbozo de una carta desde el cielo" (Sección III, A), y hablaré de los dos poemas a los que Kierkegaard les dedica una atención especial (Sección

tré con un libro que me redujo al mismo estado que aquel hombre del que el rey español observó: ‘¡O bien está loco, o bien está leyendo el Don Quijote!' La historia del 'rizado Frits' me ha hecho retorcerme de la risa. Ahora que lo atesoro en mis manos como mi justa propiedad, me siento tan abrumada de éxtasis que me cuesta trabajo encontrar las palabras para expresarle esto al tío Søren. Incluso así, se sintió un poco decepcionado de que el azar hubiera puesto en mis manos un libro de Poul Møller antes de que él lo hiciera”. Henriette Lund, Erindringer fra Hjemmet, Copenhague: Gyldendal, 1909, pp. 119-120. Cuando dice que esto ocurrió en su cumpleaños doce (Encounters, p. 165), es decir, en 1842 (ella nació en 1829), debe de estar equivocada, ya que Aventuras de un estudiante danés apareció en el volumen 3 de ES1 en 1843. También mencionaré un hecho curioso del cual Kierkegaard no estaba enterado. Henrik Hertz tenía planeado escribir una sátira —que nunca terminaría-, La quinta monarquía, en la que Kierkegaard iba a ser un personaje. Cfr. Encounters with Kierkegaard, pp. 221-224. Entre otras cosas, Kierkegaard seduciría a una muchacha dentro de una tienda de acampar, "pero bajo uno de sus seudónimos de escritor", y diría "que no es responsable de lo hecho por esa firma" (Encounters, p. 222). Con relación a Poul Møller, el personaje de Kierkegaard "también puede hacer alusión a la escena en Aventuras de un estudiante danés de Poul Møller, en la que Frits, de trece años, en su aventura romántica pretende ganarse el pan con su violín y, estando en la granja de un pobre labrador, es interpelado de forma prosaica y brusca por una campesina. Ahora bien, esto último hubiera sido representado de forma incluso más tosca por el autor de Una bistoria cotidiana. Este habría buscado una antítesis en dos personalidades: Frits, con sus inclinaciones poéticas y libres, y la campesina, sumida por completo en la prosa de la vida. Pero iqué diferente es la claridad poética y radiante que P. Møller arroja sobre la situación! La mujer descubre que era la nodriza de Fritz, y en ese momento toda la fuerza poética de su existencia (misma que se encuentra en toda existencia) se revela a través de su dura cubierta. Frits está lejos de ser absorbido por completo en lo poético" (Encounters, p. 224). 
III, B). Me enfocaré entonces en la filosofía, primero en los fragmentos de Møller sobre la ironía y el nihilismo, incluido su interés con la figura de Ahasverus (Sección III, C). Analizaré a continuación (Sección III, D), desde el punto de vista de Kierkegaard, la reseña de la novela de Thomasine Gyllembourg, Los extremos. Después compararé el ensayo "Sobre contarles a los niños cuentos de hadas" con el análisis de Kierkegaard del mismo tema (Sección III, E). El rasgo característico de Møller como escritor fragmentario aparece de forma especial en sus Pensamientos dispersos, algunos de los cuales son mencionados por Kierkegaard, incluyendo un aforismo acerca del concepto de afectación, el cual era de importancia fundamental para la filosofía de Møller (Sección III, F). Por último, hablaré de la referencias de Kierkegaard al tratado filosófico de Møller de 1837, "Pensamientos sobre la posibilidad de una demostración de la inmortalidad humana, con referencia a la literatura más reciente sobre el tema", esto visto bajo la luz del debate contemporáneo sobre la inmortalidad del alma (Sección III, G).

\section{A. "Esbozo de una carta desde el cielo"}

La pequeña pieza satírica titulada "Esbozo de una carta desde el cielo según el nuevo gusto histórico de Grundtvig, descubierto por Poul Møller" se publicó en Nyeste Skilderie af Kjøbenhavn el 19 de diciembre de $1818^{88}$. Se trata de una parodia del peculiar estilo de N. F. S. Grundtvig en sus varias contribuciones a la controversia literaria entre Adam Oehlenschläger (1779-1850) y Jens Baggesen, en la cual Møller participó como un miembro de "Tylvten" ("los doce"), un grupo de estudiantes admiradores que acudieron al apoyo del poeta laureado, Oehlenschläger, cuando Baggesen lo atacó $^{89}$. Los doce estudiantes desafiaban públicamente a Baggesen al exigir-

88 "Forsøg til et Himmelbrev i Grundtvigs nye, historiske Smag, fundet af Poul Møller", en Nyeste Skilderie af Kjøbenhavn, vol. 15, ed. por S. Soldin, Copenhague, 1818, no. 101, columnas 1696-1699; reimpreso en ES1, vol. 1, pp. 195-200.

${ }^{89}$ Sobre esta controversia, ver, por ejemplo, Kristian Arentzen, Baggesen og Oeblenschläger. Litteraturbistorisk Studie, vols. 1-8, Copenhague: Otto B. Wroblewsky, 1870-1878, especialmente el vol. 7. La dicotomía estética Grundtvig-Oehlenschläger también es tratada por Møller más tarde cuando en uno de sus pensamientos dispersos escribe lo siguiente: "Existe un modo de producir ideas que es característico de la época cristiana que está completamente en conflicto con el gusto antiguo. El autor no empieza a darle vueltas a la idea de una obra clásica sino hasta que esta ha madurado en él, y no dedica constantes críticas y esfuerzos a la producción de la idea. Por el contrario, toda su vida constituye una continua actividad literaria; sus conceptos se desarrollan durante la obra, de manera que su vida entera como autor no debería sino considerarse como un tren de pensamiento público, una 
le que defendiera en latín sus críticas y su comportamiento (varios de los estudiantes, incluido Møller, eran latinistas consumados y debatían en latín en el club de lectura llamado "Lyceum" ${ }^{90}$. Møller desempeñó un papel principal en esto al entregarle el desafío a Baggesen y, cuando este lo rechazó, al amenazarlo con que tres cuartas partes de los estudiantes residentes del dormitorio Regensen (donde también Møller vivía a veces) acudirían a abuchear una pieza compuesta por uno de los amigos de Baggesen, a saber, $\mathrm{La}$ profecía de Tycho Brahe de Heiberg ${ }^{91}$. Møller escribió una espléndida parodia, "Sobre la pequeñez de Jens", acerca de un poema de Baggesen de 1786, "Hubo un tiempo en que era muy pequeño"92. Y escribió el "Esbozo de una carta desde el cielo", al cual Kierkegaard probablemente se refiere cuando en el Diario DD, en una entrada fechada el 13 de julio de 1837, emplea la expresión: "Hecha en nuestro estudio" 93 . De forma parecida, concluye una carta dirigida a Regine Olsen en el otoño de 1840 con una mención a Mø-

especie de confesión ininterrumpida. Es posible observar su empeño en todas las etapas por las que ha pasado, como si se tratara de una corriente continua, pero no pueden verse productos terminados con una vida orgánica independiente. El Nachlass literario de Jean Paul es un ejemplo adecuado de esta productividad ilimitada, misma que tiene su principio exclusivamente en el autor mismo; para considerar un ejemplo más cercano, las obras de Grundtvig, Goethe y Oehlenschläger poseen, en cambio, un valor como arte clásico”. ES1, vol. 3, p. 233.

${ }^{90}$ El desafío a Baggesen fue impreso más tade - en latín, desde luego- en el diario Dagen, no. 236, 1816, firmado por "los doce": A. G. Rudelbach, P. M. Møller, C. Hauch, C. Lütken, C. Flor, W. R. Dichman, N. B. Krarup, H. Brøchner (un teólogo que no ha de confundirse con el filósofo, quien todavía no había nacido), G. A. Dichman, L. Abrahams, N. C. Møhl y L. C. Westergaard. En el trascurso de ese año aparecieron más contribuciones, de ambos lados, en Dagen.

${ }^{91}$ Cfr. Hauch, Minder om min Barndom og min Ungdom, pp. 317-319. En sus memorias, Hauch, quien era uno de "los doce", no señala de forma directa que la pieza en cuestión fuera, de hecho, La profecía de Tycho Brahe de J. L. Heiberg, la cual se estrenó el día del cumpleaños del rey el 28 de enero de 1819. Los motivos para no mencionar esto pueden ser que, al ser ya un anciano, lo hubiera olvidado, o, mejor, que este hecho quizá era demasiado delicado o poco halagüeño para un retrato ideal de Møller, ya que Heiberg era su amigo cercano.

${ }^{2}$ P. M. Møller, "Om Jenses Lidenhed", en Hermes. Nytaarsgave for 1820, ed. por Carsten Hauch et al., Copenhague, 1819, pp. 1-2, reimpreso en ES1, vol. 1, pp. 17-18. En sus memorias, Hauch escribe de este poema: "La perfecta ejecución y el virtuosismo con el cual volvió las propias palabras de Baggesen en su contra han mantenido a este poema por encima del río del olvido, en el cual tantas cosas escritas en su momento con ingenio y vigor se han hundido". Hauch, Minder om min Barndom og min Ungdom, p. 299.

93 "Resolución del 13 de julio de 1837 , hecha en nuestro estudio a las seis de la tarde". SKS 17, 229, DD:28.a / KJN 1, 221. 
ller: "Me permito invocar como testigo a mi P. Møller eternizado. / Hecho en nuestro estudio" 94 .

Aunque la expresión latina equivalente, "e museo meo/nostro (dabam/ datum)”, era una fórmula epistolar usual, es obvio que aquí Kierkegaard estaba pensando en la parodia de Møller, la cual sin duda había disfrutado. Como se sabe bien, su propio veredicto acerca de Grundtvig puede resumirse con las últimas palabras de la entrada NB23:67 de 1851: "Creo que Grundtvig es un disparate" 95 . Es en esa misma entrada que Kierkegaard escribe con ironía acerca del gran profeta Grundtvig, que en su entrar y salir de la Iglesia nacional la define en virtud de su presencia y la de sus seguidores, "pues, como Poul Møller señaló en cierta ocasión, la historia y Grundtvig, Grundtvig y la historia, son una y la misma cosa; de la misma manera, es preciso que Dinamarca y Grundtvig, Grundtvig y Dinamarca, sean también lo mismo... esto en el supuesto de que se trate de la verdad histórica con los 'miles de oyentes' "96. Esto es también una alusión al "Esbozo de una carta desde el cielo" de Møller, en el cual, por ejemplo, se atribuyen las siguientes palabras finales a Grundtvig: "En el final exclamaré una vez más: ¡Desdichados! Desdichados los cachorros que se han opuesto a la crónica y a mí, a mí y a la crónica, y a la crónica y a mí. Amén"97.

En el Postscriptum definitivo y no científico, Parte 1, Capítulo 1, "El punto de vista histórico", se leen al final del $\$ 2$, "La Iglesia”, algunos comentarios sobre J. C. Lindberg y Grundtvig. El primero "tiene una cabeza sana sobre los hombros; por el contrario, resulta sumamente dudoso qué es en verdad todo lo que se dice sobre Grundtvig, que es un visionario, un poeta, un bardo, un profeta con una visión sin igual sobre la historia universal y con buen ojo para lo profundo" ${ }^{98}$. Lo anterior es bastante modesto si lo comparamos con los manuscritos, en los cuales parece que Kierkegaard planeaba incluir una reflexión más extensa sobre el fenómeno Grundtvig. Ahí toca también el tema de su estilo y habla del "Esbozo de una carta desde el cielo" de Møller. Este escrito, sin embargo, no fue incluido en el libro. Entre otras cosas, se lee en el borrador que:

${ }^{94} B$ E A, vol. 1, p. 50 / LD, carta 17, p. 63.

${ }^{95}$ SKS 24, 242.36, NB23:67.

${ }^{96}$ SKS 24, 242.19-22, NB23:67.

${ }_{97}$ ES1, vol. 1, p. 200. Sobre las “crónicas” de Grundtvig, ver, por ejemplo, la nota en SKS 7, 52.4 .

${ }^{98}$ SKS 7, 52.2-5 / CUP1, 46. Jacob Christian Lindberg (1797-1857) era un seguidor entusiasta de Grundtvig. 
Grundtvig es tan absoluto que termina por ser su propia caricatura. Su naturaleza absoluta se transforma en parodia, y lo mismo sucede con su estilo, el cual no requiere sino de una reproducción cuidadosa, ya sea que se trate de algo polémico, como fue el caso con Poul Møller, o en tono de admiración, como ocurrió con Siegfried Ley. Al final termina en parodia, de modo que, como consecuencia, amigo y enemigo, haciendo lo mismo, producen el mismo efecto. En efecto, aunque estas observaciones inocentes e insignificantes pudieran conmover al pastor Grundtvig, obligándolo a hacer uso de lo mejor de sus fuerzas, estoy seguro de que me destruiría de forma tan absoluta que al final saldría completamente ileso ${ }^{99}$.

\section{B. "El viejo amante" y "Gozo por Dinamarca"}

Kierkegaard solo se refiere a Møller como traductor de la Odisea de un modo muy indirecto cuando se refiere a él como "el admirador de Homero" en la dedicatoria de El concepto de la angustia ${ }^{100}$. Con respecto a la poesía original de Møller, encontramos varias referencias en los escritos, aunque solo se mencionan algunos versos específicos de dos de sus poemas ${ }^{101}$.

${ }^{9}$ Pap. VI B 29, p. 104 / CUP2, 18-19. El "Siegfried Ley" del que se habla aquí es Christian Sigfred Ley (1806-1874), quien nunca terminó sus estudios en teología, pero trabajó como tutor. Fue un seguidor entusiasta de Grundtvig. Incluso en la copia en limpio se puede encontrar la siguiente versión, la cual, no obstante, fue borrada: "Su vida [es decir, la de Grundtvig] está diseñada de una forma tan paródica que basta con narrarla con simpleza para escribir una sátira. De forma parecida, su estilo es tan paródico que una simple reproducción suya - por ejemplo, en tono polémico, en el caso de Møller, o con admiración, en el caso de Siegfried Ley — constituye ya una parodia. Esto es una buena demostración que en sí misma es paródica: que amigo y enemigo, haciendo lo mismo, produzcan el mismo efecto". Pap. VI B 98, 17 / CUP2, 30-31.

${ }^{100}$ Kierkegaard conoció las traducciones de la Odisea de Møller, al menos después de su reimpresión en 1839 en ES1, vol. 1. En el registro de la subasta de la biblioteca de Kierkegaard, no aparece ninguna de las ediciones originales de la traducción (1816, 1822, 1825). No existe evidencia de que Kierkegaard conociera la traducción de Møller de la pseudohomérica Batrachomyomachia, "La batalla de las ranas y los ratones", probablemente elaborada en el invierno de 1816-1817, aunque publicada por primera vez en 1848 en ES2 (no está registrada en ASKB), vol. 1, pp. 254-261, donde Thaarup completa el fragmento. En cambio, por $O$ lo uno o lo otro se sabe que Kierkegaard estaba al tanto del poema griego, pues lo menciona en el pasaje donde compara a Homero con el Don Giovanni de Mozart, y señala que Homero no se ha ganado la inmortalidad por su Batrachomyomachia. SKS 2, 58.13-20 / EO1, 50.

${ }^{101}$ Además de los dos poemas de los que hablaré más adelante, hay también una referencia indirecta al poema —o pequeña escena dramática— de Møller titulada "Hans og 
Cuando visita a Constantin Constantius, el joven enamorado de La repetición (1843) repite con desesperación la sexta estrofa de "El viejo amante":

Así como los amantes recurren con frecuencia a las palabras del poeta para lograr que la dulce aflicción del amor se revele como goce jubiloso, lo mismo hacía él. Mientras andaba de un lado a otro, repetía una y otra vez un verso de Poul Møller:

Llega pues un sueño desde mi juventud

Hasta mi sillón

Por ti siento un íntimo anhelo

Tú, sol de las mujeres ${ }^{102}$.

Sus ojos se llenaron de lágrimas y se tumbó en la silla; repetía los versos una y otra vez. Yo quedé conmovido por la escena ${ }^{103}$.

Trine" (ES1, vol. 1, pp. 83-84, incluido por los editores en la colección de poemas "Escenas en el Jardín de Rosenborg"; originalmente, el poema — que fue escrito en el viaje a Chinase publicó en Gefion. Nytaarsgave for 1826, ed. por Elisa Beyer, Copenhague: Forlagt af Udgiverinden, 1825, pp. 154-159). Sin embargo, esto es solo porque Heiberg, en su vodevil Aprilsnarrene eller Intriguen i Skolen (Copenhague: F. A. C. Printzlau, 1826), estrenada el 22 de abril de 1826, alude de forma constante al poema, no solo al usar los mismos personajes y nombres de los dos jóvenes amantes, sino también al hacer que Trine, en la Escena 23, se refiera al escrito de Møller como un "pasquín” sobre ellos que ha aparecido recientemente, y que también ha sido recitado con el papel de Hans representado por el actor C. N. Rosenkilde (1786-1861). Kierkegaard se refiere a esta ilusión arruinada cuando, en Pap. I A 23 / JP 2, 2241, cita de forma libre las palabras de Trine: "Hay un viejo, llamado Rosenkilde, que te está copiando”. Las palabras originales de Heiberg son: “¿Creerás que el actor que hace tu papel es en realidad un vejestorio llamado Rosenkilde? Se le atavió de tal manera que parecía un colegial". Heiberg, Aprilsnarrene, p. 79 (Poetiske Skrifter, vols. 1-11, Copenhague: C. A. Reitzel, 1862, vol. 6, pp. 92-93). La representación tuvo lugar en el Teatro de la Corte en febrero de 1826. En esa época, Rosenkilde era un hombre maduro, al menos en comparación con Trine, cuyo papel era representado por la actriz de trece años Johanne Luise Pätges, quien más adelante se convertiría en la señora Heiberg (1812-1890).

${ }^{102}$ ES1, vol. 1, p. 12. El poema se publicó originalmente en Iris. En Samling af Poesie og Prosa, ed. por Carsten Hauch, Copenhague: B. Brünnich, 1819, pp. 112-115.

${ }_{103}$ SKS 4, 13.21-31 / R, 135-136. Constantin Constantius no podía olvidar este episodio: "Con el permiso del lector, volveré a considerar aquella época en la que llegó a mi habitación intoxicado con el recuerdo, cuando su corazón constantemente ging i hm über en aquel verso de Poul Møller, cuando me confesó que había tenido que negarse a sí mismo a fin de permanecer el día entero con la muchacha que amaba. Repetía el mismo verso aquella tarde, cuando nos separamos. Jamás podrá olvidar aquel verso. De hecho, me resultaría más fácil destruir el recuerdo de su desaparición que la imagen de aquel momento; de manera parecida, las noticias de su desaparición me perturbaron mucho menos que su situación en aquel primer día”. SKS 4, 23.2-11 / R, 146. Vilhelm Andersen, en su Poul Møller, p. 91, escribe lo siguiente acerca del poema: "Existen, en efecto, muchos más jóvenes además del joven de La repetición de Kierkegaard que han encontrado refugio en 
Este poema, publicado por primera vez en 1819, aunque redactado en 1817 o a principios de 1818, cuando Møller era tutor privado en la hacienda de Espe, parece ser un reflejo de su temprano e infeliz amor por Margrethe Bloch. Puesto que ahora esa "antigua idea fija" se ha "disuelto en una elegía absolutamente pura”, como le escribió a su amigo, B. S. Ingemann ${ }^{104}$, él se imagina a sí mismo como un anciano que recuerda su amor de juventud, si bien con cierta añoranza, a fin de buscar de nuevo a su amada. En el contexto referido, el viejo amante infeliz podría ser el alter ego de Kierkegaard, aunque esto quizá resultaría extraño, ya que, algunos años antes, había empleado la misma estrofa en varias cartas dirigidas a su prometida, Regine Olsen. En una de esas cartas, la compara con el sol: "Siempre que huelas la fragancia de ese heliotropo que tienes en casa y que está todavía fresco, por favor piensa en mí, pues en verdad mi mente y mi alma se vuelven hacia este sol, y una añoranza sincera se adueña de mí cuando pienso en ti, sol de las mujeres” 105 . Otra carta empieza de la siguiente manera: “¡Mi Regina! ¿Me encuentro soñando o 'llega un sueño desde mi juventud hasta mi sillón?’”106. La señorita Olsen probablemente conocía el poema y entendía estas citas o alusiones de forma perfecta ${ }^{107}$.

También en el Cuaderno 7 de 1840-1841, redactado durante el mismo periodo del compromiso, Kierkegaard cita la misma estrofa "soñadora” y la interpreta de la siguiente manera:

El soñar se alza constantemente a potencias cada vez más elevadas; de este modo, un sueño dentro de una existencia soñada (con lo cual se transforma en una especie de realidad) ejerce un efecto infinitamente

estos versos de Poul Møller, a fin de lograr que la dulce angustia del amor se revelara como goce jubiloso".

${ }^{104}$ Borup, carta no. 13.

${ }^{105} B \in A$, vol. 1, pp. 51-52 / LD, carta 19, p. 66. Ver también la carta 18, en la cual cita las palabras "desde mi juventud".

${ }^{106} B$ \& $A$, vol. 1, p. 57 / LD, carta 27, p. 72.

${ }^{107}$ Tal vez Kierkegaard se lo leía en voz alta o ella misma lo había leído. Niels Thulstrup afirma en $B \in \mathcal{E} A$, vol. 2, p. 33 (comentario en la p. 50.5), que Kierkegaard le había regalado el primer volumen (1839) de ES1 ("S. K. le regaló a Regine Olsen el material ya publicado de la primera edición de los Escritos póstumos de P. M.”), aunque esto no se ha podido verificar. Parece que Thulstrup confunde a Regine Olsen con Henriette Lund, quien cuenta que el tío Søren le había regalado las obras póstumas de Møller (cfr. Encounters with Kierkegaard, p. 166; ver la introducción de la presente Sección III). No obstante, eso ocurrió no en 1839, sino en 1843, después de la publicación del vol. 3 de ES1. 
volatilizador. Con qué exaltación infinita puede un joven leer las palabras del poema de P. Møller, "El viejo amante":

Llega pues un sueño desde mi juventud

Hasta mi sillón

Por ti siento un íntimo anhelo

Tú, sol de las mujeres.

Para el joven, el sueño se eleva aquí a la segunda potencia. Se sueña primero como siendo un viejo, para entonces succionar, a través del embudo de una vida entera, el instante más aromático de su primera juventud $^{108}$.

El segundo poema de Møller al que Kierkegaard hace alusión es "Gozo por Dinamarca”, con su conocida primera línea: "La rosa se ruboriza ya en el jardín de Dana”. En la dedicatoria a El concepto de la angustia, la parte "el gozo de Dinamarca en 'El gozo por Dinamarca', siempre 'recordado en el verano danés' a pesar de sus 'muchos viajes'” es una alusión al poema ${ }^{109}$. Este fue compuesto durante el largo viaje —o, podría decirse, odisea- a China (1819-1821) y expresa la añoranza por Dinamarca y los amigos en casa $^{110}$. La tercera estrofa va así:

¡Amigos míos, en el verano danés!

$¿$ Recuerdan a aquel hombre de muchos viajes

Que, lejos de las hermosas flores de Dana,

Aquí donde el viento del sur sopla en la vela,

Erra lejos de su querida tierra natal? ${ }^{111}$.

El poema se publicó por primera vez en 1823 y apareció en el primer volumen de los Escritos póstumos de 1839. No obstante, Kierkegaard lo conocía desde antes de 1839 y tenía una relación muy emocional con él, ya que estos versos sobre la "odisea" le recordaban a Møller, quien había viajado en su juventud y ahora había partido para siempre ${ }^{112}$. Esto es evidente por el he-

108 SKS 19, 208-209, Not7:9 / JP 1, 804.

109 SKS 4, 311.4-6 / CA, 5. Acerca de la dedicatoria, ver la Sección II.

110 Según Vilhelm Andersen, fue escrito en Manila en julio de 1829; Poul Møller, p. 107.

${ }^{111}$ ES1, vol. 1, p. 47. El poema se publicó por primera vez en K. L. Rahbek, Tilskuerne. Et Ugeskrift, no. 47, 1823, pp. 374-376.

${ }^{112}$ La alusión a los primeros versos de la Odisea de Homero es obvia. Con todo, Møller no emplea la expresión vidtforreist [de muchos viajes, muy viajado] en su traducción de la Odisea homérica. 
cho de que cita esta línea en el Diario DD en una entrada del 2 de abril de 1838, escrita no mucho después de la muerte del Møller el 13 de marzo del mismo año. El actor N. P. Nielsen había recitado el poema en el Teatro Real, algo que, como ya se ha mencionado, le produjo una profunda impresión ${ }^{113}$.

\section{Fragmentos sobre la ironia y el nibilismo}

Møller tenía una naturaleza humorística, algo que Kierkegaard mismo atestigua en la nota del Postscriptum, citada anteriormente, donde dice: “¿Quién lo ha conocido y olvidado su risa, la cual resultaba benéfica aunque no fuera del todo claro de qué se estaba riendo?"114. Además, si bien en sus escritos prefería la comunicación directa (en la reseña de Los extremos, menciona el ideal de que el autor, "sin cansar al lector con demasiadas broma y rodeos, debería concentrarse en el asunto en cuestión y decir directamente aquello que tiene que decir" ${ }^{115}$ ), Møller mismo era un ironista en el sentido socrático (no en el romántico) ${ }^{116}$. Incluso podría decirse que su obra dispersa o fragmentaria constituye una negación, una manifestación de ironía. En sus escritos, él aborda el tema de la ironía de forma no irónica. Si uno desea explorar esto, es importante prestar atención especial al fragmento "Sobre el concepto de ironía”, a una serie de pensamientos dispersos y a ciertos pasajes de su reseña de Los extremos ${ }^{117}$.

El fragmento de Møller, "Sobre el concepto de ironía" —el mismo título que Kierkegaard emplearía más tarde para su disertación— estaba des-

113 SKS 17, 253, DD:101 / KJN 1, 244. El actor Nicolai Peter Nielsen (1795-1860) recitó el poema en el Teatro Real la tarde del 1 de abril de 1838. Parece que era parte de su repertorio: lo había recitado varias veces después de una primera representación en el Teatro el 1 de enero de 1830. Más tarde, Kierkegaard vio a la pareja de actores, N. P. Nielsen y Anna Nielsen (1803-1856). Cfr. el borrador de una carta de 1847, B E A, vol. 1, pp. 189-190 / LD, carta 170, pp. 238-240.

114 SKS 7, 41 / CUP1, 34, nota. El humor de Møller es visible en muchos contextos diferentes, aunque también en una escala más pequeña. Un ejemplo de esto es la simpática rima de "El viejo amante" que acabamos de citar: Lænestol/Sol (silla, sol). Un poeta más "serio" difícilmente hubiera hecho esto.

115 P. M. Møller, "Nye Fortællinger af Forfatteren til en Hverdagshistorie. Udgivne af Johan Ludvig Heiberg. Andet Bind: Extremerne. Kjøbenhavn. Paa Universitets-Boghandler Reitzels Forlag, trykt hos J. D. Qvist, Bog- og Nodetrykker. 1835. 223 S. 8”, Maanedskrift for Litteratur, vol. 15, Copenhague: C. A. Reitzel, 1836, pp. 135-163; p. 139; ES1, vol. 2, p. 131.

${ }^{116}$ Cfr. Vilhelm Andersen, Poul Møller, p. 396.

117 Sobre esta reseña, ver más adelante la Sección III, D. 
tinado al Maanedskrift for Litteratur como respuesta a la reseña de Eggert Christopher Tryde (1781-1860) sobre el libro de Sibbern acerca de estéti$\mathrm{ca}^{118}$. No obstante, nunca concluyó el estudio; lo que terminó fue una introducción acerca de la ironía moral. Møller interrumpió el trabajo antes de pasar a la ironía poética. El fragmento no se publicó sino hasta 1848, en la segunda edición de los Escritos póstumos, volumen $3^{119}$. En su reseña, Tryde había incluido algunas observaciones finales sobre la ironía en el contexto del romanticismo alemán. De acuerdo con Tryde, el modus vivendi de los románticos apuntaba en la dirección incorrecta, alejándose de Dios y aproximándose a un ideal en la naturaleza ${ }^{120}$.

n su fragmento, Møller nunca llega a una discusión más amplia acerca de este profundo nihilismo de la ironía del romanticismo alemán, sino que solo introduce el concepto "tal como se ha formado en el uso lingüístico de nuestra época" ${ }^{121}$. Como puede verse también en su reseña de Los extremos, su método es el mismo del licenciado en Aventuras de un estudiante danés (quien estudia mineralogía para identificar la piedra adecuada para afilar su cuchillo para conseguir una buena pluma), comenzando, por así decirlo, ab ovo, en este caso con la moralidad griega, es decir, la antigua dicotomía

${ }^{118}$ E. C. Tryde, "Om Poesie og Konst i Almindelighed, med Hensyn til alle Arter deraf, dog især Digte-, Maler-, Billedhugger- og Skuespiller-Konst; eller: Foredrag over almindelig Æsthetik og Poetik. Af Dr. Frederik Christian Sibbern, Proffesor i Philosophie. Første Deel. Kbhvn., 1834, 392 Sider. Forfatterens Forlag”, Maanedskrift for Litteratur, vol. 13, Copenhague: C. A. Reitzel, 1835, pp. 177-202; especialmente pp. 200-202.

${ }_{119}$ P. M. Møller, “Om Begrebet Ironie”, en ES2, vol. 3, pp. 152-158.

120 Tryde, "Om Poesi og Konst i Almindelighed”, pp. 200-201: "Parece característico de las últimas producciones poéticas el que no se busca tanto enfatizar aquel ideal interior ni permanecer en los objetos... como conocer toda forma, toda figura y especie de vida, es decir, lo malo y lo bueno, lo bajo y lo elevado, como una condición necesaria para que aparezca y devenga el ideal". El carácter negativo o inmoral de esta clase de poesía consiste en que "trata de descubrir algo interesante incluso en aquello que es completamente erróneo, y esto aun cuando se siente feliz con respecto a los objetos; pese a ello, no se abstiene de una cierta burla acerca de tales objetos. De hecho, a menudo se burla de forma abierta de sus propios productos”. De modo parecido, Sibbern, en su Sobre la poesía y el arte, escribió de la ironía poética que "a fin de representar las cosas con verdadera objetividad, el poeta debe observar la vida y sus figuras como si se tratara de un juego que considera con un placer meramente contemplativo, sin ningún tipo de participación empática; lo hace, de hecho, con una sonrisa contemplativa, es decir, con una actitud semejante a la que se encuentra en la ironía real”. F. C. Sibbern, Om Poesie og Konst i Almindelighed, med Hensyn til alle Arter deraf, dog især Digte-, Maler-, Billedhugger-og Skuespillerkonst; eller: Foredrag over almindelig Esthetik og Poetik, Parte 1, Copenhague: Paa Forfatterens Forlag, 1834, pp. 387-388; citado por Tryde, p. 200.

${ }^{121}$ ES2, vol. 3, p. 152. 
entre deseo y razón, y la cuestión sobre cuál es el medio correcto para el bien moral. El idealismo moral es idéntico a la subjetividad, como cuando, tiempo después, Fichte "le confirió el máximo poder a la conciencia del individuo, de manera que este pudiera determinar en cada caso particular y según su propia convicción moral cuál sería su deber... Al identificarse la voluntad del individuo con la ley moral, la convicción subjetiva llega a ser considerada como lo supremo" 122 . La consecuencia necesaria de esta autonomía es el nibilismo moral, afirma Møller, para luego señalar el peligro universal que esta subjetividad implica, lo cual se ejemplifica con la famosa novela de Friedrich Schlegel, Lucinde (1799), misma que era considerada también en la disertación de Kierkegaard - como un evangelio de la ironía y en la cual un personaje dice: "Nada resulta más insensato que el reproche que los moralistas les hacen a ustedes a causa de su egoísmo. Están completamente equivocados, pues ¿qué dios puede ser venerable para los seres humanos, si no es su propio dios?" 123 . El placer y el vegetar se convierten en la vida genuina y la religión verdadera. Møller alude a Hegel, quien considera la ironía como algo idéntico a esta actitud vacía frente a la vida, y la define como una "subjetividad que se conoce a sí misma como lo más elevado" 124. De acuerdo con Hegel, se trata de una de "las formas morales del mal" 125 . El ironista romántico se aleja de un mundo vacío y se siente superior a este ${ }^{126}$.

122 Ibid., p. 154.

${ }^{123}$ El pasaje, que es traducido al danés y citado en ES2, vol. 3, p. 155, aparece en la sección "Idylle über den Müssiggang”. La Lucinde de Schlegel también es analizada por Møller en su reseña de Los extremos y, por supuesto, en Sobre el concepto de ironía de Kierkegaard.

${ }^{124}$ ES2, vol. 3, p. 155. En sus Elementos de filosofía del derecho, $\$ 140$, Hegel usa esta fórmula en su explicación del uso de la ironía en Solger comparado al uso de Schlegel, quien ampliaba el significado de la expresión para incluir "aquella subjetividad que se conoce a sí misma como lo más elevado”. G. W. F. Hegel, Sämtliche Werke. Jubiläumsausgabe in 20 Bänden, ed. por Hermann Glockner, Stuttgart: Friedrich Frommann Verlag, 19281941, vol. 7, p. 217, nota.

${ }^{125}$ ES2, vol. 3, p. 158. Esta visión de la ironía romántica como un mal moral y una especie de vacío es desarrollada por Hegel en Elementos de filosofía del derecho, $\$ 140$, in fine, donde se lee: "En esta forma, la subjetividad no solo está vacía de todo contenido ético a la manera de derechos, deberes y leyes, de modo que es mala, en consecuencia (mala, de hecho, en una forma inherente y totalmente universal); en añadidura, su forma es la de un vacío subjetivo, en el sentido de que se conoce a sí misma como este vacío de todo contenido y, conociendo esto, se conoce a sí misma como lo absoluto". Jubiläumsausgabe, vol. 7 , p. 219.

${ }^{126}$ Cfr. Brian Söderquist, The Isolated Self: Truth and Untruth in Søren Kierkegaard's On the Concept of Irony, Copenhague: C. A. Reitzel, 2007 (Danish Golden Age Studies, 
El concepto de ironía en el romanticismo alemán es una "aberración" que tan solo ha tenido un eco débil en la literatura danesa, pero que también se encuentra en las conversaciones cotidianas bajo la forma de un deseo de un "pensamiento libre de prejuicios" y, en términos generales, como una "desconfianza hacia el concepto de moralidad"127. Semejante a la ironía, aunque no debe confundirse con ella, es el sentimentalismo, el cual es una resignación a la vida externa y un entregarse a "una vida puramente interior que llena con anhelos y presentimientos de algo venidero que constituye la única realidad" 128.

Por supuesto, estas ideas le resultaban familiares a Kierkegaard, quien más tarde las desarrollaría con detalle en su disertación. Møller también analizó la ironía y el nihilismo en varios pensamientos dispersos y en su reseña de Los extremos, escritos a los que me referiré dentro de poco. Pero, como ya se mencionó antes, el estudio inconcluso de Møller sobre la ironía no apareció en la primera edición de los Escritos póstumos, que era la que Kierkegaard tenía. Así que, en cualquier caso, no pudo haberlo leído antes de la publicación de su propia disertación acerca de la ironía. Lo que es más importante en el caso de Kierkegaard es su relación personal con Møller y el impacto "irónico" o socrático que este llevaba a sus conversaciones: el hecho de que las ideas comentadas anteriormente y los contenidos del estudio de Møller probablemente habían sido comunicados a Kierkegaard en una o más de sus conversaciones. Por desgracia, no hay mucha evidencia sobre esto. Pese a ello, como ya se ha señalado en la Sección II, gracias a la entrada

vol. 1), p. 152. Söderquist dice, inter alia: "A primera vista, la descripción de Møller del romanticismo parece estar de acuerdo con su propia sensibilidad con relación a los derechos de lo subjetivo y de la vida interior. No obstante — y esto es importante-, para Møller la clase de subjetividad celebrada por los románticos se cierra no solo frente a la cultura burguesa, sino también frente a un orden moral más profundo a través de lo cual el yo se desarrolla y cultiva".

${ }^{127}$ ES2, vol. 3, p. 156.

${ }^{128}$ Ibid., p. 157. En su reseña de Los extremos (ver más adelante la Sección III D), Møller dice lo siguiente sobre la relación entre la poesía sentimental y la ironía: "La ironía fue, de hecho, una continuación natural de esto [la poesía sentimental], ya que el sentimentalismo, cuando es tratado como arte y es llevado a su extremo, tiene una relación muy estrecha con lo inhumano. Una conciencia vaga de esta relación es probablemente la razón de que el hombre sentimental, quien se aprovecha de su propia simpatía, desprecie al ironista más que a otras personas. Puesto que su comportamiento [del ironista] le parece una parodia de su propia naturaleza, se perturba ante su presencia, justo como un caballo ante la presencia de un camello". Maanedskrift for Litteratur, vol. 15, 1836, pp. 147-148; ES1, vol. 2, pp. 140-141. 
DD:18 sabemos de esa "muy interesante conversación" de la tarde del 30 de junio de 1837 acerca de la ironía y el humor. Esta entrada del diario constituye una importante evidencia de que hablaron con detalle de la cuestión (y es probable que lo hicieran en más de una ocasión). Me permitiré citar el texto principal de la entrada in extenso, ya que las distinciones que en ella se hacen sobre la ironía y el humor podrían considerarse como un resumen de Kierkegaard de la conversación y, desde luego, como una síntesis de sus posteriores reflexiones acerca del tema:

No cabe duda de que la ironía puede generar una cierta calma (la cual, a su vez, podría corresponderse con la paz que sigue a un desarrollo humorístico) que, no obstante, se encuentra muy lejos de ser la reconciliación cristiana (los hermanos en Cristo, donde toda otra distinción se desvanece por completo, una nada comparada con ser hermanos en Cristo; por otra parte, ¿acaso Cristo no hizo distinciones? ¿Acaso no amó a Juan más que a los demás? Poul Møller, en una muy interesante conversación en la tarde del 30 de junio). Puede generar un cierto amor, por ejemplo, como el amor con el que Sócrates abrazaba a sus discípulos (pederastia espiritual, en palabras de Hamann), pero sigue siendo egoísta, ya que se establecía como su salvador, expandía sus expresiones y puntos de vista angustiosos hacia su conciencia superior, hacia su punto de vista. Sin embargo, el diámetro del movimiento no es tan amplio como el del humorista (el cielo, el infierno; el cristiano tiene que haberlo despreciado todo; el movimiento polémico más elevado del ironista es un nil admirari). La ironía es egoísta (combate en contra de la mentalidad burguesa, pero permanece en ella, aunque, en el individuo, se eleve por el aire como un pájaro cantor, poco a poco arrojando por la borda su lastre, con lo cual se corre el riesgo de terminar con un egoísta "al diablo con todo", pues la ironía todavía no se ha destruido a sí misma contemplándose a sí misma, ya que el individuo se mira a sí mismo desde la perspectiva de la ironía). El humor es lírico (es la más profunda seriedad de la vida, una poesía profunda que no puede desarrollarse en cuanto tal y, en consecuencia, se cristaliza en las formas más barrocas; es el non fluens de las venas, las molimina de la vida superior).

Toda la actitud en la naturaleza griega (la armonía, lo hermoso) era tal que, aunque el individuo se desvinculara e iniciara la batalla, la lucha llevaba el sello de que se había originado en un punto de vista armonioso y, por lo tanto, pronto llegaba a su fin sin haber descrito el círculo completo (Sócrates). Pero entonces apareció una visión de vida que enseñaba que toda la naturaleza estaba corrompida (la más profunda polémica, el gran despliegue de alas). Sin embargo, la naturaleza buscó 
su venganza, de manera que ahora tenemos humor en el individuo e ironía en la naturaleza, y se unen en cuanto que el bumor pretende ser un insensato en el mundo, mientras que la ironía supone que eso es lo que en realidad son [los humoristas].

Algunos dirán que humor e ironía son básicamente lo mismo, con solo una diferencia de grado. Yo diré lo mismo que Pablo cuando este habló sobre la relación del cristianismo con el judaísmo: todo es nuevo en Cristo [2 Cor 5:17].

El humorista cristiano es como una planta de la cual solo puede verse la raíz, pero cuya flor se abre bajo un sol más elevado ${ }^{129}$.

Es evidente que Kierkegaard volvió más tarde a esta entrada porque hay varias adiciones marginales. Una de estas está fechada el 30 de octubre de 1837 y dice: "El efecto de Sócrates, por tanto, está dirigido solo al despertar — siendo la comadrona que era—, no a parir, salvo en el más inauténtico de los sentidos" ${ }^{130}$. En todo esto es imposible decir dónde termina Møller y dónde comienza Kierkegaard. Tomando eso en cuenta, no podemos sino señalar que Møller pudo haber dado, en un sentido socrático, el tema para la disertación de Kierkegaard, aunque solo el tema ${ }^{131}$. Por consiguiente, no será del todo justo darle la razón a Vilhelm Andersen, quien afirma que en el análisis de Kierkegaard de la ironía romántica "puede en verdad decirse sin exageración que, si bien la pluma es de Kierkegaard, el espíritu es de Møller" ${ }^{32}$. Møller era una inspiración, pero no era un "escritor fantasma”. En este mismo contexto, Vilhelm Andersen destaca la descripción que Møller hace de Sócrates, incluyendo su ironía, en las lecciones sobre filosofía antigua (las cuales no se publicaron sino hasta 1842 en el volumen 2 de los Escritos póstumos, pero que, incluso así, Kierkegaard pudo haber seguido), y señala que esta fuente como una posible inspiración no es importante,

129 SKS 17, 225-226, DD:18 / KJN 1, 216-217. Sobre la referencia a Hamann, ver SKS K17, 396 / KJN 1, 503 (nota a 216.35).

130 SKS 17, 225, DD:18a / KJN 1, 216.

${ }^{131}$ Me abstendré aquí de hablar de los contenidos de Sobre el concepto de ironía de Kierkegaard, pues eso ya se ha hecho de forma suficiente. Me referiré especialmente al minucioso análisis de Söderquist, The Isolated Self. También es importante señalar que, según parece, había un debate en curso acerca de la ironía, un tema discutido por muchos en aquella época, también en Copenhague. Cfr. Söderquist, p. 151, nota 3, con una referencia a la nota al pie de F. C. Olsen (ES2, vol. 3, p. 152), en la cual se dice, por otra parte, que el ensayo de Møller "merece publicarse porque hace una contribución a la historia del concepto en cuestión [la ironía] en nuestra literatura".

${ }^{132}$ Vilhelm Andersen, Poul Møller, pp. 396-397. 
dado que era el conocimiento que Kierkegaard tenía de la personalidad de Møller aquello que le inspiró su propia comprensión un tanto peculiar de la personalidad de Sócrates ${ }^{133}$.

Poeta de corazón, Møller no se limitó a meras abstracciones sobre el tema del nihilismo. En términos de ficción, fue más allá y utilizó la figura de Ahasverus, el Judío Errante. Una personificación o encarnación de esta clase constituía también, de hecho, un proyecto personal, una forma de salir de una crisis o estado de ánimo de desesperación (estética) en el que Møller estaba atrapado. Esto tenía que ver con una duda acerca del valor de la vida humana, la verdad, la ciencia y las artes, algo que surgía probablemente de su liberación del hegelianismo ${ }^{134}$. Esta negación o nihilismo sería expuesto y analizado a través de la figura de Ahasverus; el propósito consistiría en curar esta visión de vida negativa o pesimista exponiéndola y demostrando sus deficiencias, lo mismo que Kierkegaard haría más tarde con el esteta $\mathrm{A}$ en $O$ lo uno o lo otro ${ }^{135}$. Vilhelm Andersen sugiere que si este gran proyecto poé-

${ }^{133}$ Ibid., p. 396. Compárese esto, por ejemplo, con el énfasis que H. P. Rohde coloca en un pasaje de Møller sobre la relación entre Platón y Jenofonte como fuentes del Sócrates histórico: "Es posible que Platón sea la fuente principal, pero él no es confiable desde un punto de vista histórico en su descripción de la filosofía de Sócrates: él mismo era un pensador más bien especulativo y ofrecía una imagen idealizada de Sócrates en sus diálogos. En efecto, Jenofonte es una fuente mucho más confiable, pero su falta de talento filosófico es posible que a menudo lo llevara a entender mal a Sócrates. Por lo tanto, de alguna manera son adecuados para corregirse mutuamente, y aquello que tienen en común quizá corresponda al Sócrates histórico". (traducción de Rohde de ES1, vol. 2, p. 365, en H. P. Rohde, "Poul Møller", en Kierkegaard's Teachers, ed. por Niels Thulstrup y Marie Mikulová Thulstrup, Copenhague: C. A. Reitzel, 1982, pp. 89-109; p. 95). Entonces Rohde compara este pasaje con la tercera tesis latina de Sobre el concepto de ironia: "Si quis comparationem inter Xenophontem et Platonem instituerit, inveniet, alterum nimium de Socrate detraxisse, alterum nimium eum evexisse, neutrum verum invenisse". SKS 1, 65.6-8. No puede excluirse la posibilidad de que en un caso como este las consideraciones de Møller fueran una inspiración, pero la idea de que la verdad se encuentra en un punto intermedio no es original

${ }^{134}$ Jørgen K. Bukdahl considera esto como un análisis general y crítico del panteísmo. Cfr. “Poul Martin Møller opgør med 'nihilismen'”, Dansk Udsyn, vol. 45, ed. por Richard Andersen et al., Vejen: Askov Højskole, 1965, pp. 266-290; p. 267. Un síntoma visible de una crisis personal o spleen es el tema de la Wanderlust, también presente en Ahasverus, pero que aparece de forma muy clara en el joven Møller: sus viajes por el Oriente, la presencia del tema en las Aventuras de un estudiante danés, etcétera. Cfr. Vilhelm Andersen, Poul Møller, pp. 228ss.

${ }^{135}$ El tema kierkegaardiano de la seducción era otra característica de Ahasverus. Dos de los fragmentos dicen: "Sus ojos parecían el cristal de una ventana empañado ligeramente por los suspiros de amor de una joven" (ES1, vol. 3, p. 329) y "Sus experimentos con las 
tico de los últimos años de Møller se hubiera completado, probablemente hubiera tenido la misma importancia para su obra que la que el Fausto había tenido para la de Goethe ${ }^{136}$. No resulta claro cuál hubiera sido la forma del Ahasverus de Møller; tal vez un diario, un monólogo o una serie de escenas dramáticas. La mayoría de los pocos fragmentos o esbozos destinados a Ahasverus fueron publicados por primera vez en 1843, en el volumen 3 de los Escritos póstumos ${ }^{137}$. Kierkegaard los leyó ahí tras su publicación. No se puede decir si Møller le habló a Kierkegaard de sus reflexiones acerca de Ahasverus en alguna de sus conversaciones, pero la propia preocupación de Kierkegaard por el tema está bien documentada en el Cuaderno 2 y el Diario $B B^{138}$. Estas entradas datan de 1835-1837, es decir, mucho antes de que los fragmentos de Møller se publicaran de forma póstuma. Desde luego, la antigua leyenda del Judío Errante había inspirado antes a numerosos poetas, especialmente en el romanticismo, y esto fue también el caso con el joven Kierkegaard cuando, como parte de su proyecto personal, investigó las tres figuras "representativas": Don Juan, Fausto y el Judío Errante. El tema de Ahasverus también fue tratado por otros poetas daneses de la época; por ejemplo, por B. S. Ingemann en Páginas del diario del zapatero de Jerusalén de $1833^{139}$ y, más tarde, por J. C. Hostrup en Los vecinos opuestos de $1844^{140}$

mujeres a quienes hace que se enamoren de él. Entonces se envuelve con un encanto que está a su servicio, ya que su ingenio es infinito y se percata de cómo un verdadero amor puede surgir de él” (no en los ES, sino en la selección de Vilhelm Andersen, Udvalgte Skrifter af Poul Møller, vol. 2, p. 129).

136 Vilhelm Andersen, Poul Møller, p. 341. Por cierto, Kierkegaard señala en la entrada BB:18, SKS 17, 107 / KJN 1, 100, que en la obra de Goethe, Aus meinem Leben (Dichtung und Wabrbeit), "también está su idea de una adaptación del Judío Errante, en la cual, fiel a su costumbre, intenta motivar la desesperación del Judío Errante”.

${ }^{137}$ ES1, vol. 3, pp. 328-330.

138 SKS 19, 94-96, Not2:9-14 / JP 5, 5109-511; JP 5, 5087; JP 2, 2206, y BB:16-20, SKS 17, 107-109 / KJN 1, 100-102. Sobre el interés de Kierkegaard por Ahasverus, ver, por ejemplo, Knud Jensenius, Nogle Kierkegaardstudier: "De tre store Ideer", Copenhague: Nyt Nordisk Forlag Arnold Busck, 1932, pp. 64ss. Troels-Lund, en Bakkebus og Solbjerg, vol. 3, p. 204, dice: “Apenas puede dudarse de que estos diferentes señalamientos [de Møller acerca de Ahasverus] fueran discutidos de forma oral por ellos y de que ejercieran una influencia en Søren Kierkegaard”.

${ }^{139}$ B. S. Ingemann, Blade af Jerusalems Skomagers Lommegog, Copenhague: Andreas Seidelin, 1833 (ASKB 1571). Este es uno de los libros apuntados por Kierkegaard en BB:16, SKS 17, 107.15-16 / KJN 1, 100.15-16.

${ }^{140}$ J. C. Hostrup, Gjenboerne. Vaudeville-Komedie, Copenhague: F. H. Eibe, 1847 (las canciones se habían publicado antes por separado en Sange af Gjenboerne, Copenhague, 1844). Se representó por primera vez el 20 de febrero de 1844 en el Teatro de la Corte. En 
y por Hans Christian Andersen en $1848^{141}$. Dado que Don Juan y Fausto son analizados por Kierkegaard en varios contextos, resulta tal vez curioso que nunca desarrollara con más profundidad al Judío Errante, a quien se considera como el representante arquetípico de la época presente ${ }^{142}$. Es verdad que Ahasverus vuelve a aparecer de vez en cuando, pero solo de forma breve. Es especialmente digno de mención un corto pasaje en "El más desdichado" de O lo uno o lo otro:

Si hubiera alguien incapaz de morir, si fuera cierto lo que la leyenda cuenta acerca del Judío Errante, ¿cómo podría pasarnos por la cabeza

esta obra, el Judío Errante le presta al estudiante Klint los zapatos de la fortuna que pueden volverlo invisible. Otro personaje del drama es Søren Kirk, una caricatura de Kierkegaard. Ver antes la Sección II, nota 49.

${ }^{141}$ El poema dramático de Hans Christian Andersen, Ahasverus (Copenhague: C. A. Reitzel, 1848), se publicó el 16 de diciembre de 1847. Andersen había utilizado antes a Ahasverus en su Fodreise fra Holmens Canal til Østpynten af Amager i Aarene 1828 og 1829 (1829). Los zapatos de la fortuna, famosos por Los vecinos opuestos de Hostrup, también aparecen en el cuento de hadas de Andersen, "Los zapatos de la fortuna" (1838), en el cual, por cierto, aparece un loro, probablemente Kierkegaard, que repite con insistencia: “¡Vamos! ¡Seamos hombres!”. Para un vistazo general sobre Ahasverus y otros elementos judíos en la literatura danesa, ver la introducción de Mogens Brønsted a su antología, Ahasverus. Jødiske elementer i dansk litteratur, Odense: Syddansk Universitetsforlag, 2007 (University of Southern Denmark Studies in Scandinavian Language and Literature, vol. 78), pp. 9-54.

${ }^{142}$ George Pattison sugiere que Ahasverus sigue presente, después de todo, "enmascarado detrás del 'rostro cosmopolita' del nihilismo contemporáneo". George Pattison, Kierkegaard, Religion and the Nineteenth-Century Crisis of Culture, Cambridge: Cambridge University Press, 2002, p. 74; sobre Ahasverus, ver en general el Capítulo 4 (pp. 72-95). No estoy de acuerdo en que aquí haya algún antisemitismo, aunque —es triste decirlodefinitivamente hay algo de esto en otros pasajes de Kierkegaard. En un fragmento, se lee la siguiente broma, que quizá no le resulte tan divertida a un lector moderno: "Aquellos que escriben al modo de los judíos (Heine, Börne, Menzel) parecen ser alegres, pero su jovialidad recuerda a la sonrisa de los niños recién nacidos, la cual se debe a un dolor de estómago”. ES1, vol. 3, p. 284. En su reseña de Los extremos, Møller habla de las escuelas vanas y sin gusto de la Joven Francia y la Joven Alemania; acerca de esto, ver más adelante la Sección III, D. La relación de Kierkegaard con los judíos de la "Joven Alemania", es decir, Heiner, Börne y otros, es compleja, pero en cierto sentido es respetuosa: para Kierkegaard, se trata de representantes del escándalo; a diferencia de los cristianos nominales, ellos al menos han comprendido lo que es el verdadero cristianismo y lo han rechazado. No es claro lo que quiere decir en el Diario NB32, cuando Kierkegaard señaló que Møller "estaba consciente" de que "los judíos son especialmente aptos para ser publicistas". SKS 26, 196, NB32:108 / JP 3, 2985. No puede estarse refiriendo a El corsario, el cual comenzó a publicarse en 1840, después de la muerte de Møller. 
erigirlo en el más desdichado? Entonces se explicaría por qué el sepulcro estaba vacío, para indicar que el más desdichado es aquel que no puede morir, que no puede dejarse caer dentro de un sepulcro. Entonces el caso estaría resuelto, la respuesta sería simple; pues el más desdichado sería el que no pueda morir, dichoso el que pueda; dichoso quien muera en su vejez, más dichoso quien muera en su juventud, el más dichoso sería quien muera al nacer y más dichoso que nadie, quien nunca llegue a nacer. Pero así no son las cosas, pues la muerte es la dicha común a todos y, en cuanto el más desdichado no haya sido encontrado, es susceptible de búsqueda en esa circunscripción ${ }^{143}$.

La idea de Frithiof Brandt es que la inspiración se dio del modo inverso, es decir, de Kierkegaard a Møller, y que el Ahasverus de Møller es una imagen del joven Kierkegaard ${ }^{144}$. No obstante, esta teoría es altamente especulativa. No existe evidencia de que el joven Kierkegaard aparezca reflejado en la siguiente descripción de Møller: "Ahasverus no quiere nada. Se considera infinitamente superior a aquellos que quieren algo"; como Schopenhauer, Ahasverus no reconoce "una diferencia absoluta entre el bien y el mal" 145 . Esta clase de nihilismo moral es idéntico a la ironía moral que se encuentra también Fichte y en la Lucinde de Schlegel, y que más tarde será criticada por Kierkegaard en Sobre el concepto de ironía.

\section{La reseña de Los extremos}

En su diario de viaje, el hermano mayor de Søren Kierkegaard, Peter Christian Kierkegaard, apunta el 28 de junio de 1829 que, en Berlín, donde se estaba quedando por entonces, conoció al profesor H. N. Clausen, con quien discutió, entre otras cosas, "acerca de la nueva publicación literaria mensual, cuyos catorce miembros constituyen un consejo que dictamina todas las reseñas recibidas y escriben ellos mismos la mayoría" ${ }^{146}$. Esta descripción es bastante adecuada y proporciona una imagen precisa de la manera en que el Maanedskrift for Litteratur funcionaba como institución ${ }^{147}$. Møller se convirtió en miembro del consejo editorial a comienzos de 1835 y publicó ahí,

143 SKS 2, 214.24-35 / EO1, 220-221.

${ }^{144}$ Brandt, Den unge Søren Kierkegaard, pp. 336-446 y pp. 454-459.

145 ES1, vol. 2, p. 329.

146 Diario de P. C. Kierkegaard de 1829-1830, Biblioteca Real, NKS 907, 8 , p. 64.

147 Ver, por ejemplo, Vilhelm Andersen, Poul Møller, p. 327, acerca de cómo estaba organizado el consejo editorial y la manera en que realizaba su trabajo. 
en 1836, su extensa reseña - escrita en diciembre de 1835 - de la novela de Thomasine Gyllembourg, Los extremos ${ }^{148}$. Como era su costumbre, la escritora había utilizado el seudónimo "El autor de 'Una historia cotidiana”, aunque la mayoría sabía, también Møller y Kierkegaard, que se trataba de la madre del editor, J. L. Heiberg; con todo, constantemente se alude a la autora como un "él". Puede parecer sorprendente que figuras culturales tan importantes como Møller y Kierkegaard reseñaran a Gyllembourg con tanta minucia (Los extremos y Dos épocas, respectivamente), ya que sus novelas no son de ningún modo gran literatura ${ }^{149}$. Sin embargo, como señala Klaus P. Mortensen, era "un gran arte el ser capaz de expandir el ideal a partir de lo cotidiano", algo que hasta entonces era un territorio virgen; aunque, a pesar de su fascinación por este arte de la realidad, los reseñadores no tenían buen ojo para la dimensión femenina ${ }^{150}$. Los límites de la tolerancia frente a las

${ }^{148}$ P. M. Møller, “Nye Fortællinger af Forfatteren til en Hverdagshistorie. Udgivne af Johan Ludvig Heiberg. Andet Bind: Extremerne. Kjøbenhavn. Paa Universitets-Boghandler Reitzels Forlag, trykt hos J. D. Qvist, Bog- og Nodetrykker. 1835. 223 S. 8”, Maanedskrift for Litteratur, vol. 15, Copenhague: C. A. Reitzel, 1836, pp. 135-163; reimpreso en ES1, vol. 2, 1842, pp. 126-158. Anteriormente, Møller había publicado otras dos reseñas en el Maanedskrift for Litteratur: de F. L. B. Zeuthen, Noget om Philosophien og dens Dyrkelse, tildeels med Hensyn paa Danmark (Maanedskrift, vol. 6, 1831, pp. 266-270), y de la disertación doctoral de P. C. Kierkegaard, De notione atque turpitudine mendacii commentatio (Maanedskrift, vol. 7, 1832, pp. 65-85). La reseña de Zeuthen dio lugar a una pequeña polémica; sobre esto, ver Jon Stewart, "Poul Martin Møller. Et nyt fund”, Fund og Forskning $i$ Det Kongelige Biblioteks Samlinger, vol. 44, 2005, pp. 415-423. Las otras reseñas de Møller se publicaron en Dansk Litteratur-Tidende, la primera en 1824, y la última, de Sobre la poesía y el arte de Sibbern, en 1835.

${ }^{149}$ No fueron los primeros en reseñar a Gyllembourg. Dos de sus predecesores son mencionados por Møller. El primero, Carsten Hauch, "Noveller, gamle og nye, af Forfatteren til en Hverdagshistorie. Udgivet af J. L. Heiberg, to Bind. Kbhvn. 1833”, Prometheus. Maanedskrift for Poesie, Esthetik og Kritik, vol. 3, ed. por Adam Oehlenschläger, Copenhague: Udgiverens Forlag, 1833, pp. 289-329, y, el segundo, J. N. Madvig (con el seudó-

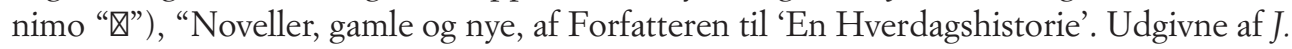
L. Heiberg. $1^{\text {ste }}, 2^{\text {det }}$ og $3^{\text {die }}$ Bind. Kjøbenhavn 1833-34. Reitzels Forlag”, Maanedskrift for Litteratur, vol. 11, Copenhague: C. A. Reitzel, 1834, pp. 363-392.

${ }^{150}$ Klaus P. Mortensen, Thomasines oprør - en familiebistorisk biografi om køn og kxrlighed i forrige ärhundrede, Copenhague: G. E. C. Gad, 1986, p. 151. Compárese con lo anterior la siguiente observación en la reseña de Møller: "Algunas veces nos encontramos con la afirmación de que, en las obras poéticas del autor, hay un énfasis parcial en la bella y acogedora organización de las formas de la vida social y doméstica. Que también es capaz de abordar temas más elevados puede verse en esta novela, en la cual religión y arte constituyen momentos esenciales en la armonía de la obra en su totalidad”. Maanedskrift for Litteratur, vol. 15, p. 153; ES1, vol. 2, pp. 146-147. 
actividades estéticas de las mujeres aparecen de forma obvia en, por ejemplo, el borrador de Kierkegaard de una reseña sarcástica de Clara Raphael: Doce $\operatorname{cartas}^{151}$, o en los esbozos de Møller sobre la "feminidad", en los cuales se lee que "es impropio y, de hecho, detestable que una mujer sea poeta de profesión" 152 . De manera superficial, las reseñas sobre Gyllembourg podrían ser fácilmente vistas como una forma de acercarse o de venerar al círculo heibergiano (Møller era amigo de Heiberg y Gyllembourg), pero, lo que es más importante, constituyen puntos de partida para algo que va más allá de los contenidos, en su mayoría triviales, de las novelas, eso que en Los extremos es una historia de amor un poco banal, pero que con su título se refiere a los conflictos o colisiones que se originan en distintos niveles en los ámbitos social, político o religioso, y en términos de edades y sexos ${ }^{153}$. En el caso de Los extremos, Møller aprovecha la oportunidad para desarrollar con detalle su propio punto de vista sobre el arte, en algo que podría considerarse una discusión crítica con el hegelianismo y con la melancolía romántica que él mismo había practicado durante su juventud. Aquí no desarrollaré esto con detalle, sino que analizaré con brevedad los puntos necesarios relacionados con Kierkegaard.

En una introducción fenomenológica de proporciones gigantescas, Møller reflexiona sobre el arte de reseñar, y distingue tres métodos. El primer tipo de reseña es un análisis estrictamente científico o sistemático; no proporciona ejemplos de semejante "hegelianismo", pero, como observa Vilhelm Andersen, quizá tenía en mente el método de Heiberg utilizado en Sobre el vodevil como una forma dramática de poesía (1826) ${ }^{154}$. Un se-

151 SKS 24, 136-138, NB22:63 / JP 6, 6709. La obra anónima de Mathilde Fibiger (1830-1872), Clara Raphael: Tolv Breve, Copenhague: C. A. Reitzel, 1851 (ASKB 1531), se publicó en diciembre de 1850, editada por J. L. Heiberg, y escandalizó a otros además de Kierkegaard con sus ideas de emancipación. Para una visión de conjunto de la controversia de Clara Raphael, ver, por ejemplo, Katalin Nun, "A Passionflower Planted in a Cabbage Garden': Heiberg, Mathilde Fibiger and the Emancipation of Women”, en Johan Ludvig Heiberg: Philosopher, Littérateur, Dramaturge, and Political Thinker, ed. por Jon Stewart: Museum Tusculanum Press, 2008 (Danish Golden Age Studies, vol. 5), pp. 493-516; ver pp. 500-505.

152 P. M. Møller, “Qvindelighed”, en ES1, vol. 3, pp. 314-321; ver p. 318. La cita proviene del tercer estudio - más tarde titulado "Carta a una dama” por Vilhelm Andersen-, que es el borrador de una carta a Vilhelmine Grüner (idéntica a la carta no. 50 en Borup). En una carta a Heiberg. Møller dice que es consciente "de que en tu madre hay muchas cosas que son inusuales en las mujeres”. Borup, carta no. 113.

${ }^{153}$ Aquí no profundizaré más acerca de los contenidos de la novela.

${ }^{154}$ Udvalgte Skrifter af Poul Møller, vol. 2, p. 163. 
gundo tipo de crítica es la denominada "crítica ridiculizante [persifleren$d e$ ]" o nueva reseña francesa, en la que una obra poética elegida al azar es utilizada como "ocasión para un torrente de comentarios ingeniosos" e ideas de carácter puramente subjetivo; esto lo encontramos en "las escuelas vanas y sin gusto de la Joven Francia y la Joven Alemania", en particular en Heinrich Heine. Su carácter atomístico hace que "el tren de pensamiento quede oculto casi por completo por las perlas artificiales de los comentarios ingeniosos" 155 . Møller recurre a una refinada metáfora para describir este abuso "conversacional" y con frecuencia político de las obras literarias: "El reseñador, preñado de comentarios ingeniosos, satisface su propio impulso accidental con medios desagradables, más o menos como un cuco que deposita su huevo en el nido del mirlo" ${ }^{156}$. Estos dos enfoques podrían interpretarse con facilidad como nihilismo, aunque esto no se expresa claramente en la reseña. Para Møller, la subjetividad personal o "personalidad" es la verdad, y este es el tercer camino o camino medio; en lo que se refiere a la crítica literaria, él llama a este camino "la reseña elemental". La tarea del reseñador consiste en sopesar la obra poética con su propia personalidad, "de manera que el reseñador considere, a partir de razones subjetivas, la relación de una obra poética con ciertas exigencias estéticas específicas, sin prestar atención a otros aspectos"157.

En O lo uno o lo otro, entre los papeles de "A", se encuentra la reseña de "El primer amor: Una comedia en un acto de Scribe, traducida por J. L. Heiberg", la cual no es una reseña, sino más bien una historia personal sobre cómo se escribió una reseña. El autor destaca el carácter accidental de su presentación:

Sin embargo, es la ocasión de esta humilde crítica la que me ha dado la ocasión de intentar decir algo absolutamente en general sobre la ocasión, o sobre la ocasión en general... Tal vez piense [el lector] que podría haberle dado unas cuantas vueltas a todo antes de ponerme a escribir y no haber empezado a decir algo que más adelante resultaría ser nada. Sin embargo, creo que el lector debería hacer justicia a mis procedimientos, aun suponiendo que hubiera conseguido percatarse por su parte de forma más convincente de que la ocasión en general es algo que no es nada... Por lo tanto, lo dicho aquí debe ser tomado como algo superfluo, como una portada superflua que no se incluye

${ }^{155}$ Maanedskrift for Litteratur, vol. 15, pp. 135-137; ES1, vol. 2, pp. 127-129.

${ }^{156}$ Ibid., p. 136; ES1, vol. 2, p. 127.

${ }^{157}$ Ibid., p. 144; ES1, vol. 2, p. 137. 
cuando la obra se encuaderna. Por eso no veo cómo podría acabar sino del mismo modo lacónico, inigualable a mi parecer, en que el profesor Poul Møller acaba la introducción a Los extremos: con esto concluye la introducción ${ }^{158}$.

Con esta última afirmación, es claro que Kierkegaard no piensa que la larga introducción de Møller a su reseña sea superflua; tan solo admira su forma de concluir. Pero hay otra observación que es preciso tomar en cuenta en el pasaje anterior: que el estilo mismo no es sino aquello que Møller, si hubiera tenido la oportunidad, hubiera considerado indiferente -o incluso como "nueva reseña francesa"-, mucha cháchara y poca sustancia, algo que a menudo es el caso con Kierkegaard, quizá especialmente cuando era joven.

Hay otra fuente por la que resulta evidente que Kierkegaard leyó la reseña de Møller de Los extremos en cuanto se publicó a principios de 1836. ${ }^{159}$ En el Cuaderno 3, se encuentra un pequeño extracto de las Vertraute Briefe über die Lucinde de Schleiermacher ${ }^{160}$. Kierkegaard había leído la segunda edición de este libro, el cual había sido publicado de forma anónima en 1800 como Vertraute Briefe über Friedrich Schlegels Lucinde, concebido como una defensa de la novela de Schlegel, Lucinde (1799), la cual era vista como inmoral, como un "evangelio de la carne" que defendía de la forma más picante la relación física entre los sexos. En la segunda edición de 1835, el editor Karl Gutzkov, en su prólogo, considera en términos generales los dos escritos de Schlegel y Schleiermacher como parte de las empresas sociales y políticas características de la "Joven Alemania", y, de forma más específica, como una crítica en contra de la supresión burguesa y religiosa del amor de la época. En la entrada de octubre de 1835, Kierkegaard alaba el libro de Schleiermacher como "una verdadera obra de arte" que "debería ser un modelo de reseña, así como un ejemplo de cómo una cosa de este tipo puede ser sumamente productiva en el sentido de que construye una multitud de personalidades a partir del libro mismo y, a través de ellas, arroja luz

158 SKS 2, 233.14-36 / EO1, 239-240.

${ }^{159} \mathrm{El}$ Manedskrift for Litteratur no aparece de forma explícita en el Registro de la subasta, y Kierkegaard no se encuentra en la lista de suscriptores. Aun así, es probable que lo leyera en una biblioteca pública o en algún club de lectura, por ejemplo, en el Athenæum o en la Unión de Estudiantes.

${ }^{160}$ SKS 19, 99, Not3:2 / JP 4, 3846. Esta entrada es analizada por Richard E. Crouter, "Schleiermacher: Revisiting Kierkegaard's Relationship to Him", en Kierkegaard and His German Contemporaries, Tome II, Theology, ed. por Jon Stewart, Aldershot: Ashgate, 2007 (Kierkegaard Research: Sources, Reception and Resources, vol. 6), pp. 197-231; ver pp. 204206. 
sobre la obra y sobre sus individualidades". Es posible que esto fuera una de las inspiraciones de Kierkegaard para su uso de seudónimos. Después de la publicación de la reseña de Møller de Los extremos, añadió lo siguiente en el margen al final de la entrada: "Ver Maanedskrift for Litteratur, año ocho, p. 140. Un ensayo de P. Møller. Febrero de 1836”161. En la citada página cuarenta — que se encuentra también en la introducción de la reseña-, Møller habla sobre si una reseña puede ser un arte libre en el sentido de que el reseñador pueda elegir el método que quiera, pues, en tal caso y de acuerdo con Schlegel, una reseña de poemas sería un nuevo poema ${ }^{162}$.

Para Møller era importante que la poesía no renunciara a "su vínculo con el resto de la vida" ${ }^{163}$. Más adelante en la reseña de Los extremos, se desarrolla con mayor profundidad su planteamiento sobre la relación entre la poesía y la realidad, es decir, su concepto del realismo poético. Dice, por ejemplo: "La poesía es la flor de la vida social, y aquello que un pueblo y sus individuos han experimentado proporciona, en cierto sentido,

${ }^{161}$ SKS 19, 99, Not3:2.a / JP 4, 3847.

162 "Ha dejado en el aire [Schlegel] la cuestión de si la serie ha de considerarse concluida con semejante poema al segundo grado - que, en este caso, sería una clase especial de obra poética imposible de reseñar-, o si la serie puede continuarse de forma indefinida. En el segundo caso, la poesía podría renunciar por completo a su vínculo con el resto de la vida; adquiriría tal independencia y autonomía que sería capaz de reproducirse a sí misma de forma continua y meramente a partir de sí misma, justo como la serpiente, la cual es símbolo de eternidad, que conserva la vida comiéndose su propia cola. La poesía alemana ofrece un planteamiento de este extremo en las muchas novelas, novelas cortas y poemas líricos que tratan casi de forma exclusiva del arte y de las obras y empresas de los artistas. Si uno se mantiene en este extremo, la reseña estética pierde su carácter académico y la poesía se traga a la estética”. Maanedskrift for Litteratur, vol. 15, p. 140; ES1, vol. 2, p. 132.

${ }^{163}$ Ibid. Mucho antes, en su sátira topográfica, "Statistik Skildring ag Lægdsgaarden i Ølseby-Magle. Af en ung Geograph” (ES1, vol. 1, pp. 201-223), escrita durante su viaje a China, señala lo mismo. En los Prolegomena observa que "No es sin motivo que en los tiempos más recientes la gente se queja mucho del número desproporcionadamente grande de estudiantes que se dedican a la filosofía, a la teoría del arte, a las visiones totales, a las observaciones sobre el espíritu de la época y cosas por el estilo que exigen un grado de erudición no pequeño. Supongamos que es verdad que la filosofía es el alma de las ciencias; en tal caso, un alma no puede, después de todo, sobrevivir por sí misma separada del cuerpo. Ya a estas alturas no queda casi nada de cuerpo. Pronto los escritores no tendrán nada más acerca de lo cual hacer observaciones más que de sus propias observaciones. Así, los poetas alemanes ya han llegado al extremo de que su poesía trata exclusivamente de poesía. En la república de eruditos prevalece una extraña emanación invertida. Todos los campos de estudio se vuelven cada día más incorpóreos, diluidos y transfigurados, de modo que uno puede temer con razón que, en algún momento, se desvanecerán por completo en el aire”. ES1, vol. 1, p. 203. 
el material para su vida más elevada a través de la poesía”. Comunicada a través de la mimesis del genio, la poesía debería surgir de la vida real "con frescura y originalidad" 164 . En el romanticismo alemán, en cambio, se da cuenta del peligro de que el arte poético haya sido considerado "como la única forma de revelación de la vida divina en el género humano” ${ }^{165}$. En el fondo, el peligro es, desde luego, la ironía romántica y sus consecuencias: "una indiferencia frente a las condiciones de vida de otras personas y, como resultado, un egoísmo constante" ${ }^{166}$. En la Lucinde de Schlegel —que Kierkegaard analizará después en Sobre el concepto de ironía-, Møller descubre la esencia de esta filosofía de vida nihilista a través de la máxima según la cual "no tiene Dios aquel que no es su propio Dios"167. Møller concluye: "Si el artista ha llegado tan lejos por medio de una ironía absoluta, al punto de que todo aquello fuera de él y de su arte le resulta completamente indiferente, entonces lo cierto es que todo termina con su arte; el verdadero poeta debe ser en primer lugar un verdadero ser humano"168. Tratándose de este conflicto entre, por un lado, el idealismo o la libertad poética de espíritu y, por el otro, la simpatía poética por la condición humana, Møller considera la "genuina disposición poética" de Thomasine Gyllembourg como una expresión de la bella armonía entre los dos extremos: "Aquí hay una simpatía cálida y profunda frente a las direcciones más heterogéneas del espíritu, combinada con una libertad de espíritu que las convierte en objetos de serena contemplación" ${ }^{169}$. Desafortunadamente, una armonía perfecta de esta clase es rara en la poesía contemporánea y es posible “compararla

${ }^{164}$ Maanedskrift for Litteratur, vol. 15, p. 145; ES1, vol. 2, p. 138.

165 Ibid., p. 146; ES1, vol. 2, p. 139. Anteriormente, esto había llevado a Peder Hjort a señalar el hecho de que, en palabras de Møller, "el arte no era el yo absoluto y eterno, sino una de sus formas de revelación”. Peder Hjort, "Om Digteren Ingemann og hans Værker”, Athene. Et Maanedsskrift, vol. 5, ed. por Christian Molbech, Copenhague: Gyldendal, 1815, pp. 73-111 y pp. 388-428; el tema es analizado en la introducción teorética, pp. 74-90. (La reseña de Hjort de las juvenilia de Ingemann continúa en Athene, vol. 6, 1816, pp. 158-198, pp. 366-383, y pp. 544-566).

166 Maanedskrift for Litteratur, vol. 15, p. 146; ES1, vol. 2, p. 139.

${ }^{167}$ Ibid., p. 147; ES1, vol. 2, pp. 139-140; Møller le atribuye erróneamente está máxima al protagonista de la novela, mientras que, en la obra de Schlegel, la palabras son: "welcher Gott kann dem Menschen ehrwürdig sein, der nicht sein eigner Gott ist?" Ver también la Sección III, C, acerca del "Sobre el concepto de ironía" de Møller.

168 Ibid., p. 147; ES1, vol. 2, p. 140.

${ }^{169}$ Ibid., p. 149; ES1, vol. 2, p. 142. Sobre este pasaje, ver también Elisabeth Hude, Thomasine Gyllembourg og Hverdagshistorierne, Copenhague: Rosenkilde y Bagger, 1951, p. 67. 
con las solitarias manzanas frescas que pueden verse de forma esporádica en los árboles cuando ha comenzado la defoliación" ${ }^{170}$. No haré aquí una comparación con la reseña de Kierkegaard de Dos épocas y con lo que, más tarde en su vida, diría sobre Gyllembourg. Sin embargo es indudable que, después de todo, tanto Møller como Kierkegaard admiraban a la escritora, aunque fuera una mujer ${ }^{171}$.

\section{E. "Sobre contarles a los niños cuentos de hadas"}

Entre los papeles póstumos de Møller, hay un pequeño ensayo inconcluso titulado: "Sobre contarles a los niños cuentos de hadas"172. Puesto que fue publicado por primera vez en 1843 , Kierkegaard no pudo haberlo leído cuando, en 1837, a finales de enero o principios de febrero, escribió una larga entrada bastante parecida, la BB:37, en el Diario BB ${ }^{173}$. No obstante, dado que, según el editor, F. C. Olsen, Møller debió escribir el ensayo en 1836 o $1837^{174}$, no es improbable que el interés de Møller por el tema fuera la principal inspiración de Kierkegaard y la ocasión de su entrada del diario (la cual es, de hecho, el borrador para un tratado). Es probable que hablaran de este tema en particular basándose en el debate contemporáneo acerca de la literatura infantil y su efecto sobre la imaginación de los niños ${ }^{175}$. En cualquier caso, es indudable que la infancia era un tema de gran interés para Kierkegaard, ya que reconocía su importancia esencial para la formación de la personalidad o, para emplear una de sus metáforas favoritas tomada de la gramática en una entrada de 1837, "La infancia es la parte paradigmática de la vida; la madurez es su sintaxis" ${ }^{176}$. También Møller, quien era padre, estaba consciente de que "cuando uno piensa en la firmeza con la que la esfera de la imaginación - la cual es formada en la infancia de una personapermanece durante el resto de la vida, resulta natural ser un poco cauteloso

${ }^{170}$ Maanedskrift for Litteratur, vol. 15, p. 157; ES1, vol. 2, p. 151.

${ }^{171}$ En la reseña de Los extremos, Møller se adelanta también al que sería, el año siguiente, el tema de su gran tratado sobre la inmortalidad. Sobre esto, ver más adelante la Sección III, G.

172 P. M. Møller, "Om at fortælle Børn Eventyr”, MS en Collinske Samling, 365, 4, Biblioteca Real, Copenhague; publicado por primera vez en ES1, vol. 3, 1843, pp. 322-325.

173 SKS 17, 122-133, BB:37 / KJN 1, 116-125.

${ }^{174}$ ES1, vol. 3, p. 322, nota.

175 Acerca de este debate, en el cual participó, entre otros, Christian Molbech, ver la nota a 122.23 en SKS K17, p. 241 / KJN 1, pp. 413-414.

176 SKS 17, 46.27-28, AA:30 / KJN 1, 40. 
en la elección de las fantasías con las que uno llena de forma deliberada sus cabezas [de los niños]"177.

¿Cuáles son, entonces, sus puntos de semejanza? En su ensayo, Møller sugiere que es dañino llenar las mentes de los niños con historias imaginarias. Lo anterior resulta también evidente por la forma en que juzgaba, por lo general, a Hans Christian Andersen. No lo dice de forma explícita, ya que en ninguna parte menciona los cuentos de hadas de Andersen — de los cuales la primera colección apareció en1835-, pero en una carta a Sibbern, fechada el 5 de mayo de 1829 y escrita desde Noruega, Møller elogia las tragedias de su viejo amigo Hauch, Bajazet y Tiberius (de las que llega a decir: "ipor mi parte, sitúo a Tiberius por encima del Julio César de Shakespeare sin titubear!") y se lamenta profundamente de que, de forma inmerecida, Tiberius no sea popular en comparación con el entusiasmo contemporáneo suscitado por el fabuloso y hoffmannesco Viaje a pie del joven Andersen. No obstante, Møller había leído algunos pasajes de esta novela en el Kjøbenhavns flyvende Post: "He leído algunas páginas sueltas, las cuales han estado a punto de desintegrarse debido al febril manoseo de la gente. En ellas todo me hace pensar en una lectura ligera ejecutada con una lengua veloz o, mejor dicho, una cháchara decadente" 178 . Aunque Andersen después cambió su estilo, es indudable que Møller, si hubiera vivido lo suficiente, hubiera disfrutado la crítica parecida de Kierkegaard en De los papeles de alguien que todavía vive. Más tarde, después de haber regresado de Noruega en 1831 al ambiente literario de Copenhague —el cual, según parece, era incluso más “artístico" que antes_, Møller manifiesta los mismos puntos de

177 ES1, vol. 3, p. 323.

178 Borup, carta 102. Møller escribió una reseña para el Maanedskrift for Litteratur de las dos tragedias de Hauch, Bajazet y Tiberius, pero nunca se publicó, pues no aceptó la exigencia del consejo editorial de cambiar algunos pasajes, especialmente donde destacaba el realismo de las obras. Según parece, el pasaje que suscitó la crítica era el siguiente: "Cuando decimos de las obras poéticas de Hauch que poseen un interés tanto psicológico como estético, y que aquello que las anima es más la idea de la verdad que la idea de belleza, estamos convencidos de que con eso no disminuimos su valor, sino que contribuimos a una descripción correcta de su calidad... Esta clase de minuciosidad en la representación de la vida espiritual humana, especialmente en sus aberraciones extremas, también la encontramos en nuestro autor, quien nos muestra en sus obras que no solo es un poeta, sino también un investigador filosófico de la naturaleza”. (ES1, vol. 2, pp. 55-56). Esto se refiere al hecho de que Hauch era también un científico natural. La reseña "Bajazet og Tiber. To Sørgespil af C. Hauch. Kjøbenhavn. Trykt paa C. A. Reitzels Forlag, i Fabritius de Tengnagels Officin. 1828”, se publicó por primera vez en 1842 en ES1, vol. 2, pp. 54-68. 
vista en su reseña del libro de estética de Sibbern, Sobre la poesía y el arte (1834), en la cual se lee, inter alia:

Otra dirección equivocada que el autor [Sibbern] tiene la oportunidad de discutir - y que, de forma reciente, ha criticado celosamente en uno de nuestros diarios- es el epicureísmo rampante que conduce al artista y a su público a considerar el arte y la poesía como meros medios para un placer refinado. En varios países, este falso gusto lleva incluso a poetas talentosos a servirse de recursos coquetos (repiqueteos métricos, por ejemplo) a fin de hacer que sus obras obtengan el favor del codicioso mundo lector. Pero aquí también es válido eso de que la búsqueda unilateral del placer impide el verdadero placer. El público no tardará en sentir tal desprecio por esta servil poesía que mirará con arrepentimiento la dureza masculina de sus padres ${ }^{179}$.

De forma parecida, en su ensayo sobre los cuentos de hadas Møller señala "como un hecho completamente claro" que "la lectura exagerada de novela les ha dado a varios de nuestros contemporáneos una disposición moral distorsionada, ha retorcido sus emociones, los ha colocado en un estado ininterrumpido de sonambulismo, les ha inculcado un rechazo por el trabajo duro y les ha enseñado a despreciar las formas reales de vida" ${ }^{180}$. Esta crítica estética se expresa en miniature en el ensayo sobre los cuentos de hadas. De acuerdo con Vilhelm Andersen, Møller estaba pensando en Hans Christian Andersen —entre otras personas-, en un fragmento de poema, probablemente de 1834, que comienza con las siguientes palabras: "Nacerá una especie carente de fuerza, / Una raza que nada puede y nada quiere..." ${ }^{181}$. Esto es válido de forma particular para la nueva generación de poetas, pero, de manera parecida, el ensayo de Møller sobre los cuentos de hadas es una obra de pedagogía práctica en la que advierte precisamente en contra de la educación errónea de la nueva generación —es decir, los niños- y del efecto perjudicial que esto puede tener en su imaginación. Al ser "un nuevo

${ }^{179}$ P. M. Møller, "Om Poesie og Konst i Almindelighed, med Hensyn til alle Arter deraf, dog især Digte-, Maler-, Billedhugger- og Skuespillerkonst; eller: Foredrag over almindelig Æsthetik og Poetik. Af Dr. Frederik Christian Sibber, Proffesor i Philosophien. Første Deel. Kiøbenhavn. Paa Forfatterens Forlag, trykt hos Fabritius de Tengnagel. 1834", en Dansk Litteratur-Tidende, 1835, no. 12, pp. 181-192, y no. 13, pp. 205-209; ver p. 209; reimpreso en ES1, vol. 2, pp. 105-126; ver pp. 125-126.

${ }^{180}$ ES1, vol. 3, p. 322.

${ }^{181}$ El fragmento se encuentra en ES1, vol. 3, pp. 16-17. Cfr. Vilhelm Andersen, Poul Møller, p. 352. 
ciudadano del mundo", dice Møller, todo niño lucha por alcanzar el conocimiento cuando su conciencia despierta, es decir, cuando el niño "tiene un poderoso presentimiento de que su vida está conectada con la vida de toda la existencia... Entonces se comete una gran injusticia al interrumpir esta fervorosa lucha para conocer el mundo real a fin de atraerlo a un mundo de fantasía" 182 . Sin embargo, esto no excluye por completo el uso de relatos fantásticos, aunque deben emplearse de forma moderada; de lo contrario, "se acostumbra a los niños a dedicarse en las cosas pequeñas a lo mismo que los adultos se dedican en los asuntos importantes cuando, como se dice, se dedican a las lecturas ligeras como pasatiempo"183.

El enfoque de Kierkegaard, por otro lado, no es tan negativo. Al principio destaca que el propósito de su tratado es solo atacar los abusos ${ }^{184}$. De los dos modos de narrar historias, señala, el método de las niñeras —los "relatos de guardería" de los que habla Møller- es dañino, pues el niño percibe la falta de honestidad del narrador, a partir de lo cual se desarrollan una falta de confianza y una cierta suspicacia. La otra clase de narrador es una persona que en sí misma no es como un niño, sino que conoce de forma fundamental lo que significa ser un niño, "y desde su perspectiva superior

${ }^{182}$ ES1, vol. 3, p. 323. En su tratado sobre la inmortalidad, del cual hablaré más adelante en la Sección III, G, Møller escribe lo siguiente. "En las obras poéticas que, en la actualidad, presentan un mundo de fantasía para la imaginación, los autores y lectores infieles suelen pensar que uno puede sentirse encantado por un mundo suprasensible y, no obstante, mantener la creencia de que no existe un mundo más elevado. Sin embargo, la consecuencia de esto es que el encanto quizá sea como se esperaba. Semejante intento de autoengaño es más infantil que el de un niño que usa un taburete y una vara como trono y cetro; a pesar de que el niño sabe que se trata en realidad de un taburete y una vara, también es consciente de que los tronos y cetros existen, mientras que el adulto cree que su mundo de fantasía no significa absolutamente nada. Existe un nivel de arte en el que el poeta presenta tradiciones mitológicas en las que él mismo cree; hay también un segundo nivel en el que las fantasías del poeta, aun cuando se originan de tales leyendas, son consideradas por él como un juego sin sentido; y hay un tercer nivel en el que el poeta contempla su producción artística como una imagen de una existencia más elevada”. Maanedskrift for Litteratur, vol. 17, p. 56; ES1, vol. 2, pp. 219-220.

${ }^{183}$ ES1, vol. 3, p. 324. En su introducción a "Sobre contarles a los niños cuentos de hadas”, Andersen señala que Møller escribió el ensayo basándose en experiencias personales, y menciona que, entre sus papeles, "hay fragmentos de un tratado sobre la vida de los indios en Norteamérica, acerca de los cuales investigó a fin de cerciorarse antes de exponer a sus hijos al romanticismo barato de las historias de indios”. Udvalgte Skrifter af Poul Møller, vol. 2, p. 117.

${ }^{184}$ SKS 17, 122, BB:37 / KJN 1, 116. 
les ofrece a los niños un alimento espiritual adecuado para ellos” ${ }^{185}$. Este es el marco de la narración de cuentos. A continuación, Kierkegaard expone en detalle cómo debería ser un narrador: en pocas palabras, debería ser un Sócrates. De forma parecida al "tío Frands", tiene que involucrarse con los niños y fomentar "una movilidad mental constante... una atención constante frente a todo lo que escuchan y ven" ${ }^{186}$. No obstante, al igual que Møller, Kierkegaard hace algunas advertencias serias acerca de posibles "falsos caminos". El sentimentalismo puede ser uno de estos caminos, así como la idea de que los niños solo necesitan entretenimiento. En lo que Kierkegaard llama la "primera etapa", el narrador "incurre en la falta de "ser un niño”, habla tragicómicamente como los niños, etcétera. La alternativa es intentar poner los juegos y los cuentos al servicio de un propósito útil. De esto resultan dos caminos: "o se les educa moralmente, como suele decirse, o se les proporciona un conocimiento útil" ${ }^{187}$. El producto ha sido el libro ilustrado sobre historia natural, pero a partir de esto, señala Kierkegaard, no se desarrolla más que un conocimiento atomístico "que no establece una relación más profunda con el niño y su existencia, un conocimiento que no queda apropiado en su alma de ninguna manera" ${ }^{188}$. En otras palabras, el impacto socrático en un caso así está ausente. Por el contrario, los niños deberían hacer preguntas y, como se dijo antes en el ensayo: "Lo que importa es hacer que lo poético tenga sus vidas un impacto global, que ejerza un influjo mágico" 189 .

Kierkegaard mismo leía cuentos de hadas y relatos populares ${ }^{190}$, y estaba convencido de su naturaleza positiva y renovadora: “¿Qué es eso que al alma le parece tan vigorizante de la lectura de relatos populares? Cuando estoy cansado de todo y 'lleno de días', los cuentos de hadas son siempre para mí el baño refrescante que me renueva" ${ }^{191}$. Møller, quien era él mismo un poeta, sentía lo mismo. Pero ambos advierten que, tratándose de niños, estos recursos deben emplearse con especial cuidado.

\footnotetext{
185 SKS 17, 123 / KJN 1, 117.

186 SKS 17, 125 / KJN 1, 119.

187 SKS 17, 130 / KJN 1, 124.

${ }^{188}$ Ibid.

189 SKS 17, 124 / KJN 1, 118.

${ }^{190}$ Cfr. ASKB 1407-1471.

191 SKS 17, 251.2-5, DD:94 / KJN 1, 241. Cfr. Grethe Kjær, Barndommens ulykkelige elsker. Kierkegaard om barnet og barndommen, Copenhague: C. A. Reitzel, 1986, pp. 127ss.; en general, ver su análisis en pp. 118ss.
} 


\section{F. Los pensamientos dispersos y el Concepto de afectación}

Una de las principales características de Møller era su incapacidad para terminar con la mayoría de las cosas que empezaba. Por esta razón, los aforismos constituían un perfecto medio de expresión. En su viaje a China de 1819-1820, en su soledad intelectual, comenzó a escribir sus pensamientos en forma de aforismos o, como él prefería llamarlos, "pensamientos dispersos”. Estos cubrían una amplia variedad de temas: la vida cotidiana, estética, psicología, religión, filología, filosofía, etcétera. Møller continuó con esta práctica por el resto de su vida ${ }^{192}$. Paul V. Rubow sugiere que una inspiración pudieron ser las Máximas (1665) de François de La Rochefoucauld (1613-1680), ya que, en términos generales, estas máximas tratan acerca de la afectación y arrojan luz sobre la idea de que las virtudes humanas son vicios ocultos ${ }^{193}$. Sin embargo, Uffe Andreasen observa de forma correcta que una influencia francesa no era muy probable y que el contacto con $\mathrm{La}$ Rochefoucauld solo pudo ser indirecto, a través de la lectura de Møller de la obra de Schopenhauer (1788-1860), Die Welt als Wille und Vorstellung, en donde se cita al francés ${ }^{194}$. Además, de acuerdo con una carta a Sibbern, Møller leyó esta obra (cuya tendencia por lo general pesimista describiría más tarde, en su tratado de la inmortalidad, como nihilista) por primera vez en enero de 1828, varios años después de haber empezado a escribir aforismos durante su viaje a China ${ }^{195}$. Como Rubow destaca en otra parte, probablemente un mejor candidato sea el autor alemán de aforismos, Georg Christoph Lichtenberg (1742-1799) ${ }^{196}$. Dentro de este contexto, también podría sugerirse el nombre de Friedrich Schlegel y sus fragmentos. Con todo, nada puede decirse con certeza al respecto y tal vez sea más sabio

192 Vilhelm Andersen sugiere que dejó de hacerlo en 1836: "Por lo que puede juzgarse, no se conservan aforismos posteriores a 1836". Udvalgte Skrifter af Poul Møller, vol. 2, p. 380 .

193 Paul V. Rubow, Kunsten at skrive-Kunsten at lase, Copenhague: Ejnar Munskgaard, 1942, p. 45.

${ }^{194}$ Uffe Andreasen, Poul Møller og romantismen, pp. 60-61. Die Welt als Wille und Vorstellung se publicó por primera vez en 1819; Kierkegaard tenía la segunda edición de 1844 (Leipzig: F. A. Brockhaus, 1844; ASKB 773-773a).

195 Borup, carta no. 91, en la que Møller dice que solo ha leído dos libros de Schopenhauer, de quien nunca había escuchado antes; uno de estos libros era Die Welt als Wille und Vorstellung.

196 Paul. V. Rubow en una reseña de Olle Holmberg, Tankar vid en kopp te, Estocolmo: Bonniers, 1958, en Berlingske Aftenavis, 25 de noviembre de 1958; cfr. Andreasen, Poul Møller og romantismen, p. 61. 
solo observar que Møller era sencillamente un pensador fragmentario por naturaleza.

Resultaría natural suponer que los "Diapsalmata" de Kierkegaard en O lo uno o lo otro estaban inspirados en Møller, pero es preciso tener en cuenta que los pensamientos dispersos de este no se publicaron sino hasta 1843, en el volumen 3 de los Escritos póstumos ${ }^{197}$. Además de esto, es claro que varios de los "Diapsalmata" provienen de una época bastante anterior, ya que algunos de ellos aparecen como entradas en los primeros diarios (en efecto, las entradas de los diarios de Kierkegaard a menudo resultan, obiter dicta, muy parecidos a los aforismos de Møller, aunque, en el caso de un aforismo, se espera una cierta conclusión y un sentido claro) ${ }^{198}$. Éstos no son necesariamente idénticos a los "Diapsalmata" posteriores, pero la forma es la misma. Por ejemplo, en el Diario CC hay una entrada en la que se lee: "Prefiero hablar con las ancianas que parlotean sobre sinsentidos de familia; después con los dementes y, por último, con la gente muy razonable" ${ }^{199}$. En O lo uno o lo otro, aparece la versión más conocida: "Prefiero hablar con niños, pues de ellos se puede esperar que acaben convirtiéndose en seres racionales; pero de aquellos que han llegado a serlo, ¡Dios mío!”200. Así, resulta curioso cuando, entre los pensamientos dispersos de Møller, encontramos lo siguiente: "En cierto sentido los niños son más racionales que los viejos: los primeros consideran a los que están por encima de ellos como más perspicaces en términos de entendimiento; los segundos, a aquellos que están por debajo" ${ }^{201}$. No obstante, el hecho de que una idea común como esta sea expresada por ambos pensadores quizá no sea más que una coincidencia. Aun así, es indudable que Kierkegaard leyó todos los pensamientos dispersos de Møller publicados. En la nota al pie citada antes del Postscriptum definitivo y no científico, alude a ellos en general cuando se refiere al antihegelianismo de Møller como algo "más notable que varios aforismos

${ }^{197}$ ES1, vol. 3, pp. 171-291, y pp. 303-313 (sobre la afectación). Es otro asunto, por supuesto, la posibilidad de que los "pensamientos dispersos" hayan llegado a Kierkegaard de forma oral a través del Møller mismo. Sin embargo, esta posibilidad no tiene nada que ver con los aforismos como género literario.

198 Sobre el uso de Kierkegaard de notas anteriores como "Diapsalmata", cfr. por ejemplo, la introducción de Frithiof Brandt a Kierkegaard-Manuskripter. Diapsalmata, publicado por la Sociedad para el Idioma y la Literatura Danesas, Copenhague: Levin \& Munskgaard, 1935, y Brandes, Søren Kierkegaard, pp. 124-129.

199 SKS 17, 208, CC:24 / KJN 1, 199.

200 SKS 2, 27.23-24 / EO1, 19.

${ }^{201}$ ES1, vol. 3, 275. 
incluidos en la colección impresa" ${ }^{202}$. Sin embargo, solo en algunos pocos casos es posible determinar con certeza absoluta que se inspiró de forma directa en él.

En el Postscriptum definitivo y no cientifico se lee lo siguiente: "Poul Møller ha señalado de forma correcta que un bufón de la corte usa más ingenio en un año que más de un autor ingenioso en toda su vida" ${ }^{203}$. Esta afirmación es típica de Møller y es, de hecho, bastante socrática. Lo que importa es la actividad práctica entre la gente; lo que importa es la existencia. No obstante, el aforismo en cuestión es un poco más complejo y dice lo siguiente in extenso:

El improvisador humorístico y otros poetas orales tienen más genio que los poetas que escriben, pero tienen menos conciencia de ello ${ }^{204}$. Son hombres ricos que se divierten arrojando oro a la multitud, sin conocer su valor. Los escritores poéticos no tienen pensamientos inspiradores tan a menudo, pero son conscientes de su carácter genuino. Cada idea afortunada con la que dan es tomada en cuenta y empleada de la manera adecuada. Sin embargo, incluso entre los autores cómicos más voluminosos no hay tanto ingenio como el que emplea en un año un destacado bufón de la corte $\mathrm{e}^{205}$.

Kierkegaard utiliza este aforismo en el Postscriptum, Parte 2, Sección 2, Capítulo 3, $\$ 4$, donde Climacus habla sobre la misión y el estilo del pensador subjetivo. Ahí explica el pensamiento de Møller de la siguiente manera: "esto sucede porque aquel [el bufón de la corte] es una persona existente que en todos los momentos del día debe tener a su disposición el ingenio, mientras que el otro es ingenioso solo de forma ocasional" 206.

En El libro sobre Adler, Capítulo 4, "La concepción psicológica de Adler como un fenómeno y como una sátira de la filosofía hegeliana y del presente”, Kierkegaard escribe: "Eso que Møller dice en alguna parte es muy verdadero y muy maduro: uno realmente puede tolerar no hacer nada; de hecho, esto incluso puede resultarle entretenido a alguien, cuando hay conciencia de que hay algo que debería hacerse. Lo entretenido reside en la

${ }^{202}$ SKS 7, 41.8 / CUP1, 34, nota.

${ }^{203}$ SKS 7, 321.30-32 / CUP1, 351.

${ }^{204}$ Compárese esto con los "genios pasivos" de Jean Paul, de los cuales se habló en la Sección I.

${ }^{205}$ ES1, vol. 3, pp. 176-177.

206 SKS 7, 321.32-34 / CUP1, 352. 
conciencia de que uno ha desatendido algo" ${ }^{207}$. En una nota a esto alude a los Escritos póstumos, volumen 3, p. 217 medio, y luego, al margen, cita uno de los pensamientos dispersos de Møller:

Dentro de un ocio casi absoluto es posible eludir el aburrimiento, siempre y cuando exista una tarea obligatoria que esté siendo desatendida durante el ocio, pues, en tal caso, uno se ocupa con la lucha constante que se entabla con uno mismo. Pero en cuanto cesa el deber o cuando ya no hay ningún recordatorio de dicho deber, el aburrimiento se establece. El tutor privado que, de forma ocasional, pospone una hora de trabajo, disfruta siempre y cuando tenga que ir inmediatamente después con su pupilo; pero en cuanto decide omitir esa hora de trabajo, su goce desaparece. El recordatorio de la conciencia en este ejemplo constituye algo desagradable que funciona como un estímulo para algo agradable. Un poeta que escribe una tragedia, aunque sea parte de un proyecto de vida para conseguir un grado, lo hará con mayor entusiasmo que si renunciara a ese proyecto ${ }^{208}$.

Kierkegaard emplea esta experiencia — tal vez trivial— de posponer y mantener los deberes en su "visión psicológica" de Adler y, en este caso, en el carácter de su productividad: "De la misma manera, tal vez también sea la vaga conciencia de que debería estar haciendo algo más en lugar de ser productivo lo que hace que Magister Adler sea tan productivo y que su productividad le resulte tan interesante, ya que, en vez de adquirir una mejor comprensión de sí mismo a través de su productividad, se defiende en contra de lo que una simplicidad ética le ordenaría hacer" ${ }^{209}$. No es posible afirmar si al mismo tiempo Kierkegaard estaba pensando en el ensayo juvenil -y en parte autobiográfico- de Møller sobre los holgazanes ingeniosos: “Algunas observaciones sobre el desarrollo de las ideas populares" ${ }^{10}$, leída originalmente como conferencia en la Unión de Estudiantes el 19 de febrero de 1825 bajo el título de "Sobre la influencia de los holgazanes en la época contemporánea”.

En sus últimos años, Møller tenía pensado escribir un tratado sobre la afectación, una teoría social y psicológica desarrollada por él mismo y

207 Pap. VII-2 B 235, p. 214 / BA, 128.

${ }^{208}$ Pap. VII-2 B 235, pp. 214-215 / BA, 128-129; ES1, vol. 3, p. 217.

${ }^{209}$ Pap. VII-2 B235, p. 215 / BA, 129.

${ }^{210}$ P. M. Møller, "Nogle Betragtninger over populaire Ideers Udvikling”, Nyt Aftenblad, no. 18, 1825, pp. 153-160; reimpreso en ES1, vol. 2, pp. 3-19. 
desarrollada en el transcurso de los años en numerosos pensamientos dispersos sobre el tema y en un fragmento que iba a ser la introducción del tratado. Este fragmento fue comenzado en 1837, según F. C. Olsen, quien lo incluyó con el título "Observaciones introductorias para un tratado sobre la afectación" 211. Esta "descripción moral de la naturaleza", como Møller la llamó, podría ser considerada como su única contribución original a una antropología filosófica o, mejor dicho, patología filosófica. Anteriormente, el concepto de afectación era utilizado para referirse a una función o a acciones extrovertidas; Møller, en cambio, lo emplea de forma principal con relación a la existencia. Por este mismo motivo, se vio obligado a renunciar al concepto hegeliano de moralidad (Sittlichkeit), ya que, para Hegel, la moralidad constituye la máxima realidad de la razón. Pero, como Møller señala, un "sistema especulativo construido de forma previa" es inútil para este propósito. Él toma en consideración cualquier engaño o falsedad frente a uno mismo, frente a la propia individualidad, y esto no puede ser definido en términos absolutos, ya que la verdad en la vida es un asunto personal que va más allá de la moralidad ${ }^{212}$. La no verdad es el engaño y la ausencia de libertad. No obstante, ciertos tipos de manifestaciones de vida no deben considerarse como afectación. Por ejemplo, una mentira o una simulación consciente. Lo mismo ocurre con diferentes modos de conducta anormal o

${ }^{211}$ P. M. Møller, "Forbredelser til en Afhandling om Affectation", en ES1, vol. 3, pp. 291-302 y pp. 303-313 (“Strøtanker; om Affectation"); ver nota al pie de Olsen en pp. 291292. Sobre este tema, ver, por ejemplo, Peter Thielst, "Poul Martin Møller (1794-1838); Scattered Thoughts, Analysis of Affectation, Combat with Nihilism”, Danish Yearbook of Philosophy, vol. 13, 1976, pp. 66-83; reimpreso como "Poul Martin Møller: Scattered Thoughts, Analysis of Affectation, Struggle with Nihilism”, en Kierkegaard and His Contemporaries: The Culture of Golden Age Denmark, ed. por Jon Stewart, Berlín y Nueva York: Walter de Gruyter, 2003 (Kierkegaard Studies Monograph Series, vol. 10), pp. 45-61.

${ }^{212} \mathrm{La}$ interpretación general (o hegeliana) de la verdad es descrita por Møller de la siguiente manera: "La vida de la persona que sigue sin fingimiento sus deseos naturales, posee una especie de verdad. Existe una verdad más elevada en la vida de la persona que ha alcanzado la virtud (en el sentido del término empleado en la Antigüedad), de modo que incluso cuando continúa extrayendo el contenido de sus acciones de sus instintos naturales, pese a ello ha adquirido el suficiente dominio sobre ellos como para mantener una cierta moderación en el momento de satisfacerlos. Hay una verdad personal todavía superior en la vida de la persona que determina todos sus propósitos mediante una autonomía puramente racional... Así, en la medida que la autodeterminación pura del ser humano sea la voluntad santificada por la religiosidad, esta operará en completa armonía con todo el mundo de la Razón. El ser humano será lo que debe ser y su vida habrá alcanzado su verdad suprema. Sin embargo, esta verdad es la moralidad misma y toda desviación de ella es inmoralidad". ES1, vol. 3, pp. 293-294. 
condiciones "alteradas", de las cuales también habla Møller en sus lecciones sobre psicología ${ }^{213}$. En su introducción, Møller distingue entre tres grados de afectación: momentánea, permanente y alternante. En pocas palabras, el engaño momentáneo o corrupción del yo ocurre cuando la virtud de una persona no se ha hecho estable y fuerte, y cuando, en ocasiones, no se es fiel al propio carácter, como cuando, al socializar con otros, uno penetra en su "círculo de conciencia". Sin embargo, de forma paradójica, suele ocurrir que una afectación de esta clase es necesaria en la existencia. La afectación permanente es cuando una persona ha perdido el control sobre sí misma y "ha adoptado como hábito un tipo determinado de afirmaciones falsas, esto en el sentido de que se imagina que tiene ciertas opiniones, intereses o inclinaciones, pues desea tenerlas por alguna u otra razón externa". ${ }^{214}$ Por último, la peor afectación es la alternante, en la cual ya no hay un "núcleo permanente en los pensamientos y voluntad de la persona, sino que en todo momento de su vida se inventa una personalidad temporal que puede ser anulada al momento siguiente" 215 . Este singular tipo de culminación constituye la falsedad absoluta en la vida personal.

Por muchos años, Møller reunió material sobre el concepto de afectación, incluyendo toda clase de observaciones y reflexiones, las cuales se encuentran especialmente entre sus pensamientos dispersos. Kierkegaard no analiza con detalle en ninguna parte el concepto de afectación de Møller ${ }^{216}$. Pero hay al menos un caso en el que se refiere a uno de los pensamientos dispersos sobre la afectación. En enero de 1847 escribe lo siguiente en el Diario NB:

Que incluso Poul Møller pasó por toda clase de dudas es algo que resulta evidente a partir de algunas expresiones bastante accidentales. En un aforismo, habla de los pastores fanáticos que discurren con fervor y no se percatan de que toda su religiosidad es una circulación potenciada de la sangre. ¡Ay! ¡Esto es solo el principio del problema! ¿Cuántos hombres viven con la suficiente transparencia para saber realmente qué es qué? Piensan en categorías completamente diferentes a aquellas en

${ }^{213} \mathrm{El}$ manuscrito con las notas de las lecciones de Møller sobre psicología no se ha publicado, pero estará presente en la nueva edición crítica. Se encuentra en la Biblioteca Real en Copenhague, en la Collinske Samling, $379,4^{\circ}$.

${ }^{214}$ ES1, vol. 3, p. 298.

${ }^{215}$ ES1, vol. 3, p. 299.

${ }^{216}$ Sin embargo, parece que eso es lo que piensan los editores de los $S K S$, por ejemplo, cuando habla de las "obras afectadas" en la entrada JJ:313. Ver la nota completa en SKS 18, 238.8 / KJN 2, 539, nota a 219.4. 
las que viven. Hablan en categorías religiosas y viven en categorías de la sensualidad, las categorías del bienestar inmediato ${ }^{217}$.

A partir de esta entrada del diario, parece que Kierkegaard estaba enterado de las dudas religiosas de Møller en el transcurso de su vida. La afectación en los siervos de Dios - la cual vemos reflejada en varios de sus pensamientos dispersos- definitivamente no le ayudó a fortalecer su fe. De hecho - y esto a diferencia de Kierkegaard—, nunca a volvió a pensar seriamente en convertirse en pastor después de su viaje a China. El aforismo al que alude Kierkegaard es un ejemplo de la afectación momentánea y dice lo siguiente:

La exaltación momentánea posee a veces una naturaleza sensual inferior con un movimiento orgánico dominante. El poderoso cambio orgánico necesariamente despierta la reflexión (pues toda afección severa debería hacerlo) y entonces la afección queda preservada como goce por su propia actividad y por sentirse perdida en la idea. Semejante deleite parcialmente demencial por la elevación de la vida vegetativa - por ejemplo, de la circulación de la sangre— puede vislumbrarse a menudo a través de la mirada de los sacerdotes fanáticos, quienes incluso llegan a apretar los dientes y torcer sus rostros en su arrebato. El segmento inferior de la multitud, especialmente las mujeres sin educación, consideran esto como entusiasmo ${ }^{218}$.

En lo que se refiere a la inmortalidad, la cual será analizada en la siguiente sección, parece que - aparte de las reflexiones intelectuales fundadas en un debate general sobre el tema en aquella época - constituyó una experiencia personal que acercó a Møller a una clarificación religiosa. Después de la muerte de su esposa Betty en 1834, escribió lo siguiente en una carta a su suegra, Elisabeth Berg:

El lamentable divorcio que hemos sufrido ha hecho que mi pensamiento acerca de otra vida superior esté más vivo y presente que nunca antes... Estoy completamente convencido de que la muerte y la vida son

217 SKS 20, 80, NB:103 / JP 1, 1044. Hay un comentario al margen sobre esto: "Para que sea evidente que uno que sufre tiene fe, entonces la fe debe aparecer al mismo tiempo que el sufrimiento. Pero ¿qué sucede? A medida que desaparecen de forma gradual el dolor, el infortunio y la oposición, su vida —interpretada por la mente secular — se vuelve más saludable y feliz... y él piensa que esto se debe a la fe. Por el contrario, esto ocurre en virtud de la vitalidad restaurada de la inmediatez". SKS 20, 80, NB:103.a / JP 1, 1045.

${ }^{218}$ ES1, vol. 3, p. 241. 
repeticiones a gran escala de la misma alternancia que hay entre el sueño y la vigilia... Me parece, no obstante, que una idea de cuya validez uno está seguro, a veces puede adquirir en la propia vida una claridad y una fuerza inusuales, y aparecer frente a uno bajo una luz que la hace ver como si fuera algo completamente nuevo ${ }^{219}$.

\section{G. El tratado sobre la inmortalidad}

En el Capítulo 2 de la novela inconclusa de Møller, Aventuras de un estudiante danés, el protagonista, el rizado Frits, les cuenta a sus amigos sobre sus reflexiones en torno a las graves consecuencias de colgarse de un manzano en flor como resultado de su desdichado amor por la hija del molinero: "Pero entonces me di cuenta de que la parte imperecedera en mí, al abandonar esta esfera temporal, tal vez se trasladaría a regiones tan lejanas que sería incapaz de ver o escuchar ninguna de las sensaciones que, de forma particular, pretendía experimentar con mi desesperada decisión" ${ }^{220}$. La pregunta sobre la existencia de "regiones lejanas" era central en el debate contemporáneo acerca de la inmortalidad en el cual Møller también participó y que es el tema de su obra filosófica más extensa, "Pensamientos sobre la posibilidad de una demostración de la inmortalidad humana, con referencia a la literatura más reciente sobre el tema”, publicada en dos partes en el Maanedskrift for Litteratur en $1837^{221}$. El complejo contenido de este

${ }^{219}$ Borup, carta no. 140. Comparemos. En el tratado sobre la inmortalidad, Møller dice: "En términos generales, el impulso de conocer a determinados seres humanos como objetos imperecederos de su amor es aquello que conduce a pensadores escépticos o no creyentes de vuelta a la visión cristiana"; y refiriéndose a ciertos científicos naturales que han renunciado al panteísmo abstracto, dice que "la muerte de los individuos a los cuales estaban relacionados por fuertes vínculos de simpatía les ha hecho ver el vacío de su visión de vida". Maanedskrift for Litteratur, vol. 17, p. 52; ES1, vol. 2, p. 215. Kierkegaard tal vez estaba pensando en esto en un borrador del discurso de Victor Eremita en Etapas en el camino de la vida, Pap. V B 178, 8, p. 308 / SLW, Suplemento, p. 548: "En tiempos pasados, uno creía que la inmortalidad quedaba demostrada por el amor erótico; era algo así como esto: esos dos se aman por toda la eternidad, ergo, debe existir una eternidad. Hoy en día, uno la demuestra al amar con mucha frecuencia, pues ¿no es acaso una perfección semejante una prueba de un espíritu inmortal?”

${ }^{220}$ ES1, vol. 3, p. 80.

${ }^{221}$ P. M. Møller, "Tanker over Muligheden af Beviser for Menneskets Udødelighed, med Hensyn til den nyeste derhen hørende Literatur", Maanedskrift for Litteratur, vol. 17, Copenhague: C. A. Reitzel, 1837, pp. 1-72 (número de enero) y pp. $422-453$ (número de mayo); reimpreso en ES1, vol. 2, 1842, pp. 158-272. El título quizá alude a la obra anónima de Ludwig Feuerbach, Gedanken über Tod und Unsterblichkeit, aus den Papie- 
largo tratado ha sido tratado con profundidad anteriormente y yo me referiré a estos análisis para una discusión más detallada ${ }^{222}$. Además de algunas observaciones generales, aquí me concentraré en las referencias o alusiones de Kierkegaard al tratado, especialmente en el Postscritpum definitivo y no cientifico.

Møller dice en uno de sus pensamientos dispersos: "El hecho de que la fe en la inmortalidad es un momento esencial en el conocimiento puede verse por primera vez de forma bastante clara cuando uno decide eliminar por completo este concepto del propio sistema; solo entonces se verá con claridad que es un momento indispensable en una visión de mundo congruente y armoniosa" 223 . Parece, entonces, que para aceptar la verdad de la inmortalidad, es preciso eliminarla por completo para después considerar las pruebas de su posible realidad. En cierto sentido, esto constituye una vez más una lucha con el nihilismo y, en este caso, con la negación de la vida eterna. Møller establece al comienzo del tratado: "Porque es muy posible que la negación no haya alcanzado todavía el punto suficiente para que sea del todo evidente que la desolación a la cual conduce no es una esfera en la que el humano deba residir" 224 . Además, en su propia época fue testigo de

ren eines Denkers, nebst einem Anhang theologisch-satyrischer Xenien, berausgegeben von einem seiner Freunde, Nürnberg: J. A. Stein, 1830. El tratado de Møller fue traducido al francés, "Réflexions sur la possibilité de prouver l'immortalité de l'homme en rapport avec la littérature récent sur le sujet”, en Lectures philosophiques de Søren Kierkegaard chez ses contemporains danois, ed. y trad. de Henri-Bernard Vergote, París: Presses Universitaires de France, 1993, pp. 149-213. Aparecerá una traducción al inglés en la serie Texts from Golden Age Denmark, vol. 9.

${ }^{222}$ De forma más reciente, el tema ha sido discutido en Jon Stewart, A History of Hegelianism in Golden Age Denmark, Tomo II, The Martensen Period: 1837-1842, Copenhague: C. A. Reitzel, 2007 (Danish Golden Age Studies, vol. 3), pp. 37-53, y en Lasse Horne Kjældgaard, Sjælen efter døden. Guldalderens moderne gennembrud, Copenhague: Gyldendal, 2007, especialmente pp. 83-112. Ver también el artículo de Kjældgaard, "What it Means to Be Immortal: Afterlife and Aesthetic Communication in Kierkegaard's Concluding Unscientific Postscript", Kierkegaard Studies Yearbook, 2005, pp. 90-112. Para un panorama general del debate sobre la inmortalidad, ver también, por ejemplo, los dos artículos de István Czakó, "Unsterblichkeitsfurcht. Ein christlicher Beitrag zu einer zeitgen" ssischen Debatte in Søren Kierkegaards Gedanken die hinterrücks verwunden-zur Erbauung”, Kierkegaard Studies Yearbook, 2007, pp. 227-254, y "Heiberg and the Immortality Debate: A Historical Overview", en Johan Ludvig Heiberg: Philosopher, Littérateur, Dramaturge, and Political Thinker, ed. por Jon Stewart, Copenhague: Museum Tusculanum Press, 2008 (Danish Golden Age Studies, vol. 5), pp. 95-138.

${ }^{223}$ Este aforismo no se encuentra en los Escritos póstumos, pero fue publicado por Vilhelm Andersen en Udvalgte Skrifter af Poul Møller, vol. 2, p. 397.

${ }^{224}$ Maanedsskrift for Litteratur, vol. 17, p. 4; ES1, vol. 2, p. 162. 
la gradual desaparición del clasicismo al estilo goetheano o, mejor dicho, del enfoque idealista al estilo griego — su poema "El artista entre los rebeldes" era una amarga protesta en contra de este proceso-, el cual sería reemplazado por el nihilismo, el conflicto y la discordancia en todos los aspectos de la existencia humana. Las artes —un anticipo de la vida eterna- debían señalar el camino.

Después de la muerte de Hegel (1831), comenzó un debate sobre la inmortalidad del alma, iniciado por la obra de 1833 de Friedrich Richter (1807-1856), Die Lebre von den letzten Dingen ${ }^{225}$. Hegel mismo nunca abordó el tema de forma específica. Como dice Møller, no resulta evidente en ninguna parte que Hegel niegue la inmortalidad, pero, aun así, "cualquiera que sea un poco capaz de leer entre líneas en los escritos de Hegel, fácilmente alcanzará la conclusión inevitable de que este filósofo considera el concepto de la inmortalidad personal como una noción sin realidad alguna" 226 . En la primera parte del tratado (Secciones I-VII), que es la más importante, Møller desarrolla su propia postura sobre el tema, y, en la segunda (Secciones VIII-XI), hace una exposición crítica de la literatura especulativa más reciente acerca de las pruebas de la inmortalidad, especialmente Christian Hermann Weiße (1801-1866) ${ }^{227}$, el joven Fichte (1797-1879) ${ }^{228}$ y Carl Friedrich Göschel (1781-1861)229. Sin embargo, él no queda satisfecho con ninguna de estas obras, aunque, en términos generales, afirma —una vez más como en el aforismo citado antes- que "es cierto que cada demostración de la inmortalidad humana tiene por sí sola la posibilidad de abrir el prospecto de una visión de mundo profunda y exhaustiva" ${ }^{230}$. No obstante, esto no es posible dentro del marco de un sistema filosófico y, de hecho, el tratado sobre la inmortalidad debe verse como el rompimiento definitivo de Møller con el hegelianismo en cuanto tal, no solo como una crítica de los

${ }^{225}$ Friedrich Richter, Die Lehre von den letzten Dingen, vol. 1, Eine wissenschaftliche Kritik, aus dem Standpunct der Religion unternommen, Breslau: In Joh. Friedr. Korn des älteren Buchhandlung, 1833; el segundo volumen se publicó en 1844: Die Lehre vom jüngsten Tage. Dogma und Kritik, Berlín: Richter'sche Buchhandlung, 1844.

${ }^{226}$ Maanedskrift for Litteratur, vol. 17, p. 25; ES1, vol. 2, p. 185.

${ }^{227}$ C. H. Weiße, Die philosophische Geheimlehre von der Unsterblichkeit des menschlichen Individuums, Dresde: Ch. F. Grimmer'sche Buchhandlung, 1834.

${ }^{228}$ I. H. Fichte, Die Idee der Persönlichkeit und der individuellen Fortdauer, Elberfeld: Büschler'schen Verlagsbuchhandlung und Buchdruckerei, 1834 (ASKB 505.)

${ }^{229}$ C. F. Göschel, Von den Beweissen für die Unsterblichkeit der menschlichen Seele im Lichte der speculativen Philosophie, Berlín: Duncker und Humblot, 1835.

${ }^{230}$ Maanedskrift for Litteratur, vol. 17, p. 453; ES1, vol. 2, p. 271. 
hegelianos de derecha, quienes, desde su punto de vista, le atribuyen incorrectamente a Hegel una doctrina de la inmortalidad.

Møller señala dos concepciones diferentes de lo divino en la filosofía moderna: la teísta y la panteísta, las cuales se derivan respectivamente de Leibniz y Spinoza. En los tiempos recientes, el panteísmo prevalece (algo que en la teología aparece como "omnipresencia", "omnipotencia”, etc.), de manera que resulta evidente que "la doctrina de las almas como cosas o sustancias independientes ha desaparecido para cualquiera que tenga aunque sea una pequeña noción de la cultura filosófica de nuestra época; pero con esto la doctrina de la inmortalidad también ha perdido su antiguo fundamento" 231 . La mayoría de las personas que pide pruebas rigurosas de la inmortalidad no posee las condiciones para hacerlo: "Solo aquel que en ciertos momentos sea capaz de experimentar una libertad genuina de todos los intereses mundanos será receptivo frente a la convicción de un mundo suprasensible realmente existente. No me refiero a la libertad de la ironía, sino a la libertad que conduce a una vida verdadera en el mundo"232. Aquí Møller usa una anécdota sobre un librero y un teólogo para ilustrar este autoengaño general. Más adelante, afirma que la inmortalidad no puede demostrarse de forma matemática u ontológica (a priori). Al carecer de una demostración lógica, lo que se necesita es una visión concreta y completa de mundo que esté totalmente justificada tanto desde un punto de vista empírico — con relación a los fenómenos del mundo de los sentidos- como desde la tradición cristiana de lo suprasensible. Los hegelianos que han intentado proponer una visión de mundo sin la doctrina de la inmortalidad nunca lo han logrado, ya fuera por medio de un panteísmo lógico o de cualquier otra forma, y el hegelianismo se ha sobrevivido a sí mismo: "Una visión de vida que ultraja el sentido de la humanidad por la verdad se ha refutado a sí misma de forma temporal por sus afirmaciones explícitas y decisivas. Así, se ha intentado presentar la tradición cristiana a través de un nuevo sistema científico que, en última instancia, reemplaza al sistema antiguo, en el cual las deficiencias se perciben de manera clara"233. Møller admite que él no es capaz de proporcionar una nueva visión universal y verdadera de mundo; eso será tarea del futuro ${ }^{234}$.

${ }^{231}$ Ibid., p. 10; ES1, vol. 2, p. 168.

${ }^{232}$ Ibid., p. 17; ES1, vol. 2, pp. 176-177.

${ }^{233}$ Ibid., pp. 45-46; ES1, vol. 2, p. 208.

${ }^{234}$ Carl Henrik Koch argumenta que el tratado de Møller está en armonía con el teísmo especulativo de I. H. Fichte, y señala que esta fue su última postura filosófica. Para 
Todo esto puede parecer muy abstracto, pero, de acuerdo con Møller, existe al menos una consecuencia visible de la negación de la inmortalidad: el creciente número de suicidios, el cual no es sino un síntoma de una visión de mundo nihilista y congruente con la negación: "De acuerdo con la doctrina de la aniquilación, la conducta que un individuo asume frente a otro será, para aquellos que estén conscientes de la brevedad de la vida, algo tan irrelevante como un largo sueño. Una visión de vida que conduce a un nihilismo práctico puede convertirse con facilidad en un esfuerzo positivo dirigido a la autoaniquilación" 235 . También el amor por el prójimo se convierte en una ilusión y pierde su valor: "El amor que considera a su objeto como perecedero posee necesariamente una naturaleza diferente que el amor que sabe que su objeto pertenece a aquello que existe de forma eterna" ${ }^{236}$. En tercer lugar, el impulso ideal y contemplativo pierde su significado, es decir, la ciencia, el arte y la religión pierden su interés. En lo que podría llamarse una "prueba indirecta", Møller argumenta que la creación del arte implica de forma necesaria la creencia en la inmortalidad:

A fin de que un ser humano posea la suficiente fuerza centrífuga para moverse en las regiones de una imaginación más elevada, es preciso que utilice - con una especie de inmortalidad libre de reflexión — a la vida como una eternidad o deberá convencerse de la realidad del concepto de inmortalidad. Aquí afirmo sin titubeos que la duda en la inmortalidad de los individuos es el cáncer del arte, y la convicción en su carácter destructible es la tumba del

esto, ver C. H. Koch, Den danske idealisme 1800-1880, Copenhague: Gyldendal, 2004 (Den danske filosofis historie, vol. 4, ed. por Sten Ebbesen y C. H. Koch), pp. 261-264.

${ }^{235}$ Maanedsskrift for Litteratur, vol. 17, p. 51; ES1, vol. 2, p. 214. Kierkegaard escribió en lo que, según H. P. Barfod, era un papel suelto (cfr. EP, vol. 3, p. 317): “¿Un discurso fúnebre? El patrón entretejido debería ser Poul Møller”. Pap. VIII-1 B 224. No es claro qué quería decir, pero en otro papel decía: "Frente a la tumba de un suicidio". Pap. VII-1 B 227.

${ }^{236}$ Maanedsskrift for Litteratur, vol. 17, p. 52; ES1, vol. 2, p. 215. En ese caso, parecería extraño que tanta gente se muestre feliz, pero esto puede explicarse con facilidad como un autoengaño: "El que muchas personas que no creen en la inmortalidad demuestren, pese a ello, una gran alegría por la vida, puede explicarse, en términos generales, como una especie de inconsciencia que explica su mediocre orientación dentro de su propio ámbito de ideas. Sin embargo, ahora el género humano ha adquirido una orientación melancólica que no permitirá que estas contradicciones permanezcan inadvertidas ni le permitirá olvidarse constantemente a sí mismo a través de una laboriosidad sin sentido". Maanedsskrift for Litteratur, vol. 17, p. 54; ES1, vol. 2, p. 228. El tema de la laboriosidad también es analizado por Kierkegaard en varios lugares; por ejemplo, en el famoso diapsalma, SKS 2, $33 / E O 1,25$. 
arte. Lo que aquí tengo que decir lo digo de forma literal: "El arte verdadero es un anticipo de la vida bienaventurada" 237 .

En su reseña en Perseus de la Doctrina de la Trinidad y la reconciliación de V. H. Rothe, Heiberg se refiere amargamente a Møller como un desertor del hegelianismo 238 . Aunque Møller respetaba a su antiguo amigo, en este momento se habían alejado el uno del otro; al menos fue así el último año de Møller, cuando, en una carta dirigida a Hauch, después de expresar su descontento con la idea de que la poesía pudiera ser "especulativa" o filosófica - lo cual presuntamente ocurría con la obra de Heiberg, Fata Mor-

${ }^{237}$ Maanedsskrift for Litteratur, vol. 17, pp. 53-54; ES1, vol. 2, pp. 216-217. La famosa tesis de Møller según la cual el arte verdadero es un anticipo de la vida eterna o bienaventurada podría estar inspirada en una de las obras que discute en su tratado, C. H. Weiße, Die philosophische Geheimlehre, en la cual puede leerse, entre otras cosas (pp. 46-47), "Daß in dem Schönen, in den Werken des Genius sich ein Ewiges und geistig Absolutes, daß in ibm sich der Weltgeist selbst nach einere der unendlich vielen Gestalten, in die er, der unerschöpfliche Proteus, sich zu verwandeln weiß, offenbart: dieß ist eine Wahrnehmung, eine Gewißheit, die man mit Recht die Grundlage aller höhern Geistesbildung unsers Zeitalters nennen kann... Wir erwäbnen dieß hier... nur, um in dem gemeinschaftlichen Boden eben derjenigen Bildungskreise unseres Zeitalters, von denen der Zweifel an persönlicher Unsterblichkeit vornehmlich auszugehen pflegt, die Stelle aufzuzeigen, von der eine wissenschaftliche Widerlegung dieses Zweifels zu beginnen hat". Cfr. Jon Stewart, A History of Hegelianism in Golden Age Denmark, Tomo II, p. 49, nota 3.

${ }^{238}$ Valdemar Henrik Rothe, Læren om Treenighed og Forsoning. Et speculativt Forsøg $i$ Anledning af Reformationsfesten, Copenhague: J. D. Quist, 1836. En su reseña, "Recension over Hr. Dr. Rothes Treenigheds- og Forsoningslære”, en Perseus, Journal for den speculative Idee, no. 1, ed. por J. L. Heiberg, Copenhague: C. A. Reitzel, 1837 (ASKB 569), p. 33 , Heiberg se pregunta si los intentos de ciertos filósofos "de progresar más allá del ámbito actual de la filosofía no será, sin querer, un retroceso. Falta ver si el sistema, al que acaban de abandonar, no contiene eso que ahora están buscando fuera de él, en cuyo caso habrían perdido el tiempo. No obstante, parece poco probable que estos desertores puedan llegar a constituir un cuerpo, ya que su propósito es demasiado indeterminado. Incluso si fueran capaces de especificar qué es lo que están buscando, por ejemplo, una visión de mundo futura, aun así no podría decir nada del camino que conduce a dicha visión. Ahora bien, esto es precisamente lo que busca la filosofía, algo que no puede lograrse buscando en la Luna". La fuerte reacción de Heiberg ha de considerarse tomando en cuenta que el tratado de Møller era también una respuesta crítica a las afirmaciones negativas de Heiberg con relación a la religión en su análisis de la crisis de la época, On the Significance of Philosophy for the Present Age (en Heiberg's On the Significance of Philosophy for the Present Age and Other Texts, trad. y ed. por Jon Stewart, Copenhague: C. A. Reitzel, 2005 (Texts from Golden Age Denmark, vol. 1), pp. 83-121 (publicado originalmente como Om Philosophiens Betydning for den nuværende Tid. Et Indbydelses-Skrift til en Række af philosophiske Forelæesninger, Copenhague: C. A. Reitzel, 1833)). Cfr. Kjældgaard, Sjælen efter døden, p. 86. 
gana (estrenada el 29 de enero de 1838) y debía suceder con su "comedia apocalíptica”, "Un alma después de la muerte" (1841)—, escribió que él y Heiberg "habían dejado de entenderse desde hace mucho"239. Sibbern, por otro lado, tiempo después defendería con fervor al ya difunto Møller en su reseña del primer número de Perseus en el Maanedsskrift de 1838; ahí lo consideraba como un pensador para el que el hegelianismo no podía ser más que una etapa temporal: "Él no podía sino pasar por el hegelianismo como si se tratara de una fase. Un pensador como Poul Møller no podía permitirse permanecer ahí por siempre. No era parte de su carácter el dejarse reclutar por una filosofía como la de Hegel para toda la vida, o dejarse convertir en un Hegelianismo adscriptus" ${ }^{240}$. Sibbern tenía razón: al ser un genio libre, Møller se encaminaba ahora hacia otra dirección, aunque, por desgracia, este camino quedó interrumpido por su muerte temprana. Antes, en la Sección II, hablé de los pasajes en Kierkegaard en los que también aparece este movimiento: por ejemplo, el fuerte veredicto de Møller sobre la locura hegeliana... y su risa franca al respecto.

El joven Søren Kierkegaard leyó la primera parte del tratado de Møller poco después de su publicación en el número de enero del Maanedsskrift for Litteratur de $1837^{241}$. Esto es evidente por el Diario BB, en el que escribió

${ }^{239}$ Borup, carta no. 168. El hecho de que esta posterior falta de comprensión sucedió solo en la esfera intelectual es evidente por los elementos personales en la hermosa, aunque también tradicional, canción de Heiberg durante el funeral de Møller, publicada en ES1, justo después de Poul Martin Møllers Levnet de F. C. Olsen (p. 116); cfr. Johan Ludvig Heibergs Poetiske Skrifter, vols. 1-11, Copenhague: C. A. Reitzel, 1862; vol. 8, pp. 386-387.

${ }^{240}$ F. C. Sibbern, "Perseus, Journal for den speculative Idee. Udigiven af Johan Ludvig Heiberg, Nr. 1, Juni 18837. Kjøbenhavn. Reitzels Forlag. XIV og 264 S. 8. Priis 1 Rbd. 84 Skill.-_Med stadigt Hensyn til Dr. Rothes: Læren om Treenighed og Forsoning. Et speculativt Forsøg $i$ Anledning af Reformationsfesten.)", Maanedskrift for Litteratur, vols. 19 y 20, 1838, en una serie de ocho artículos, de los cuales los primeros 3 se publicaron también por separado en forma de libro, Bemærkninger og Undersøgelser, fornemmelig betræffende Hegels Philosophie, betragtet $i$ Forhold til vor Tid, Copenhague: C. A. Reitzel, 1838; la cita es del Artículo I, "Angaaende det Hegelske Begreb om Philosophie med Hensyn til dens Udgangspunct og dens hele Grundlag”, Maanedsskrift for Litteratur, vol. 19, pp. 315-360; ver p. 336; Bemzrkninger og Undersøgelser, p. 54. Traducido por Jon Stewart en A History of Hegelianism in Golden Age Denmark, Tomo II, p. 198.

${ }^{241} \mathrm{El}$ Maanedsskrift for Litteratur no aparece en el ASKB y Kierkegaard no está en la lista de suscriptores. Pero, como ya se ha mencionado, Kierkegaard probablemente lo leía en una biblioteca pública o en una sociedad de lectura como el Athenæum. El hecho de que leía el Maanedsskrift con regularidad es claro, por ejemplo, por su referencia a la reseña de Møller de Los extremos (cfr. SKS 19, 99, Not3:2.a / JP 4, 3847), ver la Sección III, D, o por la entrada BB:32 (SKS 17, 121 / KJN 1, 115), en la que menciona la reseña de Marten- 
la siguiente entrada el 4 de febrero de 1837. Lo que más le llamó la atención en ese momento fue la historia intercalada del librero y el teólogo:

Es muy interesante ese episodio que Poul Møller ha incluido en su tratado sobre la inmortalidad del alma en el último número del Maanedsskrift. Esa sustitución del tono estrictamente científico por partes más ligeras, pero a su vez mucho más llenas de vida, quizá se convierta en una tendencia general, respecto de la cual el dominio científico sería algo así como el coro, como las partes cómicas de los dramas románticos ${ }^{242}$.

Con este "episodio" — que es también la palabra que emplea Kierkegaard— o "relato", para utilizar el término de Møller, en el cual un librero le pide en vano a un teólogo que le diga demostraciones rápidas y populares de la inmortalidad mientras se afeita y viste (algo que, de forma indirecta, es también una crítica en contra de la filosofía de divulgación de Heiberg), Møller anima una exposición, por lo demás pesada, de una forma tan inusual que incluso tiene que pedirle al lector una disculpa por hacerlo. Kierkegaard compara esto con el coro de los dramas antiguos — algo que no sorprende si se piensa en Møller como un "feliz amante de la cultura griega" — o con las partes cómicas en los dramas románticos. No obstante, la manera en que Møller ascendía a un modo distinto de comunicación también podría compararse a los símiles de Platón; al menos me parece claro que la inspiración de Møller son los diálogos socráticos ${ }^{243}$. Es verdad: se trata de una parte

sen de la Lección introductoria al curso de lógica (1835) de Heiberg, en Maanedsskrift for Litteratur, vol. 16, 1836, pp. 515-528.

${ }^{242}$ SKS 17, 134, BB:41 / KJN 1, 127-128.

${ }^{243} \mathrm{El}$ carácter de este relato ha sido interpretado de modo diferente. Por ejemplo, John Chr. Jørgensen lo llama una "novela corta"; Den sande kunst. Studier i dansk 1800tals realisme. Poul Møller. Hans Egede Schack, Georg Brandes, Herman Bang, Copenhague: Borgen, 1980, pp. 55-60. En la carta ya mencionada a su hermano Hans Ulrik (Borup, carta no. 151), Møller, al comparar el relato intercalado con sus aforismos, dice lo siguiente: "La pieza que aparece en el Maanedsskrift la he compuesto deliberadamente de forma inconexa o en aforismos no solo por el hecho de que, al proceder tan metódicamente en mis lecciones, necesito, para variar, librarme de mi propio dominio, sino también porque creo que esta clase de estilo se ganará algunos lectores que con el antiguo estilo se hubieran perdido. Además, porque sé que esto es entendido por muchas personas que no comprenden la parte más rigurosa de la exposición. Los aforismos, en cambio, están compuestos de forma azarosa, justo como los sombreros que salen a la venta sin que se les tome ninguna medida. Es solo por casualidad que se ajustan a una u otra cabeza. Tienen la misma posibilidad de ser entendidos y de ser malentendidos que la parte más rigurosa de la exposición”. 
"más ligera" en la mayoría de los círculos académicos. Kierkegaard parece haberse apropiado de esta técnica de introducir anécdotas a partir de Møller, especialmente en el Postscriptum definitivo y no científico, con las escenas de Johannes Climacus en el Jardín Frederiksberg y en el cementerio ${ }^{244}$. Kierkegaard también aprovecha una expresión significativa en la historia de Møller: “ $A$ propos, puesto que hemos mencionado el tema, ¿podrías, en cuanto teólogo, hacer un recuento de las mejores pruebas de la inmortalidad del alma? Por favor hazlo mientras afilo mi navaja y me afeito" ${ }^{245}$. Más adelante utilizará esto en el Postscriptum, reemplazando al librero con "un hombre serio" en busca de la verdad:

Pero alguno de estos añorantes caballeros, un "hombre serio", que realmente quisiera hacer algo por su felicidad eterna, podría decir: “¿No sería posible averiguar con claridad, certeza y brevedad aquello que es

${ }^{244}$ SKS 7, 170-172 Y 213-219 / CUP1, 185-188 y 234-240. Otros ejemplos de historias intercaladas, aunque no dentro de un contexto estrictamente filosófico, son los seis episodios en “¿Culpable? / ¿No culpable?” en Etapas en el camino de la vida. En una de estas historias titulada "Una posibilidad”, Kierkegaard, posiblemente inspirado por Møller, también hace alusión a un librero (SKS 6, 257-268 / SLW, 276-288). Kierkegaard —o Frater Taciturnus- hace que su librero hable "sucio" con un viejo capitán (SKS 6, 267 / SLW, 287-288), justo como el mismo Kierkegaard hizo presuntamente, de acuerdo con la entrada $\mathrm{JJ}: 113$, en sus conversaciones con un viejo "capitán de China", quien le dice, entre otras cosas, "cómo en Manila todo mundo tiene una golfa o de cómo se divertía en su juventud con las golfas (esta es su expresión favorita) en Londres" (SKS 18, 176 / KJN 2, 163-164). En esta entrada, que Kierkegaard utilizó en Etapas en el camino de la vida, quizá también es digna de mención su referencia a Manila, capital de las Filipinas, donde Møller estuvo en su viaje a China. Un texto en el que Møller estaba trabajando durante su viaje, pero que no llegaría a completar, era un diario o descripción de la travesía, "Apuntes sobre el viaje a China”, ES1, vol. 3, pp. 131-168, en el cual encontramos otro episodio "picante”, aunque no de Manila, sino de Anyer, en Java, el 9 de junio de 1820: "En su comercio, los malasios a menudo cancelan más tarde sus propias transacciones. Había comprado algo de mimbre para un abrigo, pero un salvaje regresó y quería deshacer el trato. En otra ocasión, un malasio se acercó a un marinero y quería regresarle su salario, diciéndole: Trada mau (no lo quiero), a lo cual el marinero replicó 'vete a...' y el malasio tuvo que retirarse nuevamente sin concluir el negocio”. ES1, vol. 3, p. 159. Kierkegaard hace alusión a este episodio en su pequeño estudio inédito de 1848, "Phister en el papel del Capitán Escipión” (Pap. IX B 67-73 / C, Suplemento, pp. 329-344): "Con respecto a una reflexión o una representación reflexiva, limitarse a decir "Bravo" o "Bravísimo" carece totalmente de sentido, es algo que no puede sino aburrir y cansar a la reflexión que es el objeto de admiración, es algo que con facilidad podría convertirse en una conversación como aquella entre el japonés [sic] y el marinero danés que Poul Møller cuenta. El japonés decía: Tanko-Panko, a lo cual el marinero comprensiblemente replicó: 'vete a...' “. Pap. IX B 68, p. 386 / C, Suplemento, p. 331.

${ }^{245}$ Maanedskrift for Litteratur, vol. 17, p. 20; ES1, vol. 2, p. 179. 
la felicidad eterna? ¿Podéis hacer una descripción de ella 'mientras me afeito', así como se describe el encanto de una mujer, la púrpura de la realeza, o algún país distante?”246.

La información más minuciosa que Kierkegaard recibió del tratado de Møller sin duda le resultó útil, aunque, como suscriptor del Tidsskrift for udenlandsk theologisk Litteratur, había tenido la oportunidad de seguir el debate alemán sobre el tema, el cual fue reportado por los editores, H. N. Clausen y M. H. Hohlenberg ${ }^{247}$. En su tratado, Møller también analiza el nihilismo de Schopenhauer, quien, al parecer, no estaba muy familiarizado con sus lectores daneses, incluyendo a Kierkegaard ${ }^{248}$. Independientemente de las lecturas de Kierkegaard, es indudable que él creía en verdad en la inmortalidad del alma humana. Esto es evidente a partir de los numerosos lugares en los que discute el tema de la inmortalidad, por ejemplo, en uno de sus Discursos cristianos (1848): "Habrá un resurrección de los muertos, de los justos y de los injustos", la Parte IV de "Pensamientos que pueden herir por detrás" ${ }^{249}$. Sin embargo, al ser consciente de las dudas religiosas

246 SKS 7, 357.28-33 / CUP1, 392. También encontramos la anécdota en El libro sobre Adler: "Estas cosas no pueden exponerse en un diario para ser leídas 'mientras uno se afeita' ”. Pap. VII-2 B 235, p. 83 / BA, 43. A propósito del afeitarse, Kierkegaard se inspiró en la imagen de Calígula empleada por Møller con relación al suicidio (Maanedsskrift, vol. 17, pp. 51-52; ES1, vol. 2, p. 214), cuando en el Diario EE, en una entrada fechada el 4 de mayo de 1839, escribió: "La idea de Calígula de querer tener todas las cabezas sobre un mismo cuello no es sino un intento cobarde de suicidio". SKS 18, 24.32-33, EE:55 / KJN 2, 20.

247 Ver, por ejemplo, NB11:74, el comentario en SKS 22, 44.13. Más tarde , también leyó, por ejemplo, K. L. Michelet, Vorlesungen über die Persönlichkeit Gottes und Unsterblichkeit der Seele oder die ewige Persönlichkeit des Geistes, Berlín: Ferdinand Dümmler, 1841 (ASKB 680), y D. F. Strauß, Fremstilling af den christelig Troeslare i dens historiske Udvikling og $i$ dens Kamp med den moderne Videnskab, vols. 1-2, trad. de Hans Brøchner, Copenhague: H. C. Klein, 1842-1843 (ASKB 803-804); vol. 2, pp. 586-601 (el original es Die christliche Glaubenslebre in ibrer geschichtlichen Entwicklung und im Kampfe mit der modernen Wissenschaft dargestellt, vols. 1-2, Tubinga y Stuttgart: Osiander, 1840-1841). Uno de los diapsalmata en $O$ lo uno o lo otro se refiere a la composición de tratados sobre la inmortalidad, aunque no podemos saber si está pensando en Møller. Cfr. SKS 2, 43-44 / EO1, 34-35.

${ }^{248}$ Todo indica que Kierkegaard no leyó a Schopenhauer antes de 1854. La primera vez que lo menciona es en la entrada NB29:26 (SKS 25, 314-315). Ver, en general, Simonella Davini, "Schopenhauer: Kierkegaard's Late Encounter with His Opposite", en Kierkegaard and His German Contemporaries, Tomo I, Philosophy, ed. por Jon Stewart, Aldershot: Ashgate, 2007 (Kierkegaard Research: Sources, Reception and Resources, vol. 6), pp. 277-291.

249 SKS 10. 211-221 / CD, 202-213. Acerca de esto, ver, por ejemplo, Kjældgaard, Sjælen efter døden, pp. 217-222, e István Czakó, "Unsterblichleitsfurcht". 
que aquejaban a Møller, también sabía lo difícil que debía haber sido para él esta preocupación por la inmortalidad. En el Postscriptum dice a través de su seudónimo:

Sé que el difunto profesor Poul Møller — de quien ciertamente se puede decir que estaba familiarizado con las nuevas tendencias filosóficas- no comprendió sino hasta el final de su vida la infinita dificultad que representa la cuestión en torno a la inmortalidad cuando se la aborda de un modo simple, cuando no se exigen nuevas demostraciones ni una serie de interpretaciones hiladas de cabo a rabo. También sé que en un tratado suyo intentó explayarse sobre el tema, y sé que en dicho tratado claramente manifestó su aversión hacia el moderno pensamiento especulativo. La dificultad en la cuestión surge precisamente cuando se le aborda de un modo simple, no a la manera en que un profesor asistente bien entrenado investiga la inmortalidad de los seres humanos, considerándolos abstractamente como la humanidad en general, de suerte que al final aquello que investiga es la inmortalidad de los seres humanos en general y, en un sentido fantástico, la inmortalidad de la humanidad ${ }^{250}$.

Él utiliza uno de los puntos principales del tratado sobre la inmortalidad y lo vuelve todavía más difícil, como es la costumbre de Climacus. Estoy pensando en otro pasaje significativo, aunque también más substancial que el del librero afeitándose, a saber, la afirmación de Møller de que el arte verdadero es un anticipo de la vida bienaventurada. Esto lo repite Kierkegaard

250 SKS 7, 159 / CUP1, 172. Con respecto a la "serie de interpretaciones hiladas de cabo a rabo", Kierkegaard se burla de esto, por ejemplo, en una entrada acerca de "La fe de los miles y millones": "Así es como funcionan las cosas. Uno impresiona a un niño: Eres inmortal. Y entonces se le dice: 'Ya no le prestes atención a eso; no vuelvas a pensar en ello. Prosigue con tus laboriosas actividades de vida (algo que, de forma frívola, llamamos seriedad), cásate, ten hijos, haz algo de tu vida, trabaja día y noche, pero, por el amor de Dios, procura no volver a pensar en la inmortalidad, ya que eres inmortalidad, de eso hay una certeza absoluta'. A esto le llamamos fe”. SKS 25, 442, NB30:70 / JP 4, 5045. Sobre la prueba del "buen salario", ver las palabras del Juez Guillermo en $O$ lo uno o lo otro: "Pero si tiene un buen salario, entonces ha alcanzado su destino, pero el destino de ganar un buen salario no puede ser la muerte, sino, por el contrario, el vivir bien con este buen salario; ergo, el hombre es inmortal. Esta demostración podría llamarse la demostración popular o la prueba del salario. Si esta demostración se añade a demostraciones anteriores, entonces cualquier duda razonable sobre la inmortalidad debe considerarse superada. Esta demostración se presta de forma espléndida a sumarse a otras demostraciones; de hecho, de esa manera se muestra en su máximo esplendor, ya que, como conclusión, implica a las otras y las confirma”. SKS 3, 265.28-266.1 / EO2, 279-280. 
en un par de lugares: en el libro que le dedicó a Møller, El concepto de la angustia, en el cual también señala que "eso que Poul Møller dijo es verdad, que la inmortalidad debe estar presente en todas partes"251, y en el Postscriptum, donde se extiende al énfasis de que la inmortalidad presupone que el humano se convierta en un yo: "toda pasión idealizante es un anticipo de lo eterno en la existencia a fin de que la persona existente exista"252.

251 SKS 4, 452.19 y 452.32-33 / CA, 153. En el borrador, Pap. V B 66 / CA, Suplemento, p. 210, el texto dice: "Por lo tanto, Poul Møller tenía razón al afirmar que la inmortalidad debe estar presente en todas partes y no ha de introducirse como un apéndice al sistema". Por lo que respecta al señalamiento de que el "arte verdadero es un anticipo de la vida bienaventurada", los editores de los SKS sugieren (en la nota a 452.19 en SKS K4, p. 520) que Kierkegaard, en este caso, estaba pensando en Martensen, ya que en la misma página del borrador (Pap. V B 60, p. 137 / CA, Suplemento, p. 207), donde en una nota al margen se añade la observación sobre el arte, también se habla de Martensen. En la versión final de El concepto de la angustia se lee: "El arte es un anticipo de la vida eterna, pues la poesía y el arte son la reconciliación solo de la imaginación y bien pueden tener la Sinnigkeit de la intuición, pero de ninguna manera la Innigkeit de la seriedad. Algunos pintan la eternidad de forma elaborada con el oropel de la imaginación y sienten anhelo por ella. Algunos imaginan la eternidad de forma apocalíptica y pretenden ser Dante, aunque Dante, sin importar cuánto terreno le cediera a las visiones de la imaginación, nunca suspendió el efecto del juicio ético". SKS 4, 452.19-24 / CA, 153. En el borrador, esta reflexión aparece al margen, después de la afirmación sobre la naturaleza del arte: "que el arte es el anticipo de la vida eterna. Lo apocalíptico, en lo cual, a diferencia de Dante, el juicio ético se suspende. En cualquier caso, se trata de una mera visión fantasiosa”. Pap. V B 60, p. 127 / CA, Suplemento, p. 207. Con sus observaciones sobre lo apocalíptico, Kierkegaard está aludiendo a la "comedia apocalíptica" de Heiberg, "Un alma después de la muerte" (en Nuevos poemas, 1841), escrito reseñado por Martensen — y comparado con la Divina comedia de Dante- en el diario Fæedrelandet, 10, 11 y 12 de enero de 1841. Mucho tiempo antes, en su ensayo "Observaciones sobre la idea de Fausto, con referencia al Fausto de Lenau", en Perseus, Journal for den speculative Idee, no. 1, ed. por J. L. Heiberg, Copenhague: C. A. Reitzel, 1837, pp. 91-164, Martensen había escrito sobre la "poesía apocalíptica" como "un anticipo del Día del Juicio" (p. 98). (En el ensayo predecesor, Ueber Lenau's Faust, Stuttgart: Verlag der J. G. Cottáschen Buchhandlung, 1836, no hay ningún indicio de un análisis de la poesía apocalíptica). No obstante, es preciso tener en cuenta que el primer número de Perseus apareció en junio de 1837, mientras que la primera parte del tratado de Møller, en la cual se discute el arte como anticipo, se publicó antes, en enero de 1837, de modo que Martensen, en su ensayo, quizá estaba pensando en Møller. En el presente contexto, El concepto de la angustia, no creo que haya motivos para dudar que Kierkegaard también estaba pensando en Møller.

252 SKS 7, 285.1-3 / CUP1, 312-313. En la nota al pie, SKS 7, 285 / CUP1, 313, se lee: "La poesía y el arte han sido llamados un anticipo de lo eterno. Si se desea llamarlos así, es necesario tener en cuenta que la poesía y el arte no se relacionan de forma esencial con una persona existente, ya que la contemplación de la poesía y el arte, 'el goce por lo bello', es 


\section{Algunas palabras a modo de conclusión}

El impacto de Poul Martin Møller sobre Kierkegaard tuvo un carácter múltiple, pero fue más personal que filosófico. Se ha convertido en una especie de mito el que eran "amigos" íntimos y que Møller era el "maestro" de Kierkegaard, pero las fuentes acerca de su relación son pocas y no muy claras. Lo que las fuentes sí muestran —especialmente el borrador de la dedicatoria a El concepto de la angustia - son los profundos sentimientos que Kierkegaard albergaba con respecto a Møller, quizá incluso en mayor medida después de la muerte de este. Él admiraba la fuerte personalidad de Møller y, de forma especial, su humor. En sus lecciones sobre historia de la filosofía antigua, Møller dice lo siguiente acerca de Sócrates (palabras que probablemente, desde el punto de vista de Kierkegaard, aplicaban también a él): "Especialmente su buen humor constante y su fino ingenio —el cual se extendía a través de sus conversaciones- hacían que la interacción con él resultara atractiva para sus jóvenes amigos" 253 . Es claro que tuvieron conversaciones profundas que fueron muy inspiradoras para Kierkegaard y, sin duda, también para Møller, quien se daba cuenta del genio de este joven verboso, aunque fuera "tan polémico". Møller decía del método mayéutico:

Pero, de hecho, lo importante era que se introducía en su círculo de
pensamiento individual, algo para lo cual poseía un don en verdad ex-
traordinario. Por un momento asimilaba por completo todo el punto
de vista de la otra persona y sabía, para alegría de esta otra persona,
cómo desarrollar su círculo de pensamiento de manera que tuviera que
adherirse completamente a él... Al introducirse de forma total al círcu-
lo de pensamiento de la otra persona, obligaba a esta a seguirlo, ya que
sus propios pensamientos eran llevados hasta consecuencias en las que
jamás había soñado y a resultados completamente inesperados ${ }^{254}$.

Si suponemos que Møller fue una inspiración para el pensamiento de Kierkegaard —algo que, como se ha mostrado, tenemos motivo para hacer en el caso de, por ejemplo, temas comunes como Ahasverus, las diversas reflexiones sobre la desesperación estética, el nihilismo, la ironía y la psicología, y, en términos generales, el énfasis en lo subjetivo-, también tendremos que

desinteresado, y el observador queda contemplativamente fuera de sí mismo qua persona existente".

${ }^{253}$ ES1, vol. 2, p. 361.

${ }^{254}$ ES1, vol. 2, pp. 363-364. 
suponer un alto grado de comunicación oral entre los dos, ya que muchas de las ideas de Møller aparecen en los escritos de Kierkegaard antes de la publicación de los Escritos póstumos. Lo que importa es la calidad más que la cantidad, algo que tal vez explica por qué Kierkegaard solo registró una conversación nocturna. Otras fuentes, en cambio, sugieren que pasaban juntos mucho tiempo. Citaré otro pasaje que quizá es más importante para la comprensión de Møller como un "confidente de Sócrates”, pues ilustra de forma espléndida su impacto socrático sobre Kierkegaard. Møller determina la importancia de Sócrates en la historia de la filosofía señalando que:

Se esforzó [Sócrates] por afirmar la razón subjetiva y por arrancar a sus conciudadanos de su sumisión inconsciente a la razón objetiva. Hizo que sus seguidores se introdujeran en ellos mismos para conformar un reino subjetivo de pensamiento que constituyera la norma para la determinación de la humanidad. Sabía, en efecto, que el bien era lo absoluto, pero cuando este bien era determinado desde el punto de vista subjetivo, el pensamiento que debía determinarlo debía en primer lugar poner en duda aquello que era considerado válido con autoridad divina ${ }^{255}$.

De forma parecida, Møller le proporcionó a Kierkegaard la comprensión de que, en la existencia humana, el conocimiento de una verdad personal individual es decisivo. Más tarde, Kierkegaard desarrolló y extendió al máximo este concepto de subjetividad, especialmente en el Postscriptum definitivo y no científico. Esta es la influencia más importante de Møller, a pesar de que a menudo ha sido eclipsada por el énfasis polémico de Kierkegaard en la religión. Como el mismo Kierkegaard reconoció: “A pesar de que soy tan polémico - y lo era ya incluso en mi juventud-, el cristianismo es casi demasiado polémico para mí”256. No obstante, en los contornos más amplios de su pensamiento, Kierkegaard estuvo profundamente inspirado por Møller, no tanto por su pensamiento, sino por su forma de ser y por su manera de mostrar el camino hacia la verdad. 


\section{Bibliografía}

I. Obras de Møller en el Catálogo de la subasta de la biblioteca de Kierkegaard (ASKB)

Efterladte Skrifter af Poul M. Møller, vols. 1-3, ed. por Christian Winther, F. C. Olsen y Christen Thaarup, $1^{\circ}$ ed., Copenhague: C. A. Reitzel, 1839-1843 (ASKB 1574-1576).

II. Obras en el Catálogo de la subasta de la biblioteca de Kierkegaard que bablan sobre Møller (ASKB)

Adler, Adolph Peter, Theologiske Studier, Copenhague: Trykt paa Forfatterens Forlag hos Louis Klein I Commision hos Universitets-Boghandler C. A. Reitzel, 1846, p. 27, nota (ASKB U 12).

Berg, Carl, Grundtrækkene af en philosophisk Propædeutik eller Erkjendelseslære, tilligemed Poul Møllers kortfattede formelle Logik. Trykt som Manuskript til Brug til Elever af det kongl. Landcadetacademie, Copenhague: C. A. Reitzel, 1839 (ASKB 426).

Hebbel, Friedrich, Mein Wort über das Drama! Eine Erwiderung an Professor Heiberg in Copenhagen, Hamburgo: Hoffmann und Campe, 1843, p. 12 (ASKB U 54).

Heiberg, Johan Ludvig, "Om Malerkunsten I dens Forhold til de andre skjønne Kunster", en Perseus, Journal for den speculative Idee, vols. 1-2, ed. por J. L. Heiberg, Copenhague: C. A. Reitzel, 1837-1838, vol. 2, pp. 101-181, ver p. 121 (ASKB 569).

—_Lyrisk Poesie", en Intelligensblade, vols. 1-4, nos. 1-48, ed. por Johan Ludvig Heiberg, Copenhague: C. A. Reitzel, 1842-1844, vol. 3, pp. 25-72, ver p. 57; p. 71 (ASKB U 56).

Martensen, Hans Lassen, Den christelige Dogmatik, Copenhague: C. A. Reitzel, 1849 , p. 540, nota (ASKB 653).

Nielsen, Rasmus, Den propæedeutiske Logik, Copenhague: P. G. Philipsen, 1845, p. 41; p. 116; p. 279 (ASKB 699).

Olsen, Frederik Christian, Poul Martin Møllers Levnet, med Breve fra hans Haand, en Efterladte Skrifter af Poul Møller, $1^{\circ}$ ed., vol. 3, Copenhague: C. A. Reitzel, 1843 (ASKB 1576). 
Ørsted, Anders Sandøe, Af mit Livs og min Tids Historie, vols. 1-2, Copenhague: Gyldendal, 1851-1852, vol. 1, p. 163 (ASKB 1959-1960).

III. Bibliografía secundaria sobre la relación entre Kierkegaard y Møller

Ammundsen, Valdemar, Søren Kierkegaards Ungdom. Hans Slægt og hans religiøse Udvikling, Copenhague: J. H. Schultz, 1912, p. 75, nota; p. 79; p. 119; pp. 126-127.

Andersen, Vilhelm, Poul Møller. Hans Liv og Skrifter efter trykte og utrykte Kilder $i$ Hundredaaret for hans Fødsel, $1^{\circ}$ ed., Copenhague: G. E. C. Gad, 1894, p. 392; pp. 394-399.

- Tider of Typer af dansk Aands Historie. Første Rakke: Humanisme. Anden Del: Goethe. Anden Bog: Det nittende Aarbundredes sidste Halvdel, Copenhague: Gyldendal, 1916, pp. 98-99; pp. 102-104; pp. 109-110.

Andreasen, Uffe, Poul Møller og romantismen - den filosofiske idealisme i Poul Møllers senere forfatterskab, Copenhague: Gyldendal, 1973, p. 16; p. 48; p. 59; p. 74; pp. 86-87.

Billeskov Jansen, F. J., Studier i Søren Kierkegaards litterære Kunst, Copenhague: Rosenkilde \& Bagger, 1951, pp. 44-45.

__ "I grandi romanzi filosofici di Kierkegaard", en Studi Kierkegaardiani, ed. por Cornelio Fabro, Brescia: Morcelliana, 1957, pp. 75-79.

__ "Den danske Idealisme eller Kjærlighedens Blomsterringe", Meddelelser fra Dansklærerforeningen, no. 3, 1968, pp. 177-180.

Brandes, Georg, Søren Kierkegaard. En kritisk Fremstilling i Grundrids, Copenhague: Gyldendal, 1877, p. 37; p. 56; pp. 65-66.

Brandt, Frithiof, Den unge Søren Kierkegaard. En række nye bidrag, Copenhague: Levin \& Munskgaard, 1929, pp. 336-446; pp. 454-459.

Brøchner, Hans, "Erindringer om Søren Kierkegaard”, Det nittende Aarbundrede, vol. 5, 1877, pp. 337-374, entrada 36.

Brückner, Paul, Lichtträger und Irrgeister, Wuppertal-Elberfeld: Verlag Die Aue, 1929, pp. 47-76.

Bukdahl, Jørgen K., "Poul Martin Møllers opgør med 'nihilismen' ”, Dansk Udsyn, vol. 45, ed. por Richard Andersen et al., Vejen: Askov Højskole, 1965, pp. 266-290. 
Caron, Jacques, Angoisse et Communication chez S. Kierkegaard, Odense: Odense University Press, 1992, pp. 25-37.

Czakó, István, "Unsterblichkeitsfrucht. Ein christlicher Beitrag zu einer zeitgenössischen Debatte in Søren Kierkegaards 'Gedanken, die hinterrücks verwundenzur Erbauung' ”, Kierkegaard Studies Yearbook, 2007, pp. 227-254.

_ "Heiberg and the Immortality Debate: A Historical Overview", en Johan Ludvig Heiberg: Philosopher, Littérateur, Dramaturge, and Political Thinker, ed. por Jon Stewart, Copenhague: Museum Tusculanum Press, 2008 (Danish Golden Age Studies, vol. 5), pp. 95-138.

Davini, Simonella, "Schopenhauer: Kierkegaard's Late Encounter with His Opposite", en Kierkegaard and His German Contemporaries, Tomo I, Philosophy, ed. por Jon Stewart, Aldershot: Ashgate, 2007 (Kierkegaard Research: Sources, Reception and Resources, vol. 6), pp. 277-291; ver p. 278.

Egeløv, Arne, "Poul Martin Møller om Søren Kierkegaards Udseende”, Politiken, 12 de mayo de 1842 .

Fenger, Henning, "Kierkegaard: A Literary Approach", in Kierkegaard and His Contemporaries: The Culture of Golden Age Denmark, ed. por Jon Stewart, Berlín y Nueva York: Walter de Gruyter, 2003 (Kierkegaard Studies Monograph Series, vol. 10), pp. 301-318; p. 306.

Fenves, Peter, Chatter: Language and History in Kierkegaard, Stanford: Stanford University Press, 1993, pp. 35-39.

Garff, Joakim, Søren Kierkegaard: A Biography, trad. de Bruce H. Kirmmse, Princeton: Princeton University Press, 2004, p. 64; p. 69; pp. 86-89; pp. 90-95; p. 126; p. 144; p. 150; p. 179; p. 193; p. 320; p. 386; p. 421; p. 474; p. 707.

Geismar, Eduard, Søren Kierkegaard: Hans Livsudvikling og Forfattervirksombed, vols. 1-6, Copenhague: G. E. C. Gad, 1926-1928, vol. 1, pp. 60-65.

__ "Poul Martin Møllers Betydning for Søren Kierkegaard. I Hundredaaret for Poul Martin Møllers Død”, Berlingske Tidende, 9 de octubre de 1838.

Glebe-Møller, Jens, "Udødeligheden er Dommen —om sjælens udødelighed”, Dansk Teologisk Tidsskrift, vol. 68, 2005, pp. 65-73; pp. 70-73.

Hansen, Valdemar, "Le príncipe de personnalité chez trois penseurs danois: Høffding, Kierkegaard, Poul Møller", Storia della filosofia moderna e contemporanea, vol. 12, Florencia: Sansoni editore, 1961 (Atti del XII Congresso Internazzionale di Filosofia), pp. 205-210. 
Heiberg, P. A., Bidrag til et psykologisk Billede af Søren Kierkegaard i Barndom og Ungdom, Copenhague: Otto B. Wroblewski, 1895, p. 108; pp. 132-133.

Henningsen, Bernd, Poul Martin Møller oder Die dänische Erziebung des Søren Kierkegaard. Eine kritische Monographie mit einer ersten Übersetzung seiner Abhandlung über die "Affectation", Frankfurt am Main: Akademische Verlagsgesselschaft, 1973.

Hermann, Jesper, "Forholdet mellem Poul Møller og Søren Kierkegaard, en dokumentation", en Extracta. Resumeer af specialeopgaver fra det Filosofiske Fakultet ved Københavns Universitet 1967-1968, ed. por Ivan Boserup et al., vol. 1, Copenhague: Akademisk Forlag, 1968, pp. 112-114.

Himmelstrup, Jens, Søren Kierkegaards Opfattelse af sokrates. En Studie i dansk Filosofis Historie, Copenhague: Arnold Busck, 1924, pp. 175-176; pp. 318-319.

_ Sibbern. En Monografi, Copenhague: J. H. Schultz, 1934, pp. 170-171; pp. 262-263.

Høffding, Harald, Søren Kierkegaard som Filosof, Copenhague: P. G. Philipsens Forlag, 1892, pp. 23-27.

— Danske Filosofer, Copenhague: Gyldendalske Boghandel Nordisk Forlag, 1909, p. 118; p. 123, nota; p. 127; p. 148; pp. 150-151.

Jensenius, Knud, Nogle Kierkegaardstudier: De tre store Ideer, Copenhague: Nyt Nordisk Forlag Arnold Busck, 1932, pp. 125-153.

Jones, W. Glyn, "Sören Kierkegaard and Poul Martin Møller”, Modern Language Review, vol. 60, 1965, pp. 73-82.

Jørgensen, Carl, Søren Kierkegaard. En biografi med særligt henblik paa hans personlige etik, vols. 1-5, Copenhague: Nyt Nordisk Forlag Arnold Busck, 1964, vol. 1, pp. 87-95.

Jørgensen, John Chr., Den sande kunst. Studier $i$ dansk 1800-tals realisme. Poul Møller, Hans Egede Schack, Georg Brandes, Herman Bang, Copenhague: Borgen, 1980, p. 33; p. 54; p. 64; p. 148; p. 152; p. 164; p. 181.

Kabll, Aage, Kierkegaardstudiet $i$ Norden, Copenhague: H. Hagerup, 1948, pp. 232-236.

Kirmmse, Bruce H., "Socrates in the Fast Lane: Kierkegaard's The Concept of Irony on the University's Velocifere: Documents, Context, Commentary, and Interpretation”, en The Concept of Irony, ed. por Robert L. Perkins, Macon, Georgia: 
Mercer University Press, 2001 (International Kierkegaard Commentary, vol. 2), pp. 17-99; ver p. 51; pp. 61-62; pp. 66-67; pp. 87-93; pp. 95-98.

Kjældgaard, Lasse Horne, "What it Means to Be Immortal: Afterlife and Aesthetic Communication in Kierkegaard's Concluding Unscientific Postscript", Kierkegaard Studies Yearbook, 2005, pp. 90-112.

- Sjalen efter døden. Guldalderens moderne gennembrud, Copenhague: Gyldendal, 2007, passim (sobre Møller las pp. 83-112).

Kjær, Grethe, Barndommens ulykkelige elsker: Kierkegaard om barnet og barndommen, Copenhague: C. A. Reitzel, 1986, pp. 118-127.

Koch, Carl Henrik, En flue på Hegels udødelige næse eller om Adolpb Peter Adler og om Søren Kierkegaards forhold til ham, Copenhague: C. A. Reitzel, 1990, pp. 24-26; p. 33; pp. 45-46; p. 57; pp. 75-76.

Den danske idealisme 1800-1880, Copenhague: Gyldendal, 2004 (Den danske filosofis historie, ed. por Sten Ebbesen y C. H. Koch, vol. 4), p. 249; p. 267; p. 269.

Kühle, Sejer, "Søren Kierkegaard og den Heibergske Kreds", Personalhistorisk Tidsskrift, vol. 48, 1947, pp. 1-13; pp. 3-7.

- Søren Kierkegaards barndom og ungdom, Copenhague: Aschehoug Dansk Forlag, 1950, p. 25; p. 77; p. 80; pp. 101-114; pp. 122-129; p. 152; p. 158.

Lilhav, Preben, Kierkegaards valg, Risskov: Forlaget Sicana, 2003, pp. 51-73.

Lübcke, Poul, "Det ontologiske program hos Poul Møller og Søren Kierkegaard”, Filosofiske Studier, vol. 6, 1983, pp. 127-147.

—_ "F. C. Sibbern: Epistemology as Ontology", en Kierkegaard and His Contemporaries: The Culture of Golden Age Denmark, ed. por Jon Stewart, Berlín y Nueva York: Walter de Gruyter, 2003 (Kierkegaard Studies Monograph Series, vol. 10), pp. 25-44; ver pp. 28-29; p. 42.

Lund, Henriette, Erindringer fra Hjemmet, Copenhague: Gyldendal, 1909, pp. 119-120.

Madsen, Børge, "Poul Martin Møller og Kierkegaard", Information, 6 de agosto de 1963.

Magnussen, Rikard, Søren Kierkegaard set udefra, Copenhague: Munskgaard, 1942, pp. 120-123.

Malantschuk, Gregor, “Søren Kierkegaard og Poul Møller”, Kierkegaardiana, vol. 3, 1959, pp. 7-20. 
— Dialektik og Existens hos Søren Kierkegaard, Copenhague: C. A. Reitzel, 1968, p. 29; pp. 141-142; p. 278.

Møller, A. Egelund, Søren Kierkegaard om politik, Copenhague: Forlaget Strand, 1975, pp. 30-35; pp. 155-156.

Mortensen, Klaus P., Thomasines oprør - en familiehistorisk biografi om køn og kxrlighed i forrige arbundrede, Copenhague: G. E. C. Gad, 1986, p. 151.

Nielsen, Svend Aage, Kierkegaard og Regensen. Kierkegaards forhold til F. C. Petersen, Poul Martin moller, D. G. Monrad, Magnus Eriksson, Carl Ploug, P. L. Møller, Hans Brøchner og J. C. Hostrup, Copenhague: Graabrødre Torv's Forlag, 1965, pp. 27-43.

Nordentoft, Kresten, Kierkegaard's Psychology, Pittsburgh: Duquesne University Press, 1978, pp. 95-96; pp. 325-326; p. 394.

__ "Hvad siger Brand-Majoren?" Kierkegaards oprør med sin samtid, Copenhague: G. E. C. Gad, 1973, p. 27.

Nun, Katalin, “Thomasine Gyllembourg's Two Ages and her Portrayal of Everyday Life", en Kierkegaard and His Contemporaries: The Culture of Golden Age Denmark, ed. por Jon Stewart, Berlín y Nueva York: Walter de Gruyter, 2003 (Kierkegaard Studies Monograph Series, vol. 10), pp. 272-297; ver p. 296.

Paludan-Müller, Martin, Udlængsel og hjemve. Personlighedsopfattelse hos Poul Møller og hans forgængere, Copenhague: Museum Tusculanums Forlag, 1987, pp. 7-8; pp. 14-15; p. 61; p. 88; pp. 92-93.

Pattison, George, Kierkegaard's Theory and Critique of Art, Its Theological Significance, Ph.D. thesis, University of Durham, 1983, pp. 89-102.

—_ "Art in the Age of Reflection", en The Cambridge Companion to Kierkegaard, ed. por Alastair Hannay y Gordon Marino, Cambridge: Cambridge University Press, 1998, pp. 76-100; ver pp. 92-93, p. 96.

“D. F. Strauss: Kierkegaard and Radical Demythologization”, en Kierkegaard and His German Contemporaries, Tomo II, Theology, ed. por Jon Stewart, Aldershot: Ashgate, 2007 (Kierkegaard Research: Sources, Reception and Resources, vol. 6), pp. 233-257; ver p. 250.

Politis, Hélène, "Kierkegaard: Documents philosophiques”, en Kierkegaard. VingtCinq Études (Les Cabiers de Philosophie, nos 8-9), 1989, pp. 443-472. 
Reuter, Hans, S. Kierkegaards religionsphilosophische Gedanken im Verbältnis zu Hegels religionsphilosophischen Sysrem, Leipzig: Verlag von Quelle \& Meyer, 1914 (Abhandlungen zur Philosophie und ibrer Geschichte, vol. 23), pp. 68-74.

Rohde, H. P., "Poul Møller”, en Kierkegaard's Teachers, ed. por Niels Thulstrup and Marie Mikulová Thulstrup, Copenhague: C. A. Reitzel, 1982 (Bibliotheca Kierkegaardiana, vol. 10), pp. 89-109.

__ "Poul Møller og Søren Kierkegaard", en Afhandlingerne på originalsproget $i$ Søren Kierkegaard - Tænkning og sprogbrug $i$ Danmark Festskrift $i$ anledning af prof. dr. Masaru Otanis 70 års fødeslsdag, Copenhague: editado en privado, 1983, pp. 1-22 [paginación separada].

Rosenau, Hartmut, "I. H. Fichte: Philosophy as the Most Cheerful Form of Service to God", en Kierkegaard and His German Contemporaries, Tomo I, Philosophy, ed. por Jon Stewart, Aldershot: Ashgate, 2007 (Kierkegaard Research: Sources, Reception and Resources, vol. 6), pp. 49-66; ver p. 60.

Rubow, Paul V., Kierkegaard og hans Samtidige, Copenhague: Gyldendal, 1950, pp. 14-16.

Schäfer, Klaus, Hermeneutische Ontologie in den Climacus-Schriften Sören Kierkegaards, Munich: Kösel-Verlag, 1968, pp. 117-120.

Scopetea, Sophia, Kierkegaard og græciteten. En kamp med ironi, Copenhague: C. A. Reitzel, 1995, p. 25; p. 57; p. 101, nota 4; p. 156, nota 31; p. 236, nota 5.

Söderquist, Brian, "Kierkegaard's Contribution to the Danish Discussion of Irony", en Kierkegaard and His Contemporaries: The Culture of Golden Age Denmark, ed. por Jon Stewart, Berlín y Nueva York: Walter de Gruyter, 2003 (Kierkegaard Studies Monograph Series, vol. 10), pp. 78-105; ver especialmente p. 79; p. 80; p. 88; pp. 90-98; pp. 101-105.

— "The Closed Self: Kierkegaard and Poul Martin Møller on the Hubris of Romantic Irony", en Kierkegaard and the Word(s): Essays on Hermeneutics and Communication, ed. por Poul Houe and Gordon D. Marino, Copenhague: C. A. Reitzel, 2003, pp. 204-214.

The Isolated Self: Truth and Untruth in Søren Kierkegaard's On the Concept of Irony, Copenhague: C. A. Reitzel, 2007 (Danish Golden Age Studies, vol. 1), pp. 144-169.

Stewart, Jon, Kierkegaard's Relations to Hegel Reconsidered, Cambridge: Cambridge University Press, 2003, pp. 74-77; pp. 81-82; p. 138; p. 453; p. 605; p. 630; p. 632. 
—_ "Introduction", en Kierkegaard and His Contemporaries: The Culture of Golden Age Denmark, ed. por Jon Stewart, Berlín y Nueva York: Walter de Gruyter, 2003 (Kierkegaard Studies Monograph Series, vol. 10), pp. 1-22; ver pp. 8-9.

—_ "Kierkegaard and Hegelianism in Golden Age Denmark", en Kierkegaard and His Contemporaries: The Culture of Golden Age Denmark, ed. por Jon Stewart, Berlín y Nueva York: Walter de Gruyter, 2003 (Kierkegaard Studies Monograph Series, vol. 10), pp. 106-145; ver pp. 136-139; pp. 145-146.

A History of Hegelianism in Golden Age Denmark, Tomo I, The Heiberg Period: 1824-1836, Copenhague: C. A. Reitzel, 2007 (Danish Golden Age Studies, vol. 3), pp. 63-64; pp. 202-203; p. 210; pp. 237-243; p. 462; pp. 506-507; p. 532.

Summers, Richard M., "Aesthetics, Ethics, and Reality: A Study of From the Papers of One Still Living”, en Early Polemical Writings, ed. por Robert L. Perkins, Macon, Georgia: Mercer University Press, 1999 (International Kierkegaard Commentary, vol. 1), pp. 45-68.

Thielst, Peter, "Poul Martin Møller (1794-1838): Scattered Thoughts, Analysis of Affectation, Combat with Nihilism", Danish Yearbook of Philosophy, vol. 13, 1976, pp. 66-83 (Reimpreso como "Poul Martin Møller: Scattered Thoughts, Analysis of Affectation, Struggle with Nihilism", en Kierkegaard and His Contemporaries: The Culture of Golden Age Denmark, ed. por Jon Stewart, Berlín y Nueva York: Walter de Gruyter, 2003 (Kierkegaard Studies Monograph Series, vol. 10), pp. 45-61).

_Livet forstås baglæns, men må leves forlæns. Historier om Søren Kierkegaard, Copenhague: Gyldendal, 1994, pp. 48-52.

Thulstrup, Niels, Kierkegaard's Relation to Hegel, trad. de George L. Stengren, Princeton: Princeton University Press, 1980, p. 33; p. 51, nota; p. 57; p. 105, nota; p. 113 ; p. 115 ; p. 146 ; pp. $150-151$; p. 154; pp. 174-175; p. 181, nota; p. 192; p. 196; pp. 199-200; p. 212; p. 243, nota; p. 351; p. 366. (Originalmente Kierkegaards Forbold til Hegel og til den speculative Idealisme indtil 1846, Copenhague: Gyldendal, 1967).

Commentary on Kierkegaard's Concluding Unscientific Postscript, trad. de Robert J. Widenmann, Princeton, Nueva Jersey: Princeton University Press, 1984, p. 75 ; pp. 83 ss.; p. 172 ; p. 174; p. 179; p. 195; p. 223; p. 243; p. 246; pp. 316-317; p. 324; p. 341; p. 373 (Originalmente Søren Kierkegaard. Afsluttende widenskabelig Efterskrift, ed. por Niels Thulstrup, vols. 1-2, Copenhague: Gyldendal, 1962).

Troelsen, Bjarne, Manden på Flydebroen. En fortælling om Søren Kierkegaard og det moderne menneskes tilblivelse, Frederiksberg: Forlaget Anis, 1997, pp. 48-52. 
Troels-Lund, Troels Frederik, Bakkebus og Solbjerg. Træk af et nyt Livssyns Udvikling $i$ Norden, vols. 1-3, Copenhague: Gyldendal, 1920-1922, vol. 3, pp. 200221.

Tudvad, Peter, Kierkegaards København, Copenhague: Politikens Forlag, 2004, p. 29; p. 73; p. 165; p. 176; p. 179-182; p. 187; p. 202; p. 204; p. 236; p. 251.

Vergote, Henri-Bernard, "Poul Martin Moeler et Soeren Kierkegaard”, Revue de Métaphysique et de Morale, vol. 75, 1970, pp. 452-476.

_Lectures philosophiques de Søren Kierkegaard. Kierkegaard chez ses contemporains danois. Textes de J. L. Heiberg, H. L. Martensen, P. M. Møller, F. C. Sibbern, F. Beck, et S. A. Kierkegaard, París: Presses Universitaires de France, 1993.

Weltzer, Carl, Peter og Søren Kierkegaard, Copenhague: G. E. C. Gad, 1936, p. 98; pp. $120-123$. 